\title{
COMMUNICATIVE DESIGN: TRANSIT ARCHITECTURE FOR GROWING CITIES
}

\author{
A Thesis \\ presented to \\ the Faculty of California Polytechnic State University, \\ San Luis Obispo
}

In Partial Fulfillment

of the Requirements for the Degree

Master of Science in Architecture

by

James Derek Holloway

June 2014 
(C) 2014

James Derek Holloway

ALL RIGHTS RESERVED 


\section{COMMITTEE MEMBERSHIP}

TITLE:

AUTHOR:

DATE SUBMITTED:

COMMITTEE CHAIR:

COMMITTEE MEMBER:

COMMITTEE MEMBER:
Communicative Design: Transit Architecture for Growing Cities

James Derek Holloway

June 2014

Umut Toker, Ph.D.

Associate Professor of City and Regional Planning

Mark Cabrinha, Ph.D.

Associate Professor of Architecture

Kevin Dong, SE

Professor of Architectural Engineering 


\section{ABSTRACT \\ Communicative Design: Transit Architecture for Growing Cities James Derek Holloway}

Increasing urban populations are currently magnifying the importance of the transit station in the context of its surrounding systems. In order to prepare our cities for higher population densities in the future, an examination of the relationships between station form and individual experience may lead to the identification of specific design objectives with implications for increased public transit riderships. Data is collected through research on sensory perception in architecture, spatial organization, and connectivity between an individual structure and it's local surroundings. Site-specific observations and information describing current professional practices are used to determine prominent design objectives for future implementation.

Keywords: Transit, Station, Design, Interconnectivity, Communication, Urban, Architecture 


\section{TABLE OF CONTENTS}

\section{Page}

LIST OF FIGURES.

viii

\section{CHAPTER}

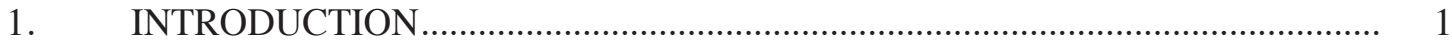

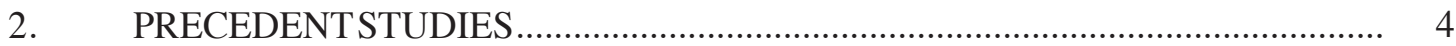

2.1. Architecture and Perception................................................................ 4

2.2. Public Sentiment Regarding Mass Transit........................................ 6

2.3. Transit Location and Corresponding Social Nodes.............................. 7

2.4. Station Design Determines Interconnectivity..................................... $\quad 9$

2.5. Site and Station Design................................................................. 10

2.6. Precedent Stations ........................................................................ 15

Station \#1 - RandstadRail Station Beatrixlaan Den Haag.............. 15

Station \#2 - Morgan Station........................................................ 17

Station \#3 - Al Rashidiya Metro Station..................................... 20

Station \#4 - Liège-Guillemins Station.......................................... 22

Station \#5 - Dresden Station ....................................................... 24

Station \#6 - Kanazawa Station................................................... 26

Station \#7 - Bilbao Metro.......................................................... 29

Station \#8 - Gateway T Station................................................ 31

Station \#9 - Dalmarnock Station................................................. 33

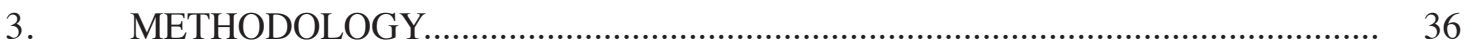

3.1. Research Design ............................................................................ 36

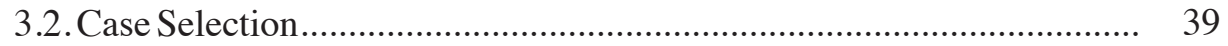


12th and Imperial Transit Center, San Diego, CA........................ 39

American Plaza Trolley Station, San Diego, CA .......................... 40

Hollywood and Vine Metro Portal and Plaza, Los Angeles, CA.... 40

3.2.1. Data Collection Protocol................................................................ 40

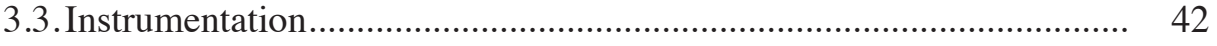

3.3.1. Behavioral Analysis ................................................................... 43

3.3.2. User Surveys............................................................................ 43

3.3.3. Professional Interviews.................................................................. 44

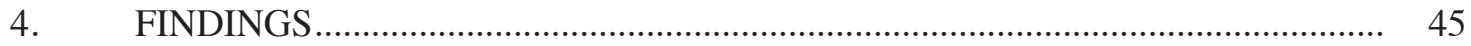

4.1. User Surveys and Behavioral Analysis............................................ 45

Station \#1 (12th and Imperial Transit Center) ............................. 45

Station \#2 (American Plaza Trolley Station).............................. 48

Station \#3 (Hollywood and Vine Metro Portal and Plaza)............ 50

4.2. Professional Interviews ............................................................... 53

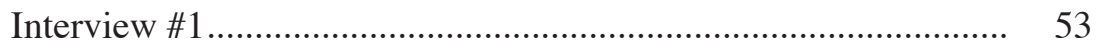

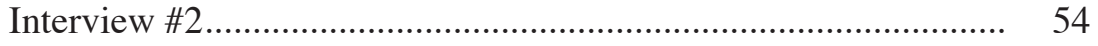

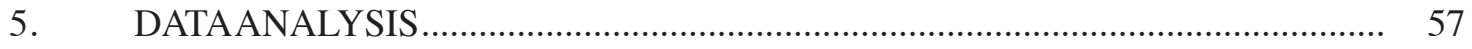

5.1. User Surveys and Behavioral Analysis........................................... 57

Station \#1 (12th and Imperial Transit Center)............................ 58

Station \#2 (American Plaza Trolley Station) ............................... 59

Station \#3 (Hollywood and Vine Metro Portal and Plaza)............ 61

5.2. Professional Interviews ............................................................. 62

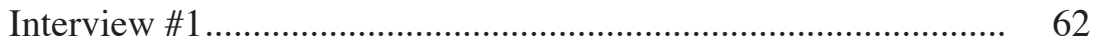

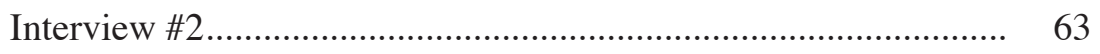

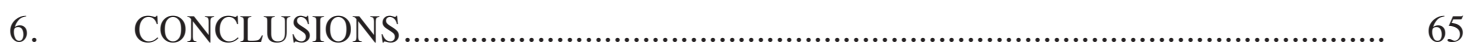

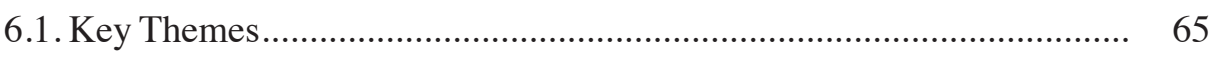

6.2. Design Recommendations .......................................................... 66 
Recommendation 1: Visual Connections Between Interior and

Exterior Spaces.

Recommendation 2: Direct Linkages Between Entrances and

Main Platforms

Recommendation 3: Interconnectivity Between Different

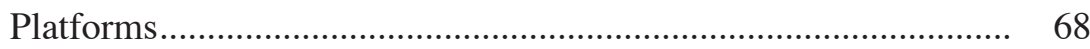

Recommendation 4: Clearly Defined Spaces............................... 69

Recommendation 5: Lighting and Ventilation............................. 70

6.3. Further Research.............................................................................. 71

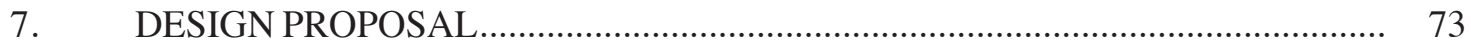

7.1. Project Description......................................................................... 73

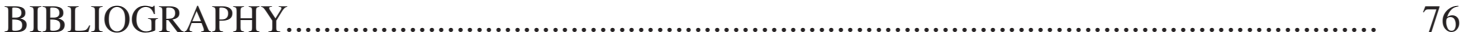

APPENDICES

A. $\quad$ 12th and Imperial Transit Center Field Notes.......................................... 80

B. American Plaza Trolley Station Field Notes............................................. 82

C. Hollywood and Vine Metro Portal and Plaza Field Notes.......................... 86 


\section{LIST OF FIGURES}

Figure $\quad$ Page

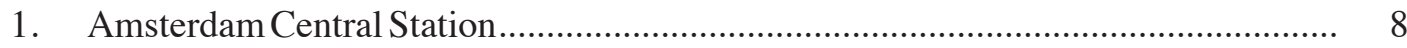

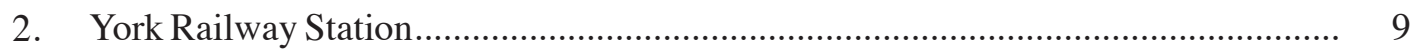

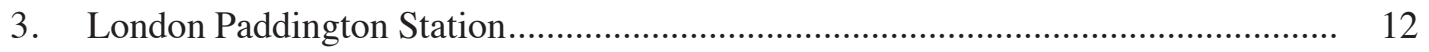

4. Hollywood and Vine Station Entrance and Plaza...................................................... 13

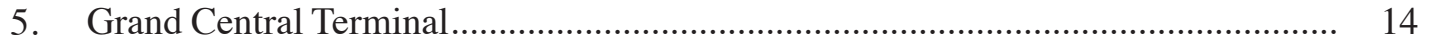

6. Street View of Elevated Space-Frame …............................................................ 15

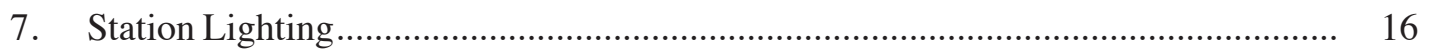

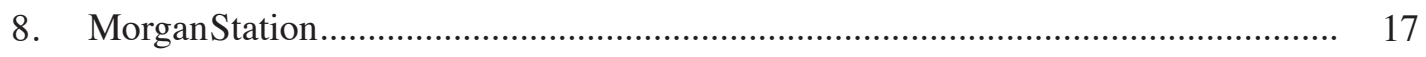

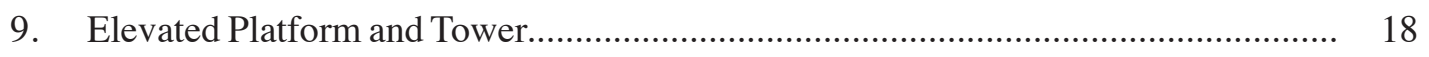

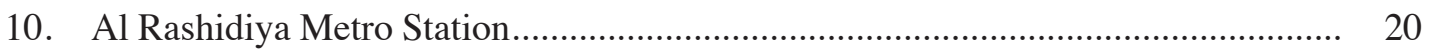

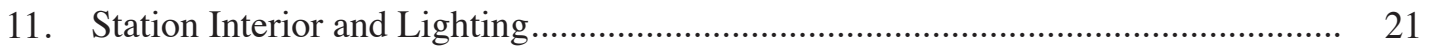

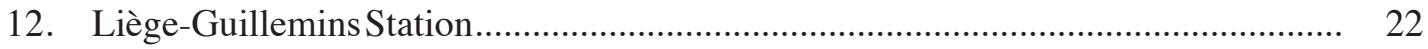

13. Liège-Guillemins Interior Platforms ............................................................... 23

14. Dresden Station Aerial View............................................................................ 25

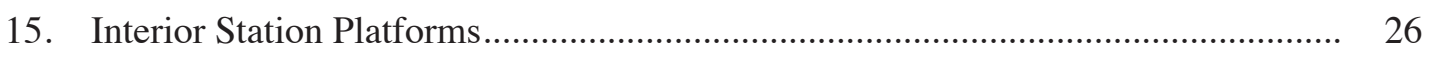

16. Kanazawa Station Main Entrance ..................................................................... 27

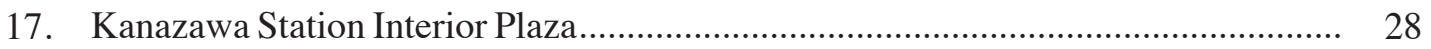

18. Iconic Entrance to Subterranean Station............................................................... 29

19. Subterranean Station Platform and Elevated Walkway.......................................... 30

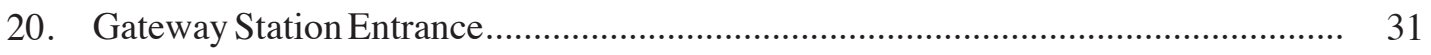

21. Interior Platform With Visual Connection to Exterior Spaces.............................. 32

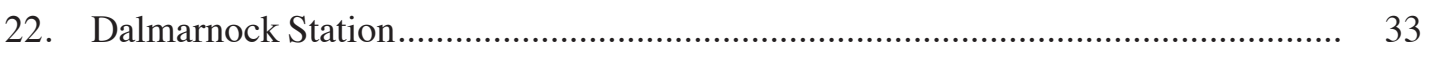

23. Interior Corridor Between Main Entrance and Platform....................................... 35

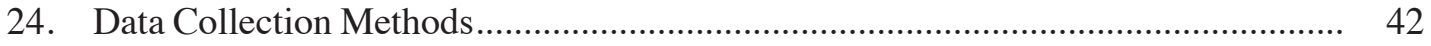


25. 12th and Imperial Transit Center, Exterior Plaza..................................................... 45

26. 12th and Imperial Transit Center, Interior Platform............................................... 45

27. Quantitative Findings From Surveys, 12th and Imperial Transit Center................. 46

28. 12th and Imperial Transit Center, Traveler Congregation Areas............................ 47

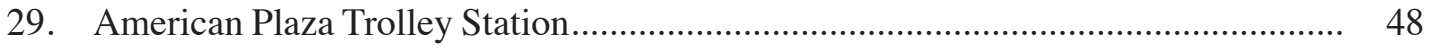

30. Quantitative Findings From Surveys, American Plaza Trolley Station................... 49

31. American Plaza Trolley Station, Traveler Congregation Areas.............................. 49

32. Main Entrance to Subterranean Station............................................................. 50

33. Efforts to Discourage Loitering .......................................................................... 51

34. Quantitative Findings From Surveys, Hollywood and Vine................................... 51

35. Hollywood and Vine Metro Portal and Plaza, Traveler Congregation Areas.......... 52

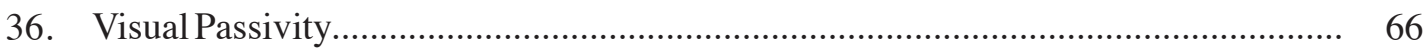

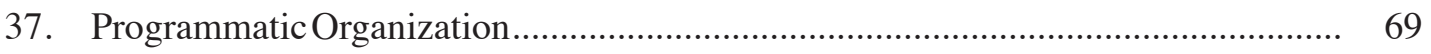

38. Site Location, Downtown San Diego................................................................. 74

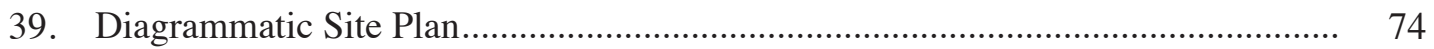

40. Parametric Study Showing City Blocks Immediately Serviced By Trolley Lines... 74

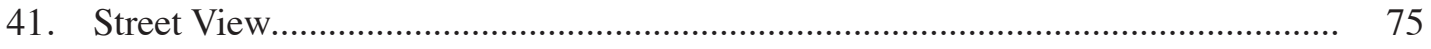

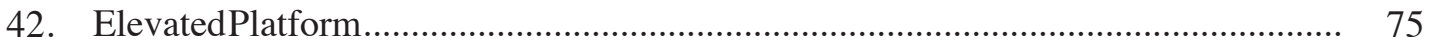




\section{Introduction}

The American urban environment has assumed many different roles over the past decade. A major increase in birth rate after World War II, combined with unprecedented housing investments and numerous anti-urban policies during the mid-twentieth century (as cited in Nelson, 2013) has led to a massive suburban sprawl away from previously emphasized urban centers. For many, the newly attainable amenities (privacy, larger houses, cleaner living conditions, etc.) provided by suburban developments catalyzed massive population movements and caused urban densities to fall from nearly 6,500 persons per square mile in 1950 to 3,700 persons per square mile in 2000 (Nelson, 2013). As a result of this suburban growth, an increased separation evolved between domestic life and employment. Urban centers were largely taken over by growing smokestack industries and rail yards, while highways were expanded in order to accommodate the increasing amount of commuters (Armstrong et al., 2012).

Currently, this urban sprawl has grown to a point where the negative externalities associated with suburban life (longer travel times, increasing fuel costs, etc.) are now competing with previously-enjoyed benefits. For many, the allure associated with the contemporary urban lifestyle is gaining influence as it is shaping another large population shift back to the original centers of American cities. Nelson (2013) posits that the urban environment will continue in its increasing popularity due to the desires of future generations. Parallel to this projection, Norris (2012) proposes that Generation Y (individuals born between the years 1981 and 1995), who will number about seventy-one million in 2030 and include about thirty-eight million households (as cited in Nelson, 2013), will make future housing decisions based on a desire to be connected, preference for convenience and low-maintenance living, car independence, and their appreciation for the ability to relocate easily to maximize their economic and social benefits. If realized, these shifts in demand will undoubtedly change the face of the contemporary urban center.

Armstrong et al. (2012) recognize that the appreciation for walkability and increased social interaction within our cities has already led to new progress in many American cities. The services sector has largely replaced manufacturing, which has increased the frequency of improvements 
such as the transformation of previous brownfield sites into social spaces for human interaction. Nearly \$20 trillion will be spent on development and redevelopment within metropolitan areas between 2010 and 2030 (Nelson, 2013). In 2050, a projected two-thirds of development in America will be constructed after 2013 (Nelson, 2013). Similar trends are commonly observed and allude to the fact that opportunities for future urban development to further address social, environmental and economic issues are likely.

Initiatives such as these are imperative if our cities are to be improved in the future. However, a large amount of contemporary projects concerned with urban sustainability focus on outcomes to be realized within the confines of a specific site, without sufficient regard for how people will travel to and from these destinations. This study emphasizes the importance of public transportation within dense, urban landscapes as it focuses on the architectural design of the individual transit station within its larger transit networks. The study recognizes the fact that simply rebuilding entire urban transit systems on a large scale is unrealistic, both spatially and economically. Therefore, a main goal of the study is to uncover ways in which the informed design of individual structures (transit stations) can generate large-scale change throughout previously developed networks.

In the context of the urban core, the transit station can be seen from many different perspectives. In its simplest form, it is a tool used for the movement of people between the transit vehicle and the street. Therefore, the goals of station design aim to integrate multiple modes of public transport while putting the passenger first (Edwards, 2011). This is often accomplished through the provision of safe environments, efficient travel between destinations and visual aesthetics.

Due to the fact that the overall utilization of public transportation relies heavily on the perceptions of its users, transportation architecture may recognize the visibility and image of structures as significant influences on human travel choices, both individually and socially (Lockton, 2011; Transportation Research Board, 2000). Moore (1979) describes Environment-Behavior Studies in Architecture (EBS) as the systematic study of the relations between the physical environment and human behavior and applications to environmental problem solving through architecture and 
urban planning. While previous studies have looked to uncover the innumerable ways in which architecture molds human behavior (Lockton, 2011; Moore, 1979 among others), this study explores successful design practices as observed through existing stations to consider how design may encourage an increased ridership in mass transit within an urban setting. 


\section{Precedent Studies}

Within an urban environment, the multi-faceted relationship between interconnectivity and design relies on factors such as public opinion, developmental processes, communicative flows, and the complexion of social spaces. Using research from previous studies, as well as an examination of nine precedents in transportation design, this section aims to identify the various roles of architecture in urban transit. Each role is expected to vary between projects based on factors such as surroundings, location and population demographics. To begin, the section discusses urban growth along with some ways in which public sentiments influence the shape of our cities. The study then explores the identification of the transit station as a social node through which people and information continually flow. Information is also presented regarding the relationship between station design and interconnectivity among varying types of transit. In conclusion, research presents contemporary approaches to transportation architecture in regards to established design practices.

\subsection{Architecture and Perception}

Stemming from performance-based objectives and connections to human action and cognizance, architectural design reveals itself as a product of man's thinking. It is a physical delineation of learned information over time, where data from observation and experience is applied to solve both current and future problems. With such a strong relationship between the contemporary physical environment and our desire to understand it's functionality, the acknowledgement of the importance of perception in architecture encourages clarity in the articulation of gathered data. The act of perceiving a building or system is the very act that creates the information upon which our future projects will depend. Therefore, it is necessary to look toward human perception as an aid in negotiating the various components of our cities.

By allowing a structure to become the information in a tangible medium, to inform and solidify the habits of its users, a natural process of movement through space is developed. Everything is connected; and everything reflects and informs the shape of the information around it (Schumacher, 2012). This perspective allows the transit station to become a prominent building type within 
the urban environment. The station may be seen as a viewport into these flows and connections, where architectural design allows users to experience the convergence of multiple information networks within a single site.

Specific to the transit structure, user experience has continually proven to be a key factor when making the decision to use public transportation over other alternatives. Due to the fact that the transit station is the specific location where travelers board and exit each vehicle, the design of the station directly influences human interaction with the built environment and creates a specific experience for station users. This experience is created not only through the visual perception of the station, but through the use of all human senses. Those who have stood inside an underground subway station can vividly recall the experience of being in such a structure. The sudden rush of air across a subterranean platform that signals a train is on its way, or the loud, clicking sound of train wheels as it echoes against tiled walls are special experiences that create emotional responses to which we can later relate.

In spite of the fact that many architectural assessments are based solely on the visual representation of a project, Juhani Pallasmaa in his essay entitled An Architecture of the Seven Senses describes a true architectural experience as more than a series of images to be understood through sight alone. Pallasmaa writes, "A building is encountered. It is approached, confronted, related to one's body, moved about, and utilized as a condition for other things (Holl, 2006)." The performance aspect of built space creates a necessity to examine the ways in which individuals may act differently based on varying situations. According to Roman Ingarden, an individual's behavior is very much influenced by the context in which they are acting. "A stonemason will work loudly when repairing the outside of a church, but quietly and respectfully when entering the building to attend mass. In one situation, the church is a building site for him. In the other, 
it is a place of worship (Mitrovic, 2011)." Due to the fact that transit stations often play various roles within dense urban districts, it is important for designers to address the needs of multiple types of visitors, rather than just catering to traveling populations.

Given the importance of the transit station concerning larger urban systems, increased future ridership will occur through the enlightenment of both current and future users. Architectural design has the power to improve and solidify urban patterns; and more importantly, to allow individuals the opportunity to better understand the environment in which they live. Insight into current human presence in space as well as implications for an improved dialogue between user and structure can be provided through the observation of travelers in current transportation settings. Methods for observation can be both obtrusive (personal interviews, surveying, etc.) and non-obtrusive (simple observation, behavior mapping, pattern recognition, etc.).

\subsection{Public Sentiment Regarding Mass Transit}

As architects begin to recognize the tasks that lie ahead, the realization that many urban centers are not adequately prepared for a substantial influx of people sets in. With growth being an inevitable part of the urban future, the decisions we make now regarding transit infrastructure will undoubtedly influence the successes and failures to come. A greater emphasis can be put on the ability to move people efficiently within the urban corridor as increasing densities may cause a larger portion of the population to rely on public vehicles while travelling from place to place.

In order to begin to understand the role of architecture in urban transportation, it is necessary to recognize the ways in which public opinion influences decisions made concerning the shape of the built environment. While public demand often dictates aspects of development such as the location and type of structure, monetary forces commonly dictate the amenities provided. As noted by the Transportation Research board in Report 63 of the Transit Cooperative Research Program, differing views on the importance of public transportation cause a lack of priority for public transit when compared to other social services. Until there is an increase in demand for a service, the support (and amount of money available) will struggle to improve. In order to address this issue, 
project designs may encourage an optimistic, utopian vision for public transportation, which could eventually lead to a larger amount of people using these facilities on a regular basis (Edwards, 2011). Therefore, one of the roles of architectural design can be to reduce the prevalence of traditionally negative qualities associated with public space. Some of these difficulties include accessibility, safety, station comfort and convenience (Transportation, 2000).

Concurrently, a larger amount of people using a structure or service reduces negative qualities associated with public space by leading to an increased societal emphasis on proper maintenance of these areas. Larger crowds draw a higher demand for attention as well as a lower tolerance for undesirable behavior. Therefore, it is reasonable to expect that a well-designed station could attract a larger ridership; and more successfully address the undesirable characteristics currently associated with public transit.

\subsection{Transit Location and Corresponding Social Nodes}

One of the most important factors in encouraging the use of public transit is the level of convenience for travelers. Development along transit routes can directly improve the travel experience by providing services and amenities for a wide variety of interests. Due to the fact that businesses are most accessible when they are located in close proximity to existing travel lines, there is a strong relationship between investment in high-capacity, high-quality transit services and land use (Cervero et al., 2013). Cervero et al. attributes the strength of this relationship to the fact that developers tend to acquire land and intensify development in highly accessible locations.

Within densely populated areas, travelers have proven to be able to accomplish daily tasks while moving from one destination to the other via public transportation. Concurrently, in areas with increased development along travel routes, businesses also benefit through the large crowds that pass by their store on a regular basis. In a densely populated urban environment where there is constant traffic and personal transportation is inefficient, the mode of transportation that allows travelers to perform necessary daily tasks most easily will prevail over others that do not. Close 
proximity between transit station and urban destination is seen as not only a benefit to patron and business, but also a possible factor in observed ridership.

In an effort to make sure that the proposed station is given the best chance to succeed once it is built, there are certain qualities that

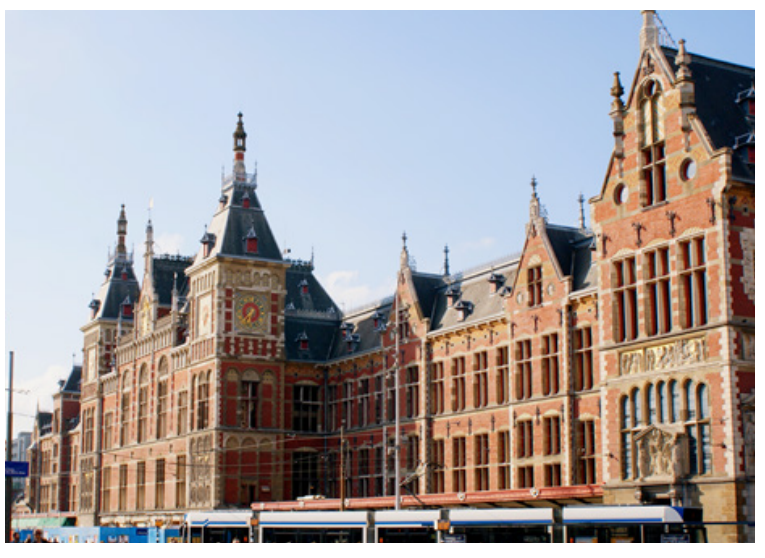

Figure 1 - Amsterdam Central Station (Source: Silva, 2012) designers and developers must look for in a site. Logically, the ideal station site is one that is central to large gathering spaces or prominent destinations within the city. Also, designers should look for a site that can link multiple types of transit routes in order to promote interconnectivity. According to Brian Edwards in Sustainability and the Design of Transport Interchanges, the important task for designers is to join the interchange with the movement patters of the city. This is achieved by positioning the interchanges (stations) along major road systems, where the existing hierarchy of streets and public transport infrastructure compliment each other (Edwards 53). An example of this is found in the Amsterdam Central Station. This station acts as a hub for the majority of transportation lines in the city. It does this not only through its location, but its role as the largest public transfer spot as it serves 250,000 people each day (“Amsterdam Central Station”, 2013). The enormous structure includes 15 tracks and 3 tunnels, which create enough space to accommodate many different types of transportation including buses, trams, and the metro light rail system ("Amsterdam Central Station", 2013). The inclusion of different types of transit allows travelers to benefit from the stations central location no matter the type of transportation they are using.

The linking of different transit lines through multi-modal stations has proven to lead toward the development of social nodes within the larger systems. These nodes become places of movement and exchange, where progression and human interaction are celebrated. With such an emphasis on a single site, travelers often develop a great sense of pride for these interchanges, as the structures become a popular meeting place, or a central landmark to the local community. The York Railway Station in York, England is an example of how a station can stand as a symbol of pride 
for the city in which it is located. The station was opened on June 25, 1877. After 3 years of construction, the station confirmed the city's status as the heart of the local transportation network ("York Railway Station", 2013). The design of the station reinforced it's impressive status as it stood 800 feet in length with a 42 foot tall roof held by massive iron columns.

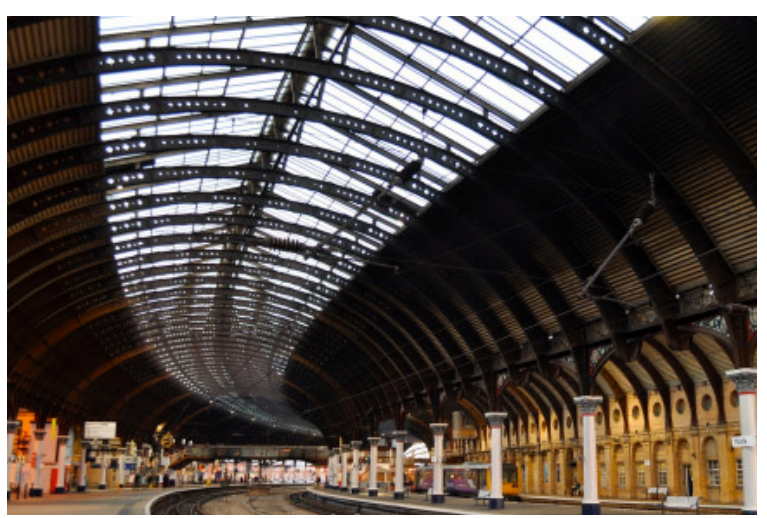

Figure 2 - York Railway Station (Source: Sangeeta, 2012) It was often referred to as "a monument to extravagance" ("York Railway Station", 2013). The large, detailed structure gained popularity quickly and became a landmark feature of the city. To this day, it provides a great example of how a station can be designed to not only serve a function but to improve its surroundings.

Currently, the concept of the multi-modal transit station is more important than it has ever been. Since many forms of transportation including light rail lines, bus routes, bike routes and pedestrian walkways surround the contemporary urban station, designers are presented with an opportunity to create a facility that accommodates them all while preserving the social qualities that many individuals value.

\subsection{Station Design Determines Interconnectivity}

Transit routes and the vehicles they guide will continually act as important factors in the successes and failures of each urban system. However, improvements in the design of the individual station not only have the power to better accommodate those who choose the urban lifestyle, but to improve the quality of life for anyone who visits these dense landscapes. This research understands the urban environment as a complex machine as it is built from separate systems that interact to produce a unique landscape. One of the most important systems is public transportation, where buses, trains and subways move people from place to place on a fixed route and 
planned schedule. Since large urban populations, and an increasing ridership, no longer allow the transit station to be mode-specific, new stations are designed with multiple transportation systems in mind, which allow travelers to move easily from one vehicle to the next.

Buses are predominantly used for short trips within the urban core due to the fact that they are able to navigate sharp turns and make frequent stops within a given area. Light rail is often the choice for commuters who travel longer distances because it has the ability to cover a large area at a rate that is much more efficient than alternative methods of travel. The strengths of each system combine to provide transportation throughout the majority of each large city, which makes connections between each type of vehicle imperative for the growth and promotion of alternative transit in the future.

Historically, train stations did not need to be designed for accommodating multiple types of transportation as the majority of trips were over long distances at varying times. As more travelers begin to embrace the idea of public transit, new stations look toward the linking of multiple modes in order to serve patrons who now travel shorter distances and more often. One independent type of transportation is no longer acceptable for contemporary urban environments. This is especially true as the main goal is to highlight the benefits of alternative transportation and encourage its use.

\subsection{Site and Station Design}

As railroad companies first began to expand their networks, they developed the land adjacent to the train stations they owned. Hotels, stores and offices were built on these properties to make the experience more convenient for the traveler (Edwards, 2011). This resulted in a similar type of development in each area due to the fact that each company was competing with one another and strove to maximize their profits by developing land where the people were. Due to the fact that each of these nodes was developed by the same enterprise, the architectural style of the buildings at each location was also very consistent. This helped to give each location it's own unique iden- 
tity when compared to others (Edwards, 2011). As these locations grew and spread outward, the station would often find itself in the middle of the city where the central location and prominence of mass transportation provided services for everyone.

While much of the development seen throughout history was focused on changing the landscape into something new and different, the goals of transportation development today have evolved to look at station design as supplemental to the existing environment. Because of an already established landscape in many areas, designers now look toward local patterns, relationships and cultures in an attempt to create something beautiful, functional and unobtrusive. The art of station design can be looked upon as most successful when the transit station appears to be woven into the very fabric that surrounds it.

While designing the layout and style of larger stations, it is not just local, urban traffic that the architect must recognize. Long distance travel will always be a major part of the urban train station. It is because of this that train architecture is often seen as more personal and unique than other forms of transportation. Due to varying sizes between different types of transit terminals, structures such as a typical airport are often disconnected from urban spaces and set aside on their own piece of land while the train station is deeply imbedded within the urban landscape, close to large civic centers and gathering spaces. These inherent differences in size and context allow train architecture to integrate better into local surroundings because each station is actually built within and among other urban structures. The opportunity to integrate the train station into the local landscape adds to the travel experience by reinforcing the unique identities of the station's surroundings through site-specific design.

The architectural design of a facility can pay tribute to the local scene and history of the area, just as the first stations did. In many cases, older train stations have been renovated in order to accommodate modern demands. The reasons for these renovations can include new transportation types, the need to provide services for increasing populations, or necessary updates to structural systems. This type of renovation has been seen in the London Paddington Station, which was originally opened on January 16,1854 . This station has been seen as an iconic piece of architec- 


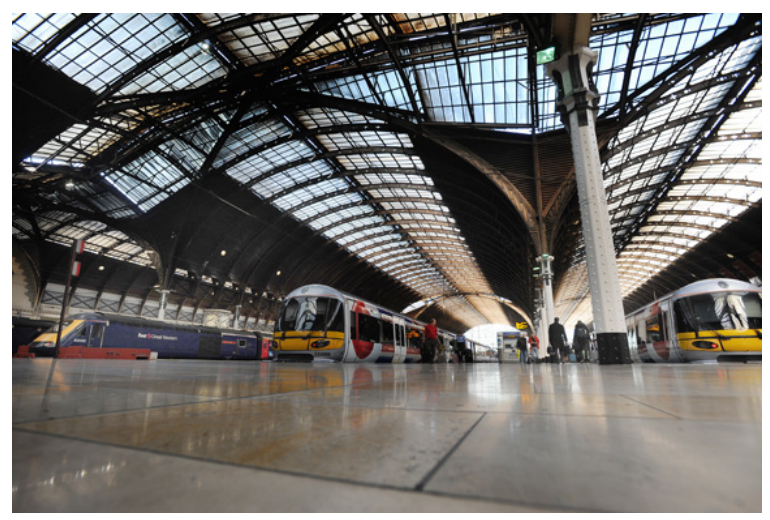

Figure 3 - London Paddington Station (Source: Ortiz, 2012) ture from the beginning even through numerous renovations. These improvements, the most recent being in 2009 , have allowed the station to adapt to changing times and growing populations ("History of Paddington Station", 2013).

The contemporary goal of integrating trans-

portation development with existing infrastructure can be achieved in many different ways. Some of the most successful projects are able to create an identity for themselves by complimenting the designs of other buildings or structures in the area. The Hollywood and Vine station in Los Angeles, CA is an example of how the design and orientation of a station can draw from its surroundings to help define it. While the station entrance itself is located on the same property as the W Hotel, it uses the architecture of surrounding buildings to paint a picture of the history and culture behind the location. This particular station does this through the orientation of its main entrance ("Hollywood and Vine Metro Portal and Plaza", 2013). As travelers exit the station and walk toward Hollywood Boulevard, the first thing they see is the Pantages Theatre, located directly across the street. The ornamentation of the old theatre is nothing like the new designs which define the W Hotel property where the station resides. However, the theatre is used as a tool to remind travelers of the area's history, without being directly connected to the station site.

The relationship between the exterior and the interior of each station is also important for contemporary designers to acknowledge, especially when developing new transit structures. While the exterior of the train station provides protection from the elements and creates a sense of place for the structure itself, station layout organizes various amenities and guides travelers to and from the transit vehicles. Due to the fact that the successes of station design are often most apparent through the design of station interiors, contemporary designers look for innovative ways to promote easy navigation within the structure. This can be accomplished through many different approaches. Large platforms and wide corridors seen in many station designs not only help to open up the interior space visually, they also ensure safety as travelers move past each other. 
Another successful strategy is the usage of natural light to illuminate the inside of the station (Edwards, 2011). The visual appeal that natural light induces is important because it maintains a connection with the world outside of the station, even though the platform might be located underground, away from the noise and commotion associated with the street.

The more successful stations are able to blend these differing spaces in a seamless manner, making the act of traveling more enjoyable.

The experience of the traveler should be the number one concern for designers. The architecture of the transit station is the interface between visitors and their preferred form of

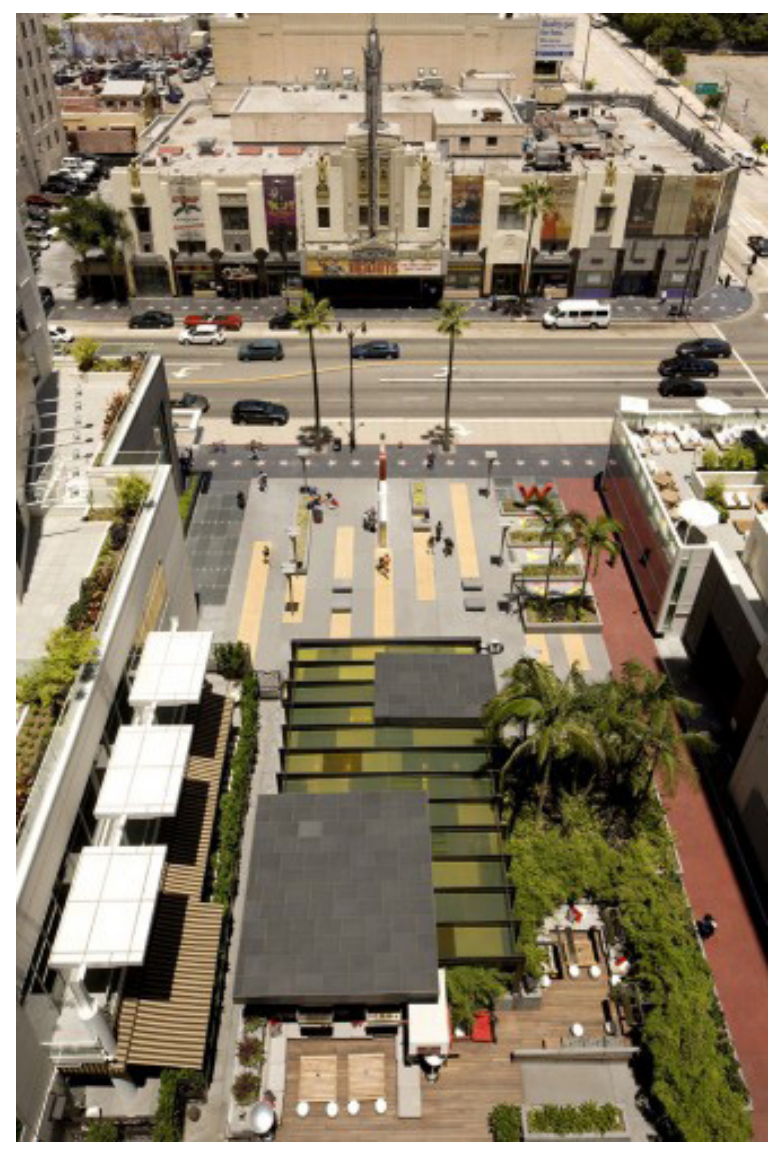

Figure 4 - Hollywood and Vine Station Entrance and Plaza (Photo Credit: Tom Bonner; Source: "Hollywood and Vine Metro Portal and Plaza", 2013) transportation. The layout is their map and the linkages between platforms, hallways and concourses are their tools. Travelers are not moving through the structures at high speeds. They are walking, which means they are looking and feeling. According to Le Corbusier, "Architecture is experienced by eyes that see, a head that turns and legs that walk".

When the enormous train shed for the original Grand Central Terminal in New York was built in 1900 , it revealed how a structure can serve a familiar function while taking on an identity of its own. The glass and steel building measured 650 feet long and 100 feet wide. It featured a classical façade, a 16,000 square foot waiting room and unique ornamentation including monumental cast-iron eagles with 13-foot wingspans ("History", 2013). The structure was so impressive that it was considered to have rivaled the Eiffel Tower and Crystal Palace for primacy as the most dramatic engineering achievement of the 19th century ("History", 2013). The original station stood for 3 years until a switch from steam locomotives to electric trains lead to a complete renovation 
of the station, and ultimately, the demise of the original Grand Central (“History”, 2013). The Grand Central Terminal was built on the idea that the train station can provide more than a service. Through design, it has the ability to become something that is experienced, felt and remembered by each visitor.

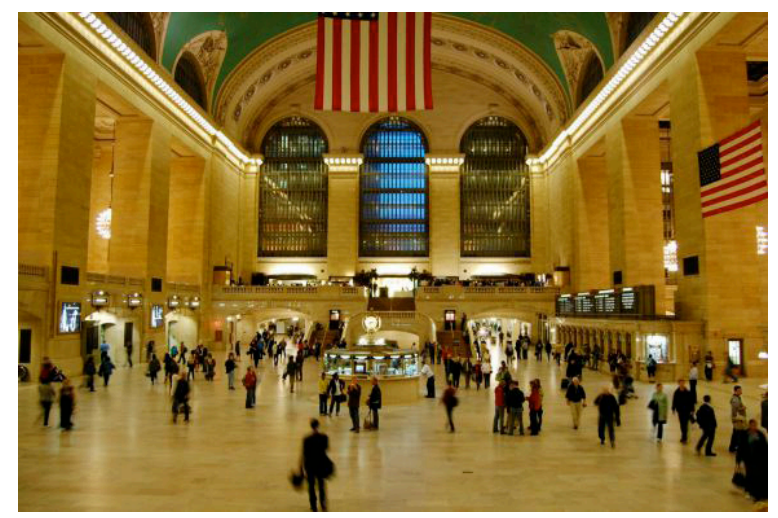

Figure 5 - Grand Central Terminal (Source: “Grand Central Station's $\$ 20$ Million Clock”, 2009)

According to Sustainability and the Design

of Transport Interchanges by Brian Edwards, there are specific design objectives that must be included in the planning of the interior spaces. Some of these include:

- Allowing the most frequently used transport mode to be the closest to ground level

- Providing a visual connection between concourses of differing elevations

- Ensuring that speed of transfer and exit remains a top priority

The designer can also look for ways to enhance the travel experience and encourage special moments through the provision of large open spaces in meeting areas with natural lighting and proper air circulation (Edwards, 2011). The interior environment must be comfortable for visitors instead of being an experience that people avoid. This approach to design can also add to the appeal of mass transit by making the transit station a place that people want to be. The same design techniques used to improve office buildings and private homes can be the catalysts for the evolution of public views toward making mass transportation a part of society's daily routine. As 
these factors are acknowledged in station design, the act of traveling by means of light rail or bus takes on a new face within the public eye and may soon become widely accepted within the urban center.

\subsection{Precedent Stations}

This section reviews a total of nine precedents around the world that are widely considered to be innovative, current and successful on a large scale. The section recognizes that each station has been designed in the context of their local surroundings, and attempts to highlight the reasons for each of their unique successes in urban transit.

\section{Station \#1 - RandstadRail Station Beatrixlaan Den Haag \\ Zwarts \& Jansma Architecten}

The Hague, The Netherlands

\section{Location}

The RandstadRail Station is located in the center of The Hague, which is the government city of Holland in the Netherlands (NBTC, 2013). The elevated station marks the halfway point of the viaduct over the entire length of the Beatrixlaan, which links the tram viaduct at the Ternoot stop and the NS railway embankment (RandstadRail, 2009). Contem-

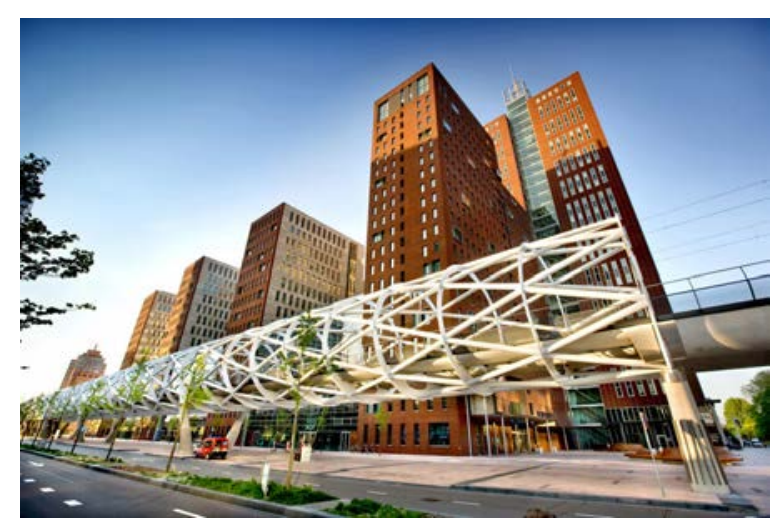

Figure 6 - Street View of Elevated Space-Frame (Source: RandstadRail, 2009)

porary Architecture describes The Hague as a "prison city", as the sea, the highway connecting Amsterdam and Rotterdam, and other neighboring cities surround it.

\section{Circulation and Program Analysis}

Access to the central platform is compact due to the fact that the tracks split apart when entering the station. With a limited amount of space on the elevated platform, the station noticeably 
provides room where passengers are expected to wait while smaller spaces are reserved for areas with lower traffic (RandstadRail, 2009). The program is uncomplicated, with the main portion of the station as a single, central platform with tracks on each side. Travelers are brought up to platform level by way of stairs. The central location of the platform and stair connection alleviates the need for passengers to cross the tracks at any time.

\section{Design Characteristics}

The white space-frame is made of mildsteel strips in the shape of rings that encircle the train tracks. At the station's core, large, concrete beams support the structure with the

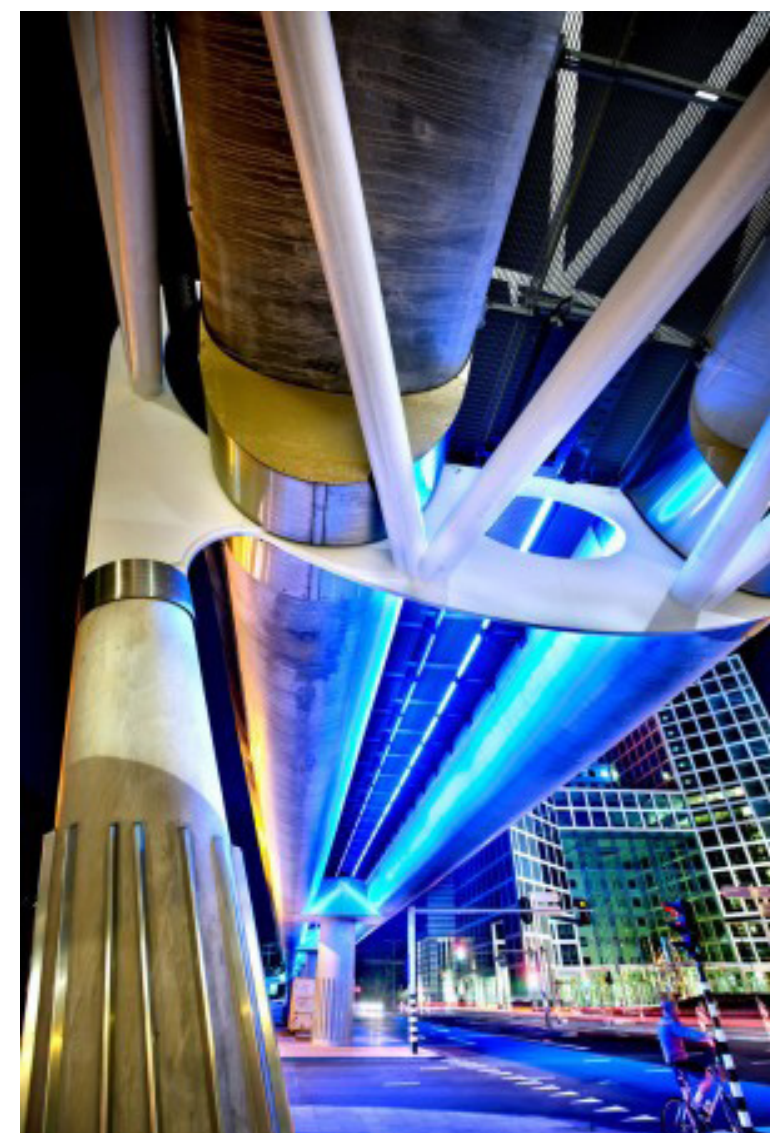

Figure 7 - Station Lighting (Source: RandstadRail, 2009) platform surface suspended in between. Glass windbreaks are also mounted to these concrete supports to provide protection and comfort to station inhabitants (RandstadRail, 2009). The contrasting elements between bulky concrete supports and glass walls allow the station to stand confidently among the surrounding buildings while maintaining transparency and connection to the street. Beneath the station, neon lights glow from between the structural elements and are visible the structure, the lights create a level of theatricality and highlight the station as a key element in the local landscape.

\section{Key Features}

A tubular space-frame encloses the platform of the station, implying an extended sense of protection from the outside world while simultaneously acknowledging the surrounding buildings. The framed structure extends 400 meters along the viaduct with a diameter of about 10 meters RandstadRail, 2009). The two tracks are supported by V-shaped collumns at spans of 40 and 50 meters, which allow for an increase in social and traffic safety due to a reduced visual obstruction at 
eye level (RandstadRail, 2009). The design of the train platform remains fairly simple as much of the artistic expression is accomplished through the large space-frame. The visual impact created by this economical design is noteworthy as the structure provides a dynamic appeal to passengers without appearing exorbitantly complicated.

\section{Interpretation of Research}

Through the meticulous development of specific design features, this station successfully achieves impressive character without overly expressive efforts in its layout. Specific design features include the usage of lighting, transparent materials and an emphasized space-frame. The large frame implies an initial level of separation between station occupants and their surroundings. However, due to the fact that the frame is completely passive and does not provide protection from the elements, views from the platform are not obstructed. Also, the glass windbreaks at the center of the structure suggest a protective core for passengers from which the rest of the station extends, which provides a comfortable and easily navigable spatial organization.

\section{Station \#2 - Morgan Station}

\section{Ross Barney Architects}

\section{Chicago, Illinois}

\section{Location}

The new Morgan Station is an updated realization of transportation in Chicago. Originally opened in 1893, the station later suffered from a reduction in demand and was forced to close in 1948 (Gerfen, 2013). Currently, the local environment is experiencing a new influx of people, which has led to the reimagining of the

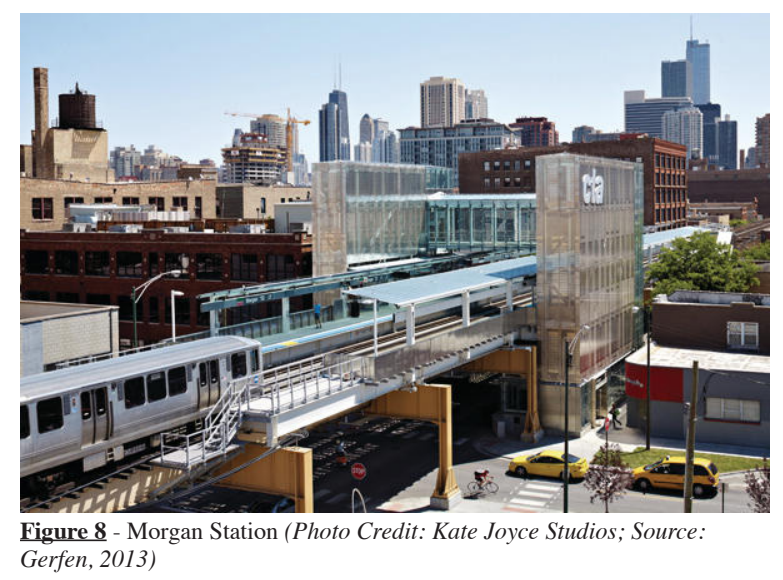
light rail station along Chicago's "El” system. Located in the neighborhood of West Loop, between Chicago's central business district and western suburb of Oak Park, the station provides a new form of transportation to local travelers 
(Witcher, 2012; Gerfen, 2013). While larger amounts of people begin to move into the West Loop area, the neighborhood remains strongly influenced by it's industrial roots through both architecture and commerce.

\section{Circulation and Program Analysis}

The station design includes two fare collection entrances at ground level that each lead up to separate elevated platforms above the roadway. By locating the majority of the structure at ground level, the architects were able to design a much lighter, transparent platform that floats over the surrounding landscape (Witcher, 2012). According to T.R. Witcher in his

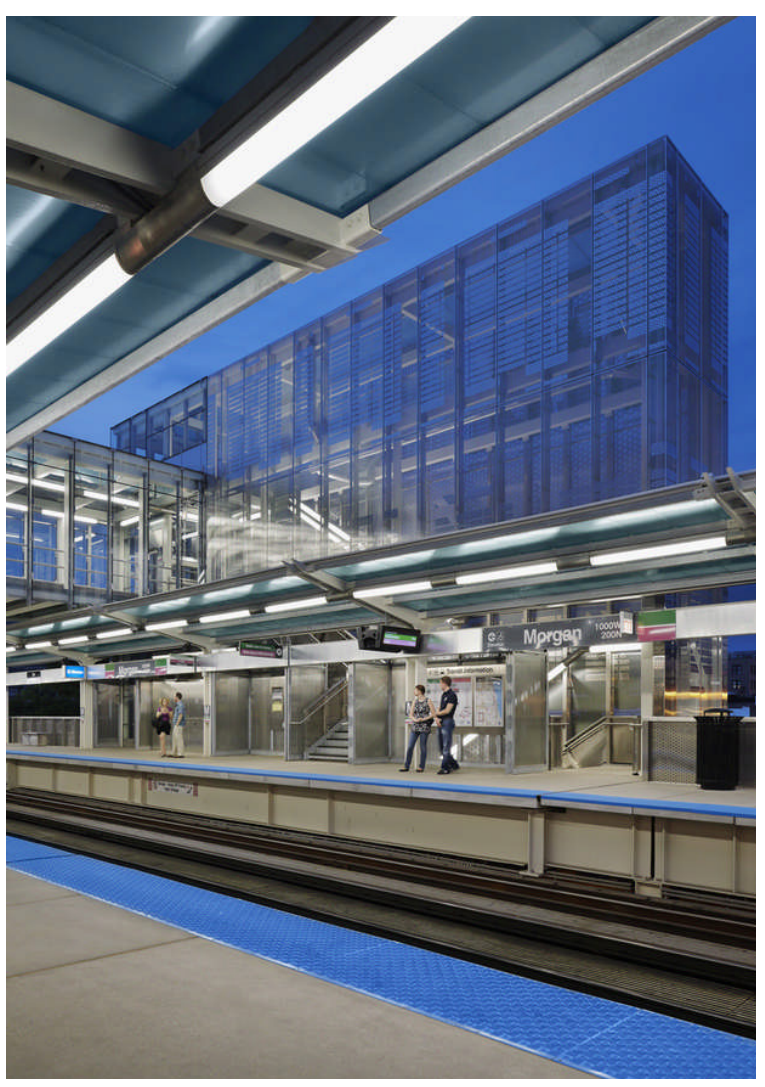

Figure 9 - Elevated Platform and Tower (Photo Credit: Kate Joyce Studios; Source: Gerfen, 2013)

article for Civil Engineering magazine, many

of the station in the local area have the fare collection on the platform of the station. However, this was not realistic for the Morgan Station site as the road below the station caters to high truck traffic, causing the station platform to need to be raised at least 14 feet 6 inches form street level (Witcher, 2012).

\section{Design Characteristics}

Taking cues from the local semi-industrial area of Chicago, the glass and steel station continues the tradition of a "revealed" architecture, where the structural supports of the station are empha- 
sized and used as ornamentation (Witcher, 2012). The station design uses modern materials such as perforated stainless steel, translucent polycarbonate and exposed structural steel framing to identify itself with it's surroundings (Motchan, 2013).

\section{Key Features}

Due to the fact that the station's fare collection system is located at ground level, the elevated sections of the lightweight structure are covered in glass cladding. This transparency provides a beautiful contrast to the rough, industrial area and also allows clear views of surrounding skyscrapers (Witcher, 2012). While the translucent geometries float above their hard-faced, concrete neighbors, the station maintains it's industrial identity through modern design. The station contains two platforms that are staggered and framed by large towers. Each tower is covered on three sides by perforated stainless steel panels that not only add dimension during daylight hours, but protect the glass from vandalism (Gerfen, 2013).

\section{Interpretation of Research}

The new station's unique layout and appearance, which was created by the design obstacle of not being able to locate the ticket window at platform level, allows a taller structure to be constructed due to reduced weight. The highly regarded appearance of the new station's glass walls mimics the rectangular shape of surrounding industrial buildings, but because of the considerable weight reduction, sits above the surrounding landscape and announces itself as a local hub for urban transportation. This is especially noticed after dark as the stations glass walls are illuminated to further emphasize their beauty. Also, by separating the ticket window from the platform areas, 
the tedious duty of waiting in line and purchasing a ticket is detached from the experience of being in the station, which may improve traveler perception of the structure as visitors are able to associate their use of the station with a more pleasant experience.

\section{Station \#3 - Al Rashidiya Metro Station}

\section{AEDAS}

\section{Dubai, UAE}

\section{Location}

The Al Rashidiya Metro Station is located in

Deira near the Rashidiya Park, south of the

Dubai International Airport ("Rashidiya Metro Station", 2009; "Rashidiya", 2013). The station operates as the terminus for the Red line of the Dubai Metro System where it's central location allows connections to six different bus lines ("Rashidiya", 2013).

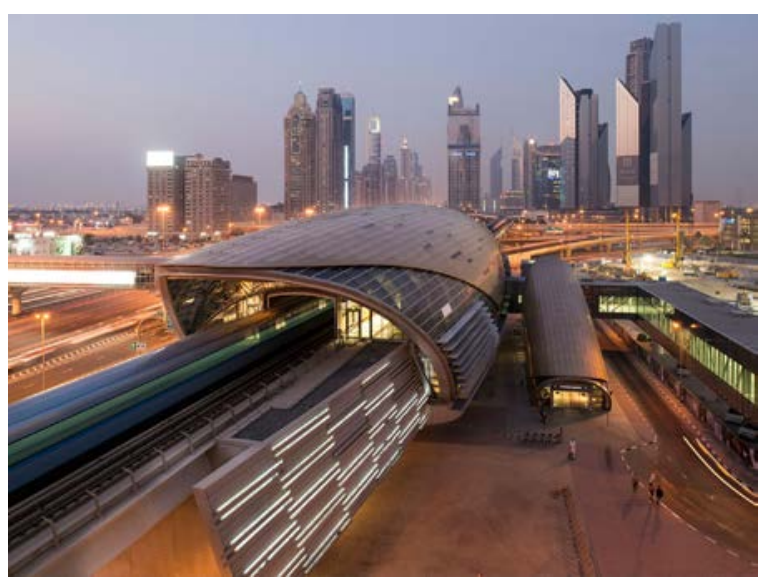

Figure 10 - Al Rashidiya Metro Station (Source: “Dubai Metro”, 2014)

\section{Circulation and Program Analysis}

The station has two entry points with escalators and lifts to ensure efficient traffic movement at all times (Staff Report, 2009). The design includes a footbridge spanning over existing roadways to connect platforms to one of the major Park and Ride options on the Dubai Metro System ("Rashidiya", 2013; Staff Report, 2009). The ground floor of the station serves as a major bus center and has been designed to accommodate both articulated and double-deck busses in times of high traffic on the site (Staff Report, 2009). Due to the fact that the station acts as both beginning 
and end to the first-completed line on the new transit system, the design of the structure aims to accommodate massive amounts of people at one time while simultaneously providing a high level of comfort and brilliance to the transit experience.

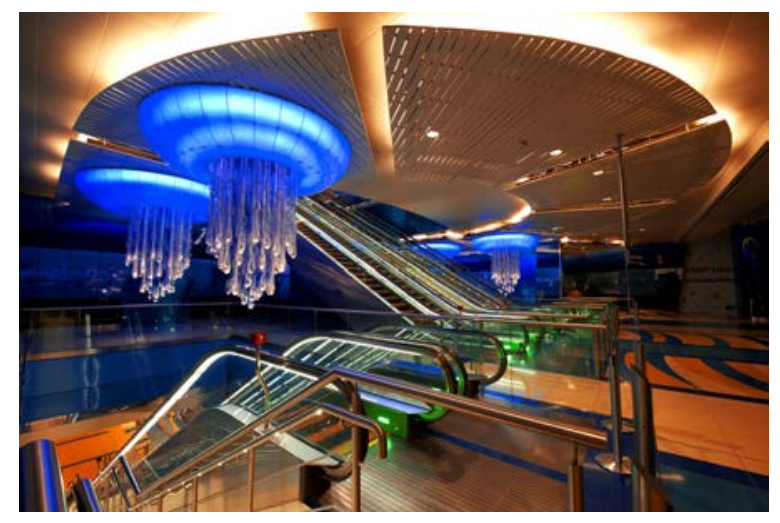
Figure 11 - Station Interior and Lighting (Source: "Summer is Dubai", 2014)

\section{Design Characteristics}

The strength of the station's design is displayed through the culturally significant, shell-shaped roof that pays tribute to Dubai's early successes in pearl diving ("Dubai Station Architecture", 2009). Similar to the pearls that inspired the station's form, the design concept aims to connect the State's early successes with those in the future due to the monumental improvements made through the construction of the metro system ("Dubai Station Architecture", 2009). Furthermore, the textures and colors of the roof's inner surfaces provide a brilliant enclosure that is meant to resemble that of a pearl ("Dubai Station Architecture", 2009). In an effort to avoid an overwhelming amount of glass, and to make the structures as eco-friendly as possible, lead architect Adrian Lindon reduced the initially-estimated peak cooling load by $35 \%$ with a reduction in glass used and an increase in insulation ("Dubai Station Architecture", 2009). Due to the fact that the station has been designed along with the new transit system, architects and designers on the project were allowed many opportunities to build a seamless interconnectivity between each individual structure and its larger network.

\section{Key Features}

The elevated station is directly connected to large attractions such as the Rashidiya Shopping Center and Rashidiya Bus Center ("Rashidiya", 2013). The site offers close to 3,000 spaces for travelers to leave their car while they traverse throughout the system's expansive transit networks ("Rashidiya", 2013). The station stretches 130 meters and 30 meters in width as it has the capacity to handle up to 11,000 passengers per hour in each direction (Staff Report, 2009). The final stage of construction, completed in 2010, included the opening of 10 new bridges and roads to 
ensure free traffic movement for travelers driving from Abu Dhabi toward the large parking areas ("RTA Opens Bridges Leading to Entry \& Exit Points of Rashidiya Metro Station on 15 July.", 2010).

\section{Interpretation of Research}

While the Rashidiya Metro Project is not limited to the design of a single transit station, it provides relevant and important information to this study. Due to the fact that each station was designed simultaneously with the complete system, it can be expected that the decisions made in the designs of the included stations reflect the values thought to be most important in transportation architecture. Design qualities most emphasized in these stations include connections to large transit networks of varying types, substantial parking opportunities in close proximity to the station, retail opportunities for travelers and protection from the elements without sacrificing a connection to the surrounding environment.

\section{Station \#4 - Liége-Guillemins Station}

\section{Santiago Calatrava}

\section{Liége, Belgium}

\section{Location}

Liége is located in the valley of the Meuse River, near Belgium's eastern borders with the Netherlands and Germany. Due to its location, the city also acts as a major node in the European high-speed rail network, which links London, Paris, Brussels and Germany ("Liége Guillemins TGV Station”, 2009). This association with such a large network demands a

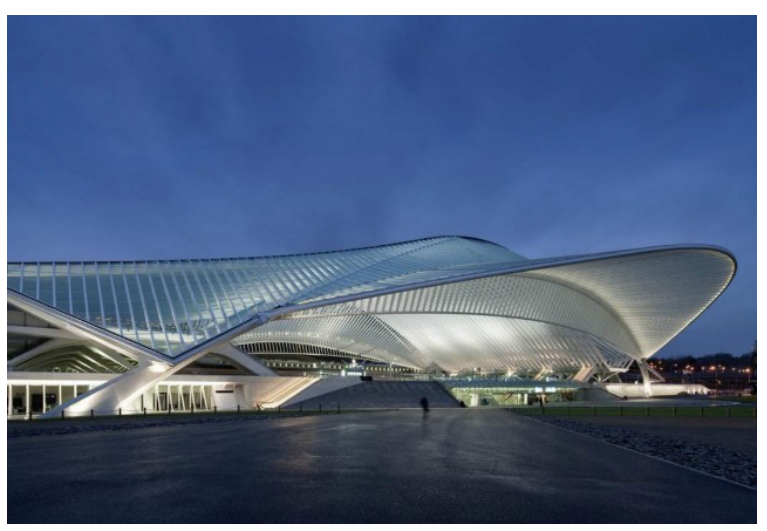

Figure 12 - Liège-Guillemins Station (Source: "Liège-Guillemins Station by Santiago Calatrava”, 2013) 
transit station that has the capability of handling large amounts of passengers at once as well as multiple types of transportation vehicles. The existing station replaced a post-war building from the 1950's.

\section{Circulation and Program Analysis}

At street level, the station aims to extend the local streetscape through it's inclusion of a strip of commercial units (“Liége Guillemins TGV Station”, 2009). Pedestrian walkways and bridges under the tracks allow improved communication between both sides of the station as the passenger hall and ticketing area are both centrally located on the main axis ("Liége Guillemins TGV Station", 2009). With such an emphasis on communication between the exterior and interior qualities of a single structure, the station allows free movement through all areas, while maintaining exceptional level of comfort for visitors.

\section{Design Characteristics}

The concept for the design was transparency and to create an urban dialog between the transit structure and the city ("Liége Guillemins TGV Station”, 2009). These concepts were realized through the monumental vault, constructed of glass and steel and extending two hundred meters in length and thirty-five meters high over five platforms. ("Liége Guillemins TGV Station", 2009; "Liége-Guillemins Railway Station", 2013). This glass building is meant to replace the traditional façade in an attempt to more effectively connect the interior of the structure with the surrounding environment ("Liége Guillemins TGV Station”,2009). The roof is also designed to be experienced from both sides as it reveals the inner organization of the station from the outside, and frames views of the landscape from the interior (“Liége Guillemins TGV Station”, 2009).

\section{Key Features}

The station is organized vertically in two sections. The first section is oriented towards the Place de la Gare and consists of multiple

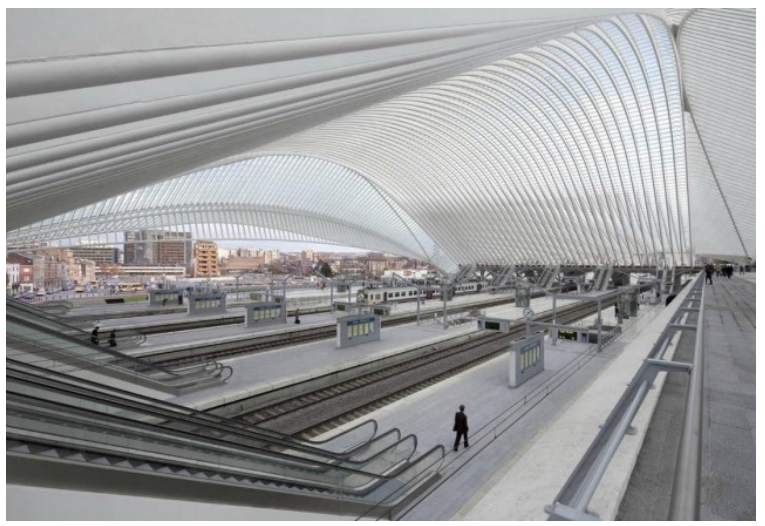

Figure 13 - Liège-Guillemins Interior Platforms (Source: "Liège-Guillemins Station by Santiago Calatrava”, 2013) 
platforms and a footbridge, which stack over 3 Levels ("Liége Guillemins TGV Station”, 2009). The other section of the station is oriented towards Cointe Hill and includes three parking levels, a vehicular access deck linking with the footbridge and a raised pedestrian walkway that comprise a total of five levels ("Liége Guillemins TGV Station", 2009). One of the most special qualities of this station is that it sets out to create a unique character for itself through the holistic viewing of both exterior and interior. An appreciation for each on its own is definitely possible. However, the true identity of the station is revealed when both are understood simultaneously.

\section{Interpretation of Research}

Similar to other stations observed within the study, the Liége-Guillemins station achieves a high level of transparency between interior and exterior spaces. However, it is the architectural recognition of differing visual perspectives between travelers outside of the station and those on the inside that makes this design uniquely successful. The structure is perceived differently based on the location of the traveler. On the inside, the structure is interpreted as superior as it frames views of the exterior surroundings. Conversely, when the station is seen from the outside, holistically and in the context of local landscapes, it becomes subordinate to the region as a whole, while maintaining its identity as an important piece to a larger system.

\section{Station \#5 - Dresden Station \\ Foster + Partners \\ Dresden, Germany}

\section{Location}

Dresden's central location between large German cities such as Berlin and Prague allowed its early industrial and economic development through connections to these larger networks via railway (“Dresden Station Redevelopment", 2013). Extensive damage was cause to the region during 
World War II, which left the original station in poor shape. After the war had ended, efforts were made to repair the structure, but they remained ineffective as the station was significantly stripped of its original character ("Dresden Station Redevelopment”, 2013)

\section{Circulation and Program Analysis}

The design of the new site draws attention to

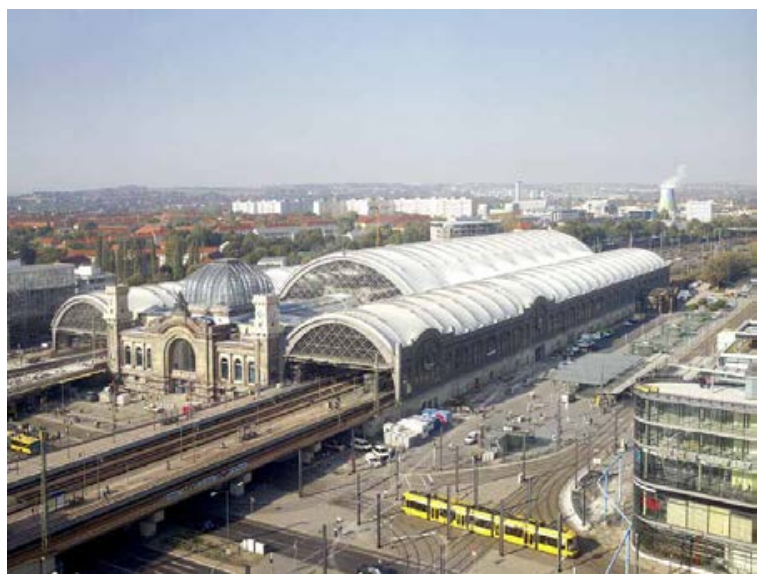

Figure 14 - Dresden Station Aerial View (Photo Credit: Nigel Young; Source: Welch, 2014)

the importance of the original structure by po-

sitioning it in the center of the new layout with the expanded concourse and high-speed rail tracks on three sides. Numerous shops and cafes surround the station as this acts as a central location for many different types of transportation. The station design

\section{Design Characteristics}

Since the redevelopment, the termination point of the central tracks has been pulled back to create a large open space at the heart of the building to be used as a market place or event space ("Dresden Station Redevelopment", 2013). According to the architect's website, "The surviving structure and original surfaces have been exposed wherever possible, but there has been no attempt to recreate old forms or replace lost ornament." The ability to create a new type of architecture on top of an existing building without the two styles colliding is seen in this redevelopment project through the glass dome, which sits above the main circulation crossing in the station, and the dramatically vaulted roofs above the train platforms ("Dresden Station Redevelopment", 2013).

\section{Key Features}

According to the architect, the original roofs over the train platform were partially glazed. However, after the damage caused by the war, the surface was boarded over. During the redevelopment efforts by Foster +Partners, the wrought iron structure, which holds the roof in the air, was restored and covered in a Teflon-coated, glass-fiber fabric that transmits 13 percent of daylight causing a reduced need for artificial lighting in the building ("Dresden Station Redevelopment", 
2013). Concurrently, this covering also reflects interior light in the station after dark in order to efficiently illuminate the concourse (“Dresden Station Redevelopment", 2013).

The covering also highlights the importance of the relationship between previously- existing station infrastructure and the improvements recently made. The smooth lines of the white roof flow nicely with the curvature of the

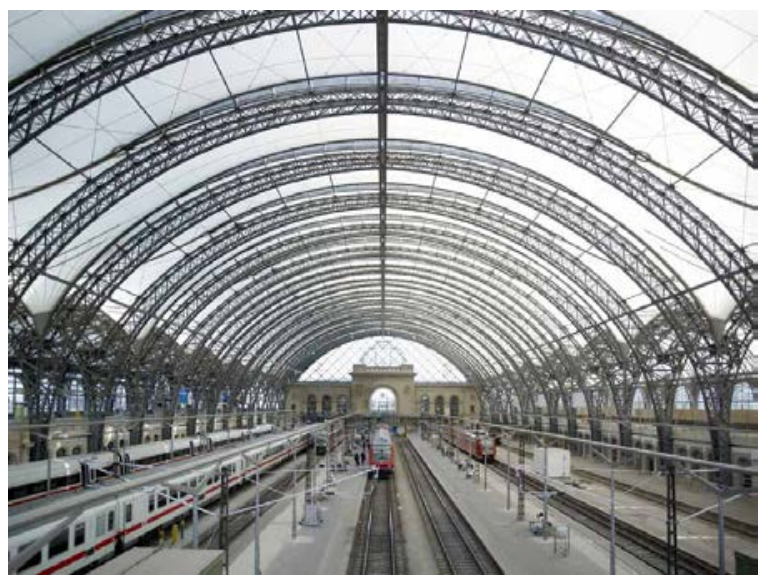

Figure 15 - Interior Station Platforms (Photo Credit: Nigel Young; Source: Welch, 2014)

tracks it protects as it embraces and pays tribute to the original station building.

\section{Interpretation of Research}

The redevelopment of Dresden Station is a contemporary example of how modern technology can improve a transit station while maintaining an awareness of existing infrastructure and historical significance. The large platform canopy is not only designed to be able to accommodate future expansion due to the probable inclusion of a high-speed rail line, but it employs a fabric roof covering that filters natural light during the day while reflecting interior light after dark to provide consistent illumination for station occupants. Multiple types of transportation and retail options are also included within the design to solidify the stations position as a major transit hub for the region.

\section{Station \#6 - Kanazawa Station}

\section{Tameo Kobori}

Ishikawa Prefecture, Japan

\section{Location}

Kanazawa Station is J.R. West Railway's major transit structure in Kanazawa ("Kanazawa Tourist Information Guide", 2008). It is located in the Ishikawa Prefecture and acts as a movement hub 
for the local areas as numerous hotels and travel destinations surround it. Due to the dense urban environment surrounding the station's site, the structure is separated from related parking by the tracks it serves.

\section{Circulation and Program Analysis}

The underground of the dome serves as both an information corner and event space

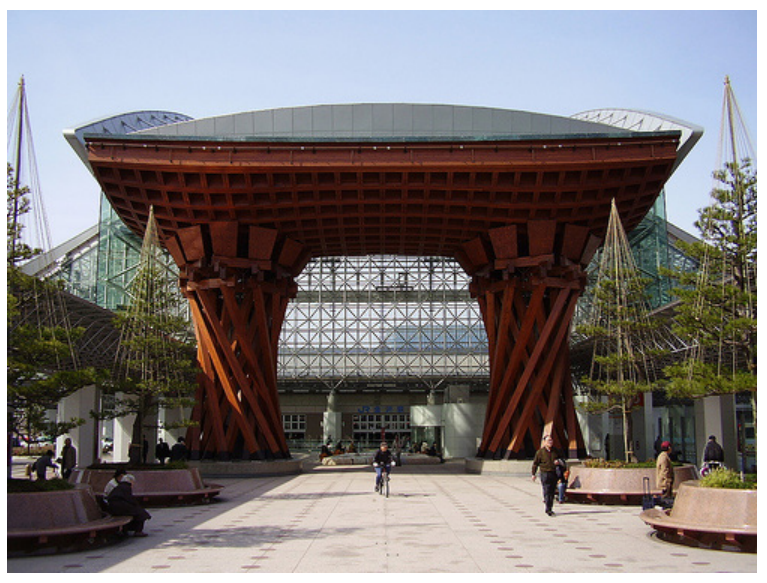

Figure 16 - Kanazawa Station Main Entrance (Photo Credit: Adam Kahtava; Source: "Train Stations", 2014)

("Kanazawa Tourist Information Guide", 2008). In recent years, the addition of large retail stores within the station has turned many of the spaces into a busy shopping quarter ("Kanazawa Tourist Information Guide", 2008). The addition of these amenities has transformed the station from a one-dimensional building into a multi-faceted social destination where local populations and visitors from throughout the world come to visit and experience the architecture of the structure.

\section{Design Characteristics}

In anticipation of the Hokuriiku Shinkansen High Speed Railway Line, a major reconstruction is occurring in the station's surrounding landscape ("Kanazawa Tourist Information Guide", 2008). The location of many hotels and shopping centers around the station allow it to be a major hub for local travelers to meet and spend time ("Modern Structure", 2013). At the east entrance of the station is a large wooden gate called "Tsuzumi-mon". This celebrated entrance symbolizes a traditional Japanese instrument called tsuzumi, meaning hand drums ("Kanazawa Tourist Information Guide", 2008). Once through the gate, travelers enter a large, glass dome called "Mote- 
nashi (Welcome) Dome" where natural light and open spaces connect visitors to the outside world while they are protected under the transparent ceiling ("Kanazawa Tourist Information Guide", 2008).

\section{Key Features}

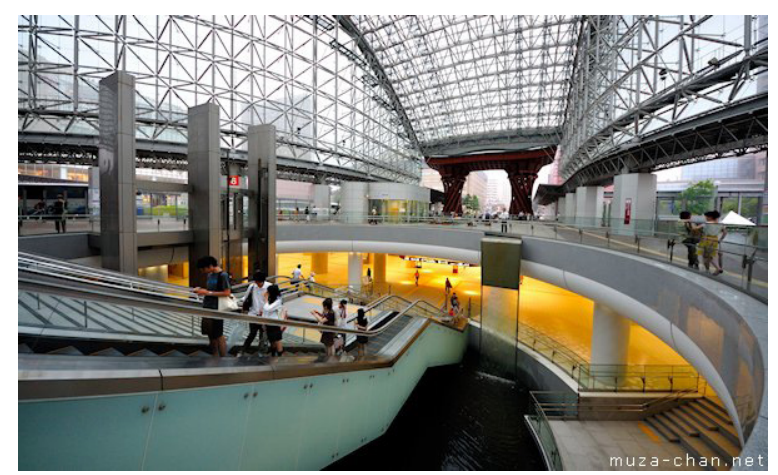

Much of the architectural emphasis in Kanaza-

Figure 17 - Kanazawa Station Interior Plaza (Photo Credit: Muza-chan; Source: Muza-chan, 2013)

wa Station is observed in areas around the east entrance. The ornate gateway and glass dome create a large atrium with benches and water features where visitors can relax and greet others. The station, through these covered gardens, become more than a portal for travel. The architectural design of the building transforms it into a landmark piece for the area, which undoubtedly influences the amount of people who do use the station for travel.

\section{Interpretation of Research}

It is important to recognize the impact of design on this station. Much of the architectural effort observed in the structure is at the station's east entrance. Here, the impactful gateway and glass dome welcome visitors and provide an experience that is uncommon in many other places. 
However, the rest of the station may seem fairly simple when compared to its celebrated plaza.

The focused efforts in one area of the structure prove to be enough to not only create a respected identity for the station, but to attract visitors from all over the region.

\section{Station \#7 - Bilbao Metro \\ Foster + Partners \\ Bilbao, Spain}

\section{Location}

Each station is located along a rapid transit system that caters to the city of Bilbao as well as the Greater Bilbao region. The line, in its entirety, begins as two separate lines along the Nervión River and then combines into a single line as it heads toward its termination in the southern part of Bilbao (“Presentation”, 2013).

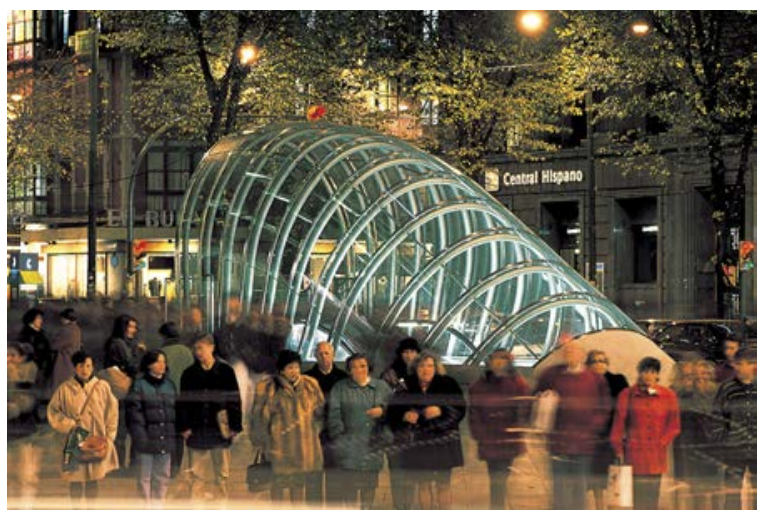

Figure 18 - Iconic Entrance to Subterranean Station (Source: "Bilbao Metro", 2013)

\section{Circulation and Program Analysis}

According to the architect, one of the main goals for the design of this project was to make the layout of the station understandable to its inhabitants ("Bilbao Metro", 2013). Each decision made throughout the project was to improve the urban experience for the traveler while taking note of other approaches to transportation architecture that may not be regarded as successful. It is noted that the majority of contemporary subway systems can be confusing and difficult to navigate without an abundance of signage on every wall ("Bilbao Metro", 2013). This complicated type of layout does nothing but extract from the experience of the traveler. Given that sim- 
plicity and elegance are often at the forefront of a Norman Foster design, the Bilbao Metro station accomplishes the goal of providing an improved travel experience by emphasizing the effects that each design decision will have on the station occupants.

\section{Design Characteristics}

The iconic entrance canopies that connect the

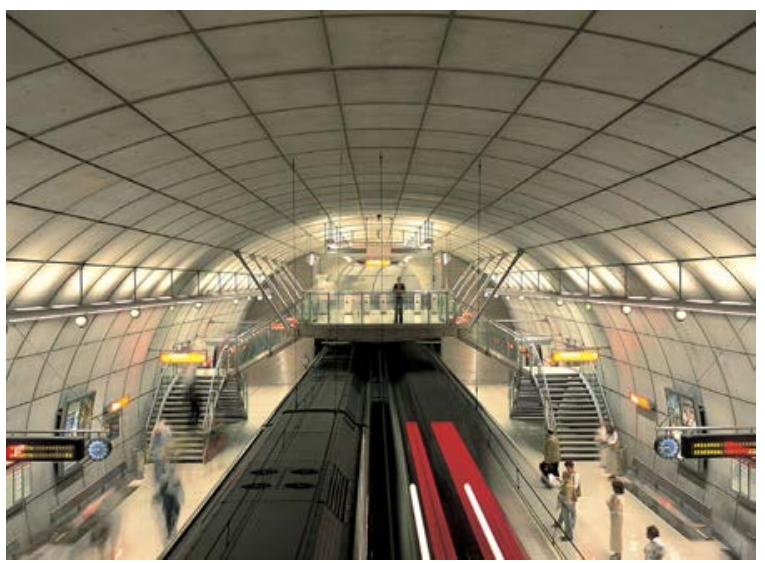

Figure 19 - Subterranean Station Platform and Elevated Walkway (Source: "Bilbao Metro", 2013

inner-city Line 1 stations at street level are completely influenced by the profile of the escalator tunnels moving travelers into and out of the subterranean station ("Bilbao Metro", 2013). This transparency of the canopies admits daylight into the tunnel during the day, but also allows each canopy to become a landmark beacon for pedestrians at night as they are both lit from the inside to stand out in the local streetscape ("Bilbao Metro", 2013). The elevated viewing areas within the station also help to create a sense of place in an underground word, where other stations might not be able.

\section{Key Features}

In an attempt to avoid the confusion often associated with traditional subway stations, the design of Bilbao Metro allows for oversized caverns below street level. The increased amount of underground space allows the experience of moving through a single grand volume to be more dramatic for the traveler ("Bilbao Metro", 2013). It also creates an opportunity to include stainless-steel mezzanines and staircases above the level of the trains in order to allow better orientation perception while in the station ("Bilbao Metro", 2013).

\section{Interpretation of Research}

Important design strategies are observed throughout each of the Bilbao Metro stations. The transparent entry coverings effectively announce their location among surrounding landscapes without overwhelming local aesthetics. Once inside the station, the additional vertical space provided 
in the tunnel allows the station to seem less claustrophobic than a traditional subway platform. Here, the ability to communicate freely between different levels of an underground station is proven to enhance the traveling experience drastically.

\section{Station \#8 - Gateway T Station}

\section{EDGE Studio}

\section{Pittsburg, Pennsylvania}

\section{Location}

The new Gateway Station is located in the heart of Pittsburg's Golden Triangle and Cultural District (TPlus, 2012). It is surrounded by the Highmark Building, Gateway Center and scenic green spaces. It is also located in close proximity to a newly renovated Market Square and Point State Park, which makes it a regular choice for travelers visiting the urban

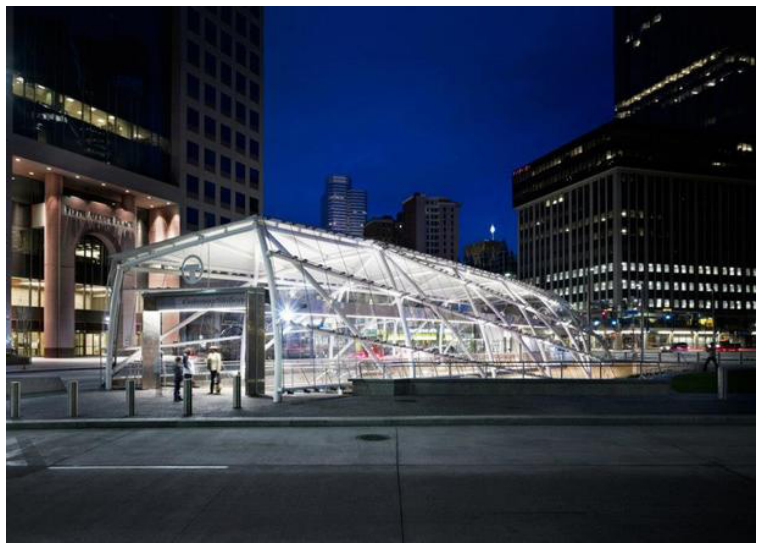

Figure 20 - Gateway Station Entrance (Source: “Gateway Station”, 2013) area. In addition to these destinations, other attractions include theatres, museums and hotels (TPlus, 2012). The central location of the station is ideal for any transportation project and undoubtedly aids in the provision of opportunities for both architects and transit users.

\section{Circulation and Program Analysis}

A main goal of this project was to allow transparency between the exterior plaza and the subterranean station platforms. Visually sensitive materials and innovative geometries are used in the design of the structure to allow free movement throughout the station as well as to provide clear visual cues within the structure (Pagnotta, 2011). In order to maintain a high level of communication between different parts of the station, the layout is designed to clearly guide visitors from 
the street and plaza level into the underground portions of the station. While moving along this path, travelers are able to maintain a strong connection to the exterior landscape through an unobstructed view of the city.

\section{Design Characteristics}

The designers of the Gateway Station developed a concept around the "Gateway Experience", where transit users are transported into the heart of the Golden Triangle through the proposed under-river transit tunnel of the North Shore Connector Project (Pagnotta, 2011). In order to realize this concept through the design of the structure, a sloped plaza was developed adjacent to the station which allowed one of the station's platform-level walls to be opened up, revealing unobstructed views of surrounding buildings from the interior of the underground structure (Pagnotta, 2011).

\section{Key Features}

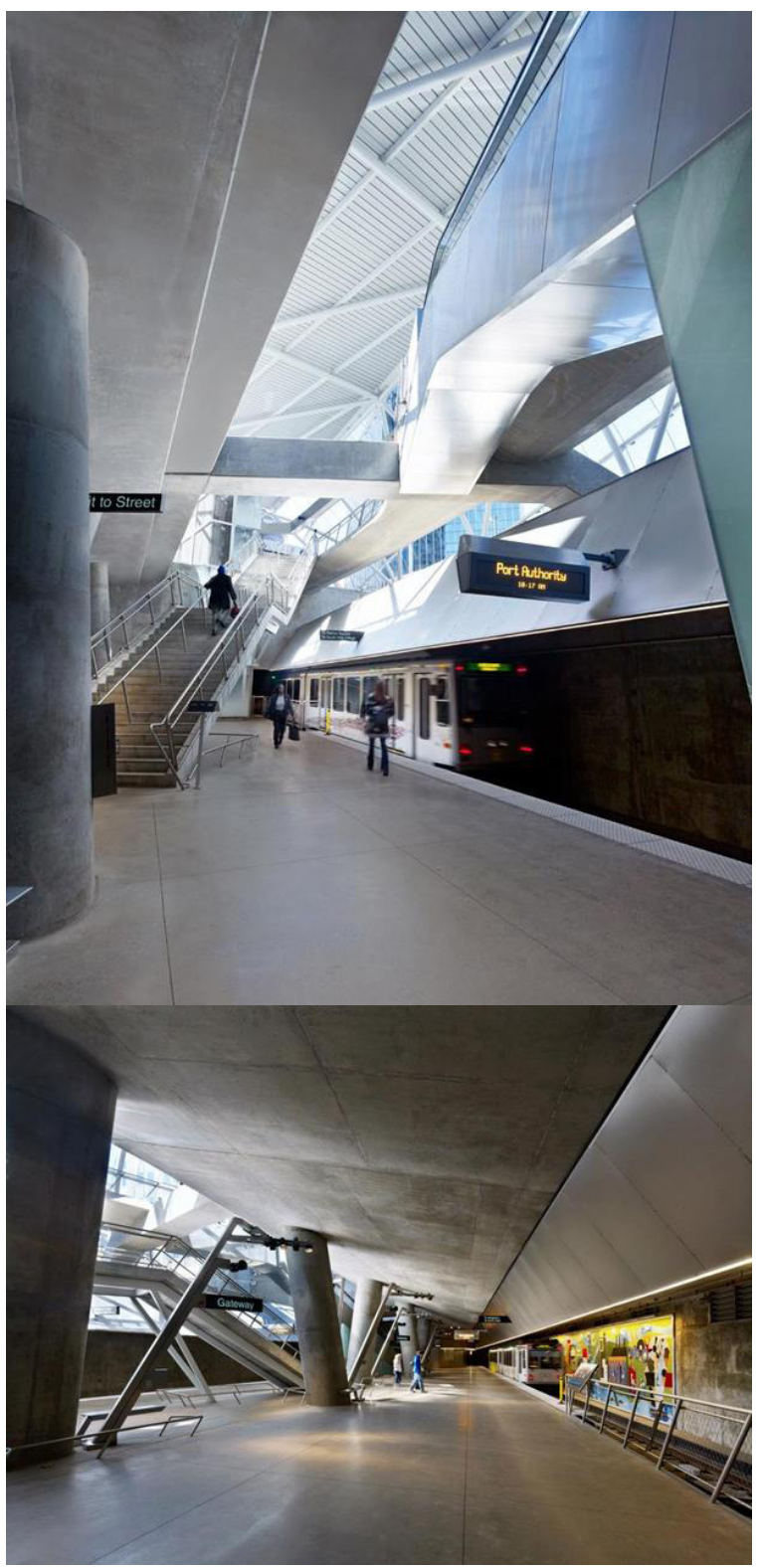

Figure 21 - Interior Platform With Visual Connection to Exterior Spaces (Source: "Gateway Station", 2013)

The transparency in the design of this station extends beyond the basic clarity of materials used and into the core concepts that molded final design decisions. The "Gateway Experience" design allows arriving transit passengers to view the city that surrounds them as they exit the train. Conversely, pedestrians at street level are able 
to look through the clear façade and observe the stations interior as trains arrive and depart on a regular schedule (Pagnotta, 2011). The design of the station celebrates the arrival of an individual to a destination by creating a theatrical production from regular activities.

\section{Interpretation of Research}

The unobstructed connection between station platform and surrounding landscape allows this subterranean station to feel like it is above ground. This type of design is particularly successful within an urban environment, where travelers often demand a direct link between different types of transit, as it allows the interior of the station to directly communicate with exterior surroundings. Among these surroundings is the site's outdoor plaza, which has been designed as an extension of the station structure to benefit urban travelers by creating a social node in close proximity to mass transit.

\section{Station \#9 - Dalmarnock Station}

\section{ATKINS}

\section{Dalmarnock, Glasgow, UK}

\section{Location}

Dalmarnock railway station is an intermediate station on the Argyle line and is located $4 \mathrm{~km}$ southeast of Glasgow Central, the largest and busiest station in Scotland ("Dalmarnock Station Redevelopment", 2012). The station currently accommodates around 80,000 pas-

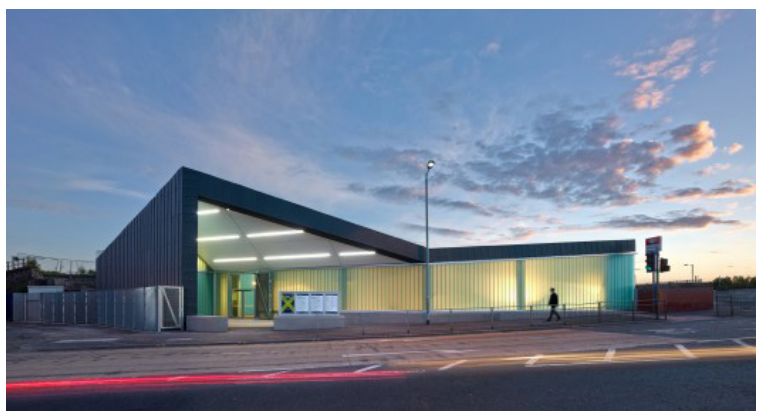

Figure 22 - Dalmarnock Station (Source: “Dalmarnock Station”, 2013) 
sengers per year, but this figure is expected to increase dramatically in the future as Glasgow will host the 2014 Commonwealth Games with the event's main venues located in close proximity to the station site (“Dalmarnock Station Redevelopment”, 2012).

\section{Circulation and Program Analysis}

In comparison to the previously inadequate station at this particular site, the new public entrance and ticket hall lead to two new stairways and an improved platform experience for the traveler ("Dalmarnock Station/ATKINS", 2013). A linear program arrangement can often improve the enjoyment of travel as it allows passengers to relax as they move from the street toward the train platform. The architect notes that a main objective for the project was to design a sequence of spaces that lead visitors through the station in a simple, elegant manner ("Dalmarnock Station/ ATKINS", 2013). Furthermore, carefully planned transitions between high and low spaces help to form an identifiable route between the platform and street ("Dalmarnock Station/ATKINS", 2013). These efforts to clearly guide visitors through the structure are also supplemented by the materials used in the station's construction.

\section{Design Characteristics}

According to the architect, the design philosophy used for this project was to improve the overall experience for the passenger with the overall quality of place making ("Dalmarnock Station/ATKINS", 2013). The interior of the station uses materials such as galvanized steel and acid-etched concrete in large format panels that help to describe the descent from street level to the lowered platforms ("Dalmarnock Station/ATKINS", 2013). Externally, a single skin of translucent, cast glass is used as a seamless surface to present the striking relationships between modern architectural expression and existing structure (“Dalmarnock Station/ATKINS”, 2013). This skin allows the passage of daylight into the interior of the station during the day as well as provides an illuminated backdrop to the surrounding landscape at night ("Dalmarnock Station/ATKINS", 2013).

\section{Key Features}

The angular geometries of the roofscape have been designed to echo influences from the surrounding city. These movements are also translated to the interior of the station through the 
arrangement of steel beams holding a series of narrow folded planes and capturing the stations built elements on both sides of the line (“Dalmarnock Station/ATKINS”, 2013) As a result, the orchestration of these peaks and valleys created by the folds in the roof structure work to inform travelers of the station's history and connection to the railway ("Dalmarnock Station/ATKINS”, 2013).

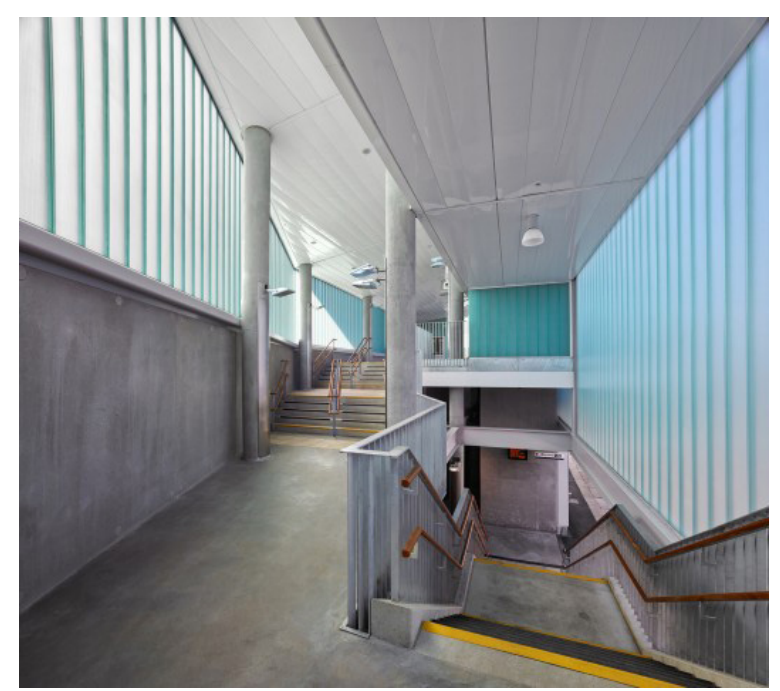

Figure 23 - Interior Corridor Between Main Entrance and Platform (Source: "Dalmarnock Station", 2013)

\section{Interpretation of Research}

The straightforward layout of the station makes it easy for travelers to find their way between each area within the structure. However, the larger success observed in this design is the clarity in communication between the built structure and station inhabitants. This is achieved through the pairing of building materials and movement corridors to guide visitors by their own visual interpretations, instead of relying on signage alone. 


\section{Methodology}

\subsection{Research Design}

As populations rise and cities become increasingly dense, the importance of functionality in urban networks is magnified. Specific to urban transportation, the individual station operates not only as a gateway between the street and transit vehicle, but also as a liaison between urban populations and the identity of public transportation as an imperative in regular travel. Due to this mutual reliance, the successes and failures experienced by the individual station are consequently shared throughout the entire network. The emerging principle role of the transit station in the urban environment has created a paradigm where focus in design is not only toward the communication that occurs between humans, but also between humans and the environment. This methodology views existing transit stations through three lenses: behavioral studies and the physical movement of station users, semiotics (legibility, context, etc.) and phenomenology (emotion, character, identity, etc.). In order to begin compiling information that may ultimately define the evolving role of the individual station among urban communicative networks, specific questions have been raised:

- How do the design objectives identified by professionals compare to the desires of transit users?

- How does communication between transit users and the built environment relate to station design?

- How can a structure's identity be influenced by its surroundings?

- Can the exploration of emotional response to building design reveal patterns in perception that suggest alternative methods for future station design?

- How does individual station design relate to complete transportation networks?

This section looks toward perceptions of the built environment to explore behavioral determinants in design using a multi-faceted approach and pattern identification. The interview method is used to address question 1 and gather data on vocational practices from three working professionals in 
the architecture and urban design fields. Behavioral analysis methods are implemented to address question 2 as this type of observation yields empirical results that will better represent the level of communication between the station and it's occupants. Question 3 is addressed using the survey method, which allows a large amount of relevant information to be collected at once. Question 4 is addressed using both survey and interview methods as responses concerning connectivity are crucial for understanding the role of the individual station within it's connected networks. The unit of analysis for questions 1,3 and 4 is the individual person. While semiotic information is often provided through the accounts of one's experiences, as is also expected within this study, the unit of analysis for question 2 is the transit station due to the fact that visual cues provided through station design are the cause of the observed behavior and thus, the focus of the experiment.

Architecture's ability to express emotion and show character in otherwise inanimate objects is not limited to a certain type of building or landscape. It is because of this versatility that the urban transit station can be viewed through a similar lens. Qualities such as materiality, scale and location define building identity and often provide observers with specific emotional responses. Provided that phenomenological factors have the ability to influence individual choices, it is relevant to look toward emotional response in search of possible relationships between building design and influence on transit ridership.

A prominent goal of this study is to acknowledge the ability of architectural design to focus on the functional requirements of a project while allowing the final form to explicate the information used in its creation. Environment-behavior studies in architecture addresses this directly by focusing on the relationship between the information that the environment is providing (visual cues, space, flows, etc.) and individual perception, which is the information we act and make decisions upon.

On the urban scale, the anonymity of a large population makes it easy for designers to ignore unique needs and characteristics (Moore, 1979). In order to address this issue, a semiotic approach to station analysis can accommodate a variety of societal influences provided the legibility 
of a structure may define the actions of its users. The study aims to underline the importance of semiological consideration in architecture, and looks toward spatial comprehension in an attempt to understand various relationships between buildings and their users. Patrik Schumacher, in his 2012 lecture on twenty-first century parametric order at Harvard Graduate School of Design, proposes that among architecture's core competencies are articulation and signification, "where cognitive, sentient bodies navigate space via perception, and act on the basis of signs". (Schumacher, 2012) Schumacher proposes that architecture may look toward natural flows in existing environments to mold and inform the design of future structures (to learn from existing structures, habits, flows, etc.) and to use this information to build on top of what has previously been discovered.

The study proposes that while many professional design goals may be similar to the desires of station users, some disparities remain. As responses from interviews are compared to the information gathered on user demands, it is imperative to recognize that any conclusions based upon these comparisons are not completely representative of the communication between designer and user in all circumstances. Stations located in different settings may require different approaches to design in order to provide the best service possible. Therefore, information gathered is analyzed within the study to determine some of the more prominent practices in the professional world, not the exact set of rules used by all designers in all situations. Similarly, the opinions of station users in the study are not meant to serve as a complete representation of all station requirements, rather as an exploration into some of the more prominent views on station accommodation.

It is also recognized that different station users will have varying levels of familiarity with public transportation, which can cause certain annoyances to be less bothersome, or more bothersome depending on the person. The study compiles all data and examines responses in the context of 
user familiarity in order to highlight which perceptions are most widely shared. Since the study aims to uncover design practices that may encourage ridership (generate new transit users), it is relevant for the design practices to appeal to those who do not regularly use public transportation.

The weather and time of day for each site visit are also documented for each site visit to account for variables such as traffic volumes, station comfort and convenience of travel. It is necessary to compare collected data to the amount of people in the station due to the possibility that, in times of high traffic, station occupants may make decisions according to the actions of others instead of their perception of station design. It is also important to note these behaviors during times of high traffic to understand the level of influence certain design characteristics have on human behavior. This can be accomplished by comparing these observations to data collected in times of low station occupancy. Furthermore, as station capacities differ greatly based on variables such as expected usage and location, traveler responses in times of high occupancy may provide new information on how smaller stations can accommodate larger crowds more effectively during times of unusually high congestion.

\subsection{Case Selection}

The data collected in the methodology study aims to generate information that may lead to an improved understanding of behavioral determinants in transportation-oriented architecture. Stations were chosen for analysis based on qualities such as distance between station platform and street, station proximity to landmarks, size of connected transportation networks and recognized modes of transit, artistic expression in design that exceeds the basic requirements for the implementation of a service and the feasibility of a researcher being able to accurately observe traveler habits. Within this methodology, the following transit centers have been selected as cases:

\section{2th and Imperial Transit Center, San Diego, CA}

This station is included in the study because it is located on the site chosen for development within the design section of this project. Information gathered at the development site will help to 
better understand the specific requirements associated with San Diego public transit in that area. Information gathered is expected to underline existing successes in site development as well as possibilities for future improvements given the possible addition of a new stadium in the area.

\section{America Plaza Trolley Station, San Diego, CA}

As this station is one of the larger and more developed transit centers in the downtown area, it is expected to provide information describing a larger portion of the San Diego public transit ridership. Information collected from travelers in this station may reveal unique qualities about transit users who travel longer distances as they commute into downtown San Diego.

\section{Hollywood and Vine Metro Portal and Plaza, Los Angeles, CA}

Not only is this particular station widely recognized by the architectural world for its innovative design and connection to local surroundings, it serves a large amount of people on a regular basis due to the fact that it is located on Hollywood Boulevard, where pedestrian activity can dominate other forms of movement. At street level, the small plaza assumes multiple roles as it serves as a landmark for the underground station below and also as a main entrance for the neighboring $\mathrm{W}$ Hotel property.

\subsubsection{Data Collection Protocol}

Within this methodology, site visits are planned in order to produce the most consistent type of data possible. This consistency is achieved through the selection of identical times and days of the week for each visit. Due to the fact that variables such as weather and location can also 
influence information gathered, this study aims to acknowledge these factors as it underlines the ways in which each structure responds to its unique environment rather than focus on the inherent differences between station surroundings.

The behavioral mapping and user surveys are implemented on consecutive days and identical times during peak travel hours. The scheduling of these visits is designed to produce information from consistent sources so the gathered data may be examined and compared in a similar context. Station surveying and behavioral mapping are implemented on the following dates:

\section{2th and Imperial Transit Center, San Diego, CA}

- Monday, January 6, 2014 (4pm-6pm)

- $\quad$ Tuesday, January 7, 2014 (4pm-6pm)

\section{American Plaza Trolley Station, San Diego, CA}

- Monday, January 13, 2014 (4pm-6pm)

- $\quad$ Tuesday, January 14, 2014 (4pm-6pm)

\section{Hollywood and Vine Metro Portal and Plaza, Los Angeles, CA}

- Monday, January 20, 2014 (4pm-6pm)

- Tuesday, January 21, 2014 (4pm-6pm)

Behavioral mapping at each station is conducted on Monday. Survey interviews are administered on each Tuesday. In order for each visit to yield as much data as possible, peak travel times are 


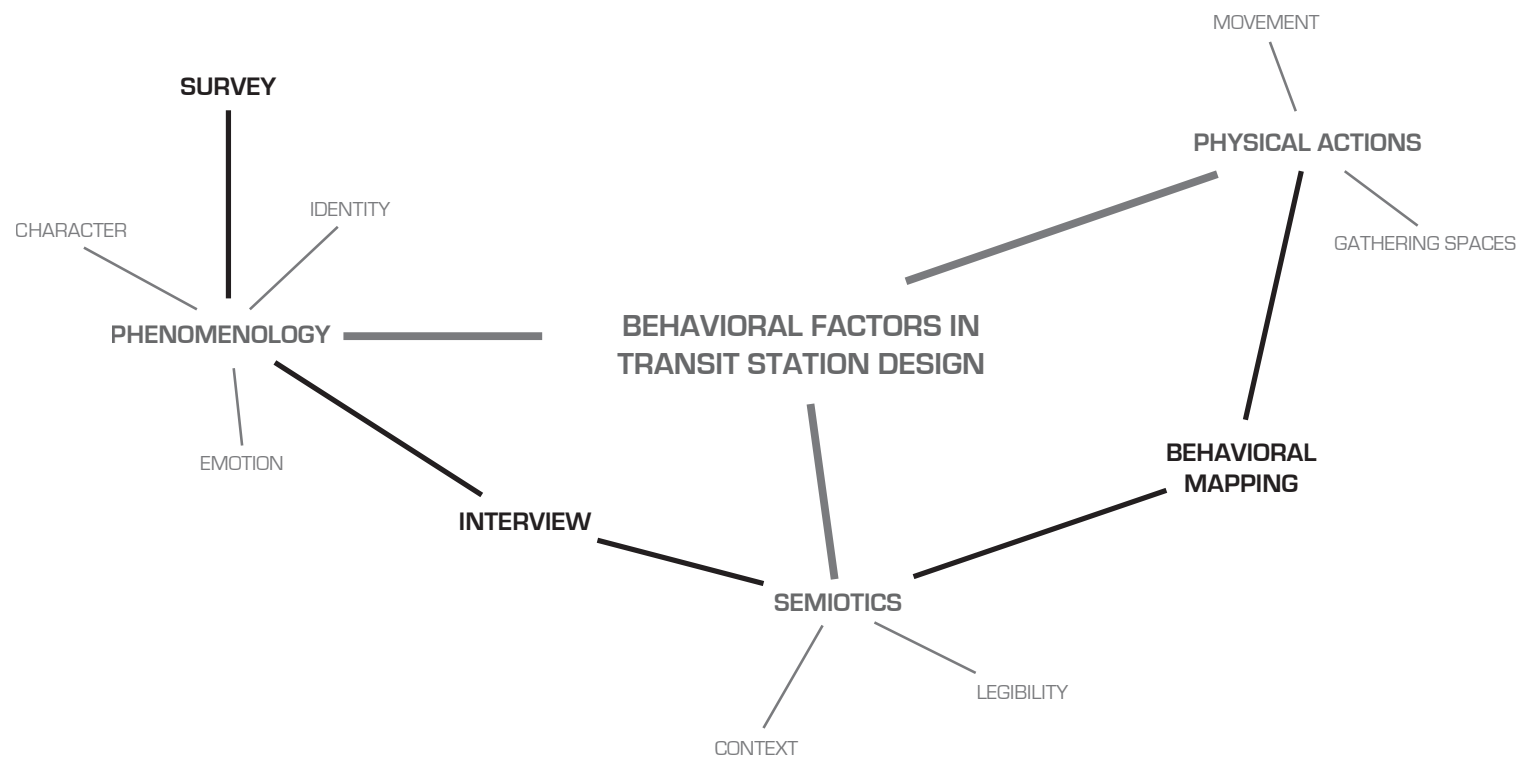

Figure 24 - Data Collection Methods

expected to occur during these weekday afternoons when many transit users will be travelling home. Also, data collected on weekdays is expected to describe the daily habits of transit users, which reduces the chance of information irregularity due to unusual circumstances.

\subsection{Instrumentation}

Methods of evaluation aim to (i) compile information on traveler habits in the context of overall site layout, (ii) provide perceptions of station design from a professional perspective and (iii) organize qualitative data concerning station comfort, usability and convenience. The selected instruments used for observation in the study include a map of each case study floorplan for recording traveler habits and their relationship to station layout, an eleven-question interview to be 
conducted with design professionals concerning site evaluation techniques, project objectives and post-construction evaluation, and a seven-question survey to be completed by station users during each specified site visit. Each instrument can be seen in the appendix of this book.

\subsubsection{Behavioral Analysis}

Within this study, the relationship between structural design and human behavior is emphasized on the premise that the built environment can affect human cognition and thus, may inform decision-making to the extent where public transportation ridership is influenced. Spatial predictors such as programmatic relationships, corridor size and visibility may often have a notable effect on traveler behavior as observed through pedestrian movement patterns within the station, locations of popular gathering spaces, modes of transportation used and the overall interconnectivity between a given station and its surroundings.

In order to accurately compile information reflecting individual perceptions of each station, the behavioral maps are designed as simple floorplans of each structure with notations regarding the location of attributes such as main entrances and exits, designated waiting areas, retail provisions, and platform location. Concurrently, visitor attributes such as gender, age, mode of transit used to arrive at the station and amount of luggage possessed are noted in order to possibly reveal further patterns in observed behavior.

\subsubsection{User Surveys}

The survey group consists of station users. For this study, station users are observed as individuals who do not design transportation structures or systems as a vocation, but still interact with transportation architecture throughout their daily routines.

Within this group, varying levels of transportation familiarity are expected as the daily schedules and individual circumstances of some riders will cause them to use public transit more often than others. In order to account for variances in prior knowledge, survey questions are designed to 
be easily understood and focus on cognitive reactions to each location. The simplicity of each question also aims to alleviate the inclination for some respondents to evaluate artistic relevance instead of providing information regarding their unrehearsed interpretation to the structure.

\subsubsection{Professional Interviews}

Interviews are conducted with design professionals currently working within the architectural field in order to gain perspective on contemporary goals in transit station design. Each interview consists of eleven questions that were constructed to focus on general design principles instead of acting as individual project evaluations.

The study acknowledges that each site is inherently different from the other, and thus requires a specific approach to meeting the needs of station users. Therefore, the information gathered focuses on popular practices in the architectural field as it analyzes information from the professional world alongside recorded user experiences in order to present new information that may be used to improve transit facility design in the future. 


\section{Findings}

\subsection{User Surveys and Behavioral Analysis}

Due to the fact that each survey was conducted in a different location with different people, each station visit produced varying results. Initial visits were conducted during the planned time periods on each Monday and Tuesday. After each visit, based on gathered information and observed behavior within each station, survey times were then adjusted to provide the best chance for a greater amount of information to be gathered. Survey responses were recorded as single words and short phrases with tally marks after each response to indicate repetition.

\section{Station \#1 (12th and Imperial Transit Center)}

The 12th and Imperial Transit Center, located on the southeast side of PETCO Park in downtown San Diego, handles a larger number of daily passengers when compared to the American Plaza Trolley Station. While the 12th and Imperial station acts as a terminus for those visiting the stadium during events, typical circumstances show the station as a major transfer point in the trolley network, where travelers move between trains without leaving the structure. The fact that this

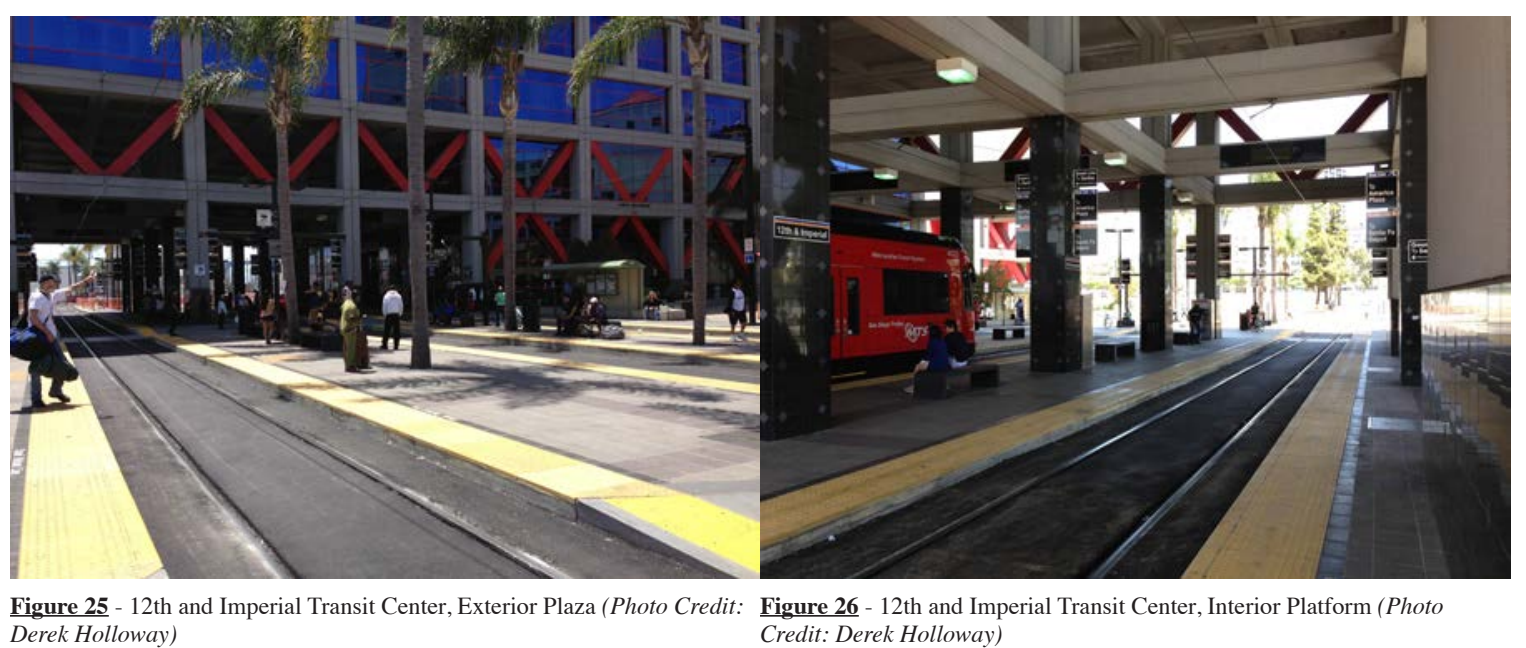


Survey Responses

12th and Imperial Transit Center

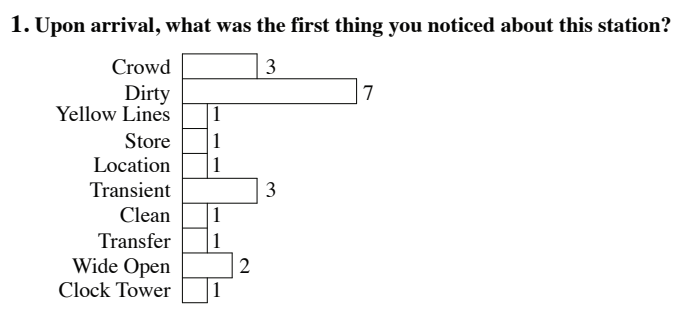

2. Would you describe the area surrounding this station as inviting? Sometimes $\square$

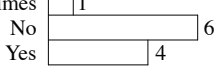

2a. Would you describe this station as comfortable and inviting?

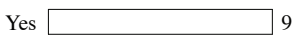

2b. Are there any parts of this station that you try to avoid?

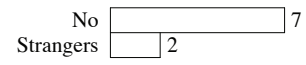

2c. Is there anything that you would change about this station?

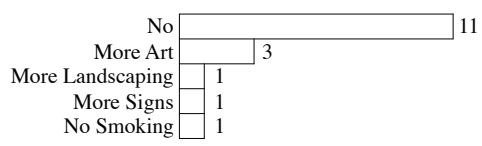

3. What makes you prefer to use this station?

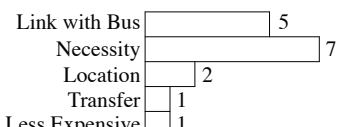

Less Expensive 1

4. How often do you use public transit?

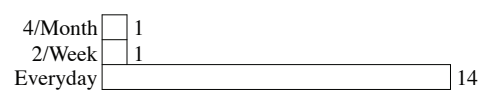

5. What are the best and worst things about using public transit?

\begin{tabular}{|c|c|c|c|c|c|}
\hline \multicolumn{3}{|c|}{ Best } & \multicolumn{3}{|c|}{ Worst } \\
\hline Schedule & 11 & \multirow{6}{*}{5} & Dirty & 1 & \\
\hline Less Expensive & & & Small Network & 1 & \\
\hline Dependable & 1 & & Bad People & 1 & \\
\hline Convenient & \multirow{3}{*}{1} & & Time Delay & & 4 \\
\hline & & & Signage & 1 & \\
\hline & & & Crowded & & \\
\hline
\end{tabular}

6. When you think of this area, which buildings come to mind?

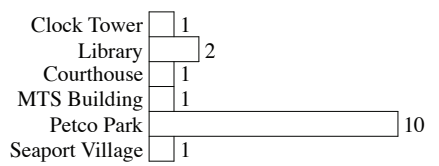

Figure 27 - Quantitative Findings From Surveys, 12th and Imperial Transit Center ( $n=21$ respondents)

station is a major transfer point between the San Diego Trolley's Green Line and Blue Line makes information gathering more efficient due to large amounts of people inside the station on a regular basis.

The first question of the survey aims to uncover station qualities that immediately stand out to visitors. Contrary to anticipated responses, the most popular answer to this initial question described the condition of the structure rather than any aspect of its constructed form, as seven of the twenty-one total respondents replied that the station appeared dirty. Question two asked station occupants about their comfort level both inside and outside of the station. While respondents to this question predominantly thought of the station's surroundings as uninviting, the interior of 


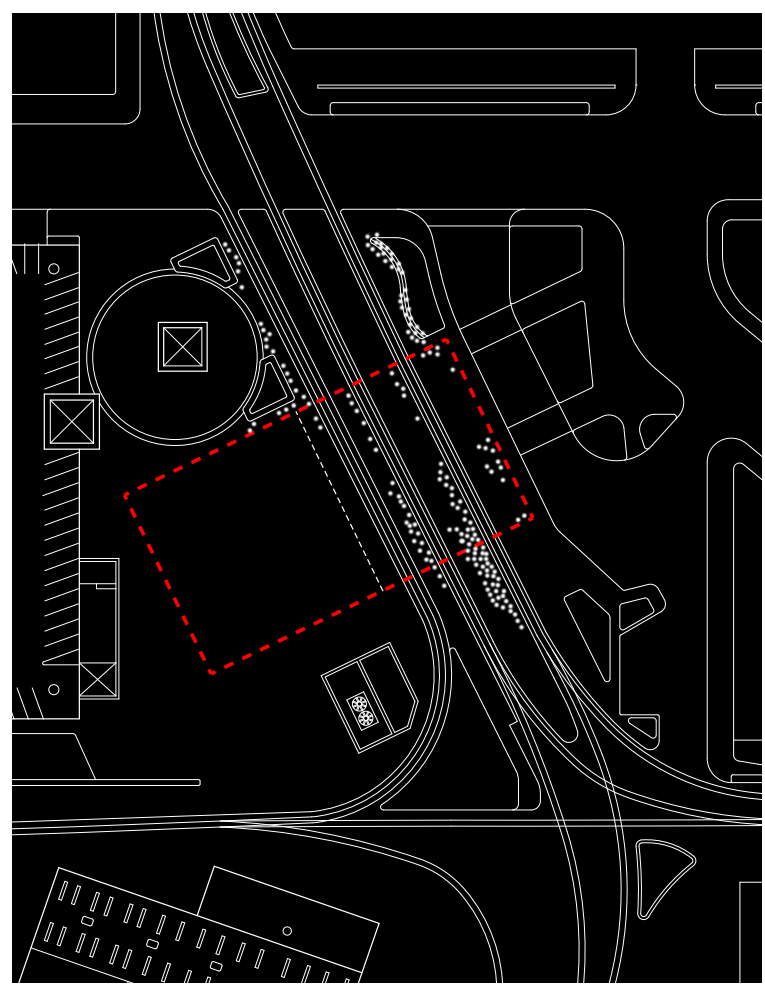

Figure 28 - 12th and Imperial Transit Center, Traveler Congregation Areas

the station was described as comfortable without any particular area they would make an effort to avoid. Some travelers attributed these feelings to the three police officers patrolling the station grounds.

The third question of the survey asks travelers why they prefer to use this station to others. The majority of responses described their use of the station as a necessity due to switching trains or moving between trolley and bus lines. The remaining questions in the survey aim to uncover station qualities that are most relevant to passengers in the context of their expected differences in usage. When asked how often they use public transportation, fourteen respondents answered that they use it everyday. Predictability in scheduling, affordability, convenience, and dependability were most popular among responses concerning the best qualities of public transit with affordability being the most observed answer. Responses concerning the worst parts of public transit included large crowds, limited travel networks, undesirable people in the station, and inadequate signage. However, the most observed answer to the question of the worst part of public transit was the act of waiting for the trains to arrive.

By observing traveler behavior within the station, it was noticed that the majority of station users entered and exited the site via train instead of walking or driving a car. Once on station property, most preferred to stand beneath the roof of the structure, with this number steadily increasing as daylight faded. The station has a total of 3 platforms, with the most consistently crowded being 
the center. Based on observations during the site visit, the most highly populated areas within the station seemed to occur in places with seating opportunities, away from the on-site convenience store.

\section{Station \#2 (American Plaza Trolley Station)}

Similar to the previous station, the American Plaza Trolley Station is located in Downtown San Diego. This station serves as the end of the San Diego Trolley Network's Blue Line, and is located in the northwest corner of the downtown region. The station is surrounded by hotels and business high rises to the east, and the San Diego Bay waterfront to the west. Initial visits to this station, on January 13-14 between the hours of $4 \mathrm{pm}$ and $6 \mathrm{pm}$, yielded few results as the station and surrounding businesses were vacant. A second attempt to gather data from the site occurred the fol-

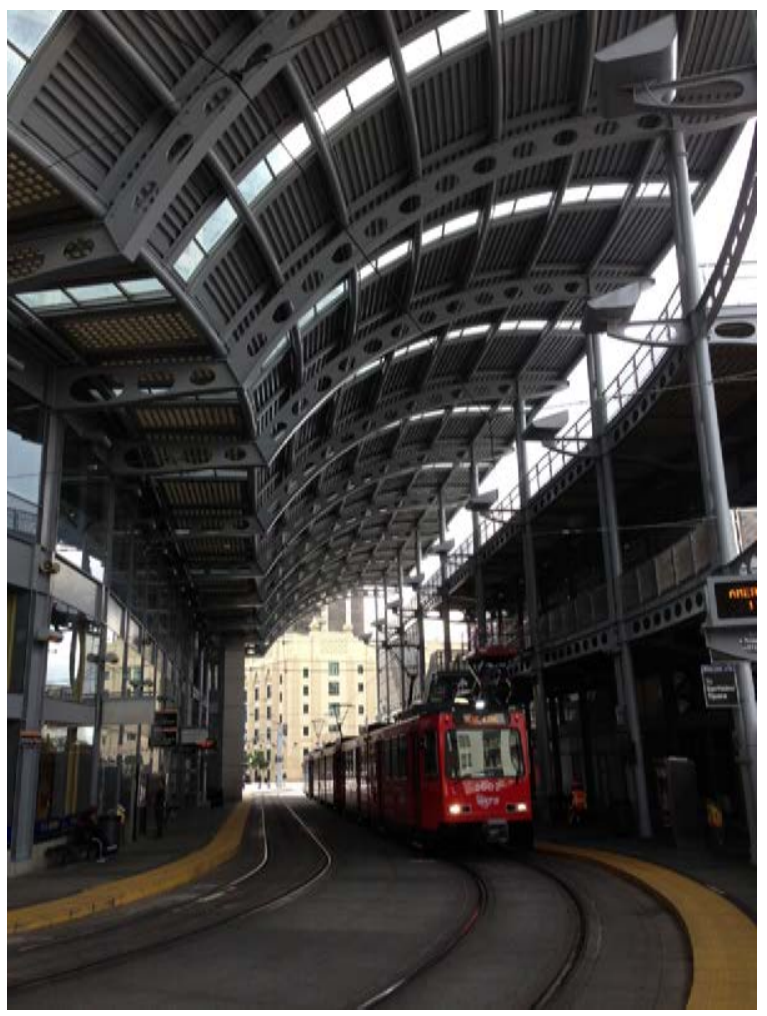
lowing week (Jan. 20-21) during the hours of $10 \mathrm{am}$ and $12 \mathrm{pm}$, where a more active environment throughout the site allowed a greater amount of information to be recorded.

As with the previous station, the initial survey question concerning prominent station attributes produced answers describing station conditions rather than structural organization. Eight of 
Survey Responses

American Plaza Trolley Station

1. Upon arrival, what was the first thing you noticed about this station?

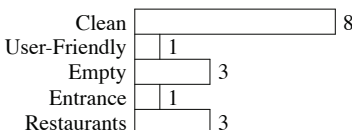

Restaurants

2. Would you describe the area surrounding this station as inviting?

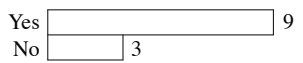

2a. Would you describe this station as comfortable and inviting?

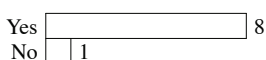

2b. Are there any parts of this station that you try to avoid?

$$
\text { No }
$$

2c. Is there anything that you would change about this station?

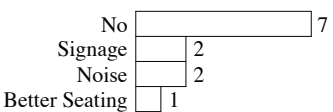

3. What makes you prefer to use this station?

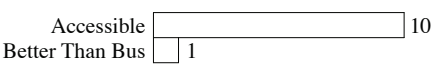

4. How often do you use public transit?

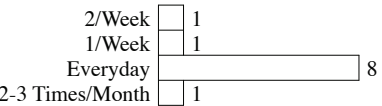

5. What are the best and worst things about using public transit?

\begin{tabular}{|c|c|c|c|c|}
\hline \multicolumn{2}{|c|}{ Best } & \multicolumn{3}{|c|}{ Worst } \\
\hline Cheap & 3 & Bad People & & 2 \\
\hline Works Best & & Crowds & 1 & \\
\hline Connections & $\square 2$ & Distance & 1 & \\
\hline Day Pass & 1 & & & \\
\hline
\end{tabular}

6. When you think of this area, which buildings come to mind?

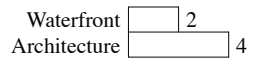

Figure 30 - Quantitative Findings From Surveys, American Plaza Trolley Station ( $n=12$ respondents)

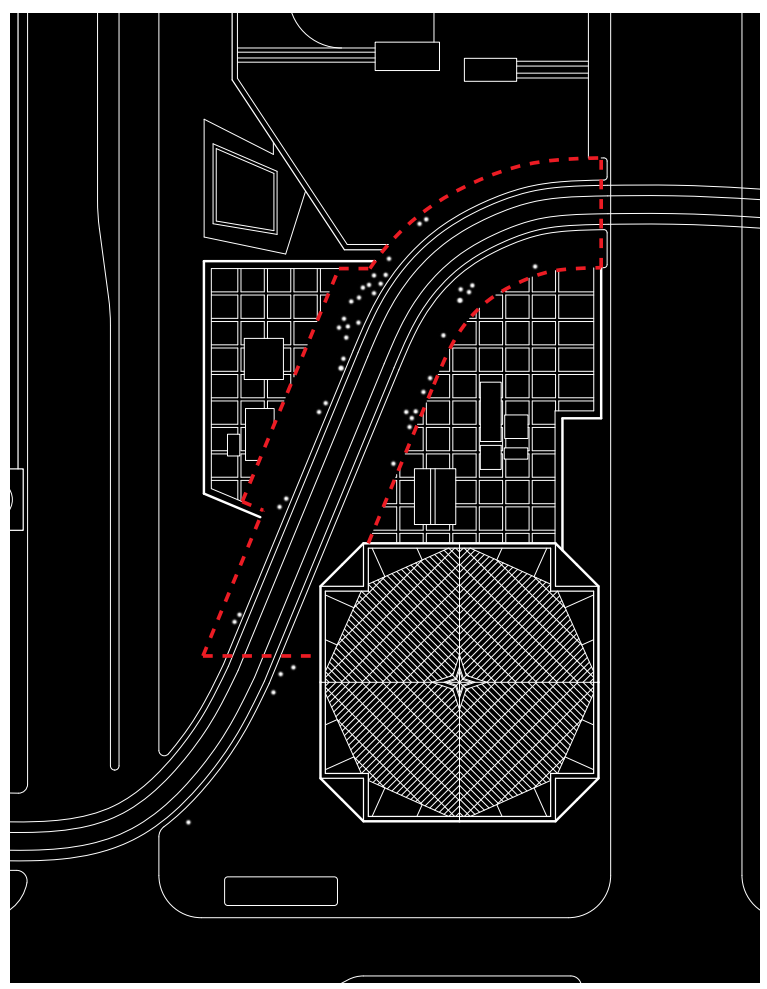

Figure 31 - American Plaza Trolley Station, Traveler Congregation Areas the total twelve respondents noticed that the station looked clean before anything else. Furthermore, the majority of respondents also agreed that both the station's interior and local surroundings appeared comfortable and inviting.

Location is a major factor in attracting people to this station as ten travelers noted that accessibility was their main reason for choosing to use the station during the time of the survey. Also similar to the findings from the 12th and Imperial Station was the regularity in which passengers use public transportation throughout their daily routines. Two-thirds 
of the sample population said they use public transit on a daily basis, which supports answers to question \#5 in the survey where passengers noted that price, reliability, and interconnectivity were all among their favorite qualities of public transportation. The aspect of public transportation that was least favored by respondents at this location was the presence of transients, both inside the station and on the trolley cars themselves. The last question of the survey asks station occupants about specific landmarks that come to mind when they think about the area surrounding the station. For this site, respondents were undecided on a specific building in the area, but noted that the contemporary architecture of many newer buildings in this corner of the downtown area was noticeable and memorable. The waterfront was also mentioned by two travelers as something that comes to mind when they think of the area, which reflects similar responses from the 12 th and Imperial site visit.

Also, through observing traveler behavior between the earlier hours of $10 \mathrm{am}$ and $12 \mathrm{pm}$, it was noticed that the majority of people waiting for the train stood on the west platform, away from the restaurants and stores. A significant number of station occupants entered the various eateries and shops on the east side of the site, but most chose to wait for the train away from the high traffic of the businesses. It was also noticed that the majority of travelers entered the station through the larger opening at the south side of the site.

\section{Station \#3 (Hollywood and Vine Metro Por- tal and Plaza)}

In comparison to the San Diego transit station site visits, the Hollywood and Vine station yielded considerably fewer opportunities to collect data on user opinion of the station and it's design. This was largely due to the

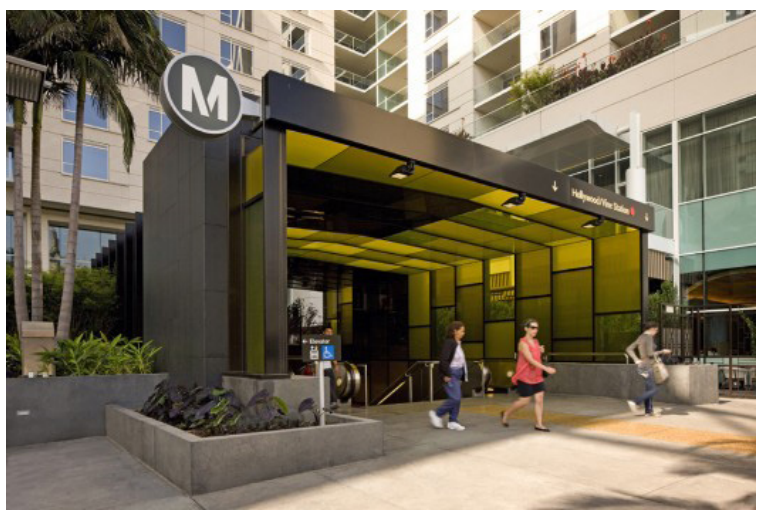

Figure 32 - Main Entrance to Subterranean Station (Photo Credit: Tom Bonner; "Hollywood and Vine Metro Portal and Plaza", 2013) fact that the station does not allow loitering of any kind on the property due to past issues with the local vagrant population. Brief, informal interviews with an on-site security guard and local vendors revealed that troubles had become so 
frequent in the area that new rules had been put into effect for the station, rendering the decorated street-level plaza and underground hallways to be unoccupied at all times. During each visit to the site, there were no undesirable issues observed. However, reminders of past difficulties were apparent through the presence of small, vertical rods outlining the perimeter

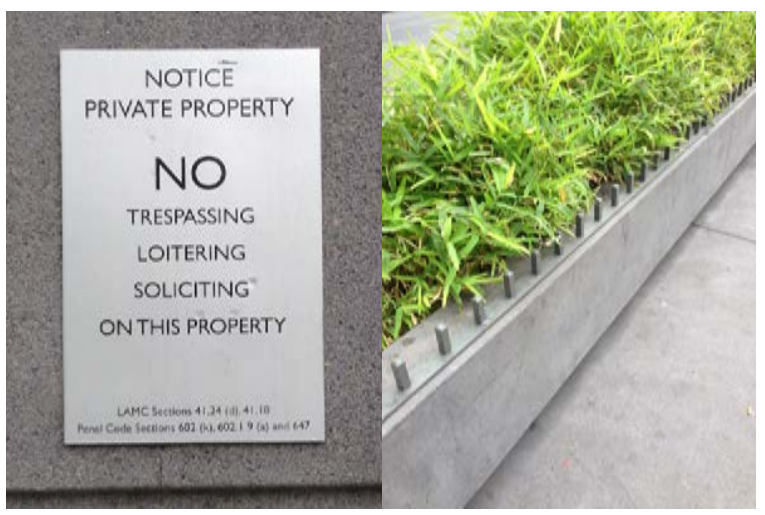

Figure 33 - Efforts to Discourage Loitering (Photo Credit: Derek Holloway) of each planter box to prevent sitting as well as awkwardly empty corners where benches once stood. Due to these unanticipated circumstances, observation and survey times were changed from $4 \mathrm{pm}-6 \mathrm{pm}$ to $2 \mathrm{pm}-4 \mathrm{pm}$ on the same days of the week. During these altered times, a total of three station occupants were surveyed for their opinions.

Concerning the first attribute noticed when entering the station, two of the three individuals recognized the W Hotel sign in the plaza as the design element that stood out to them the most.

\section{Survey Responses}

Hollywood and Vine Metro Portal and Plaza

\section{Upon arrival, what was the first thing you noticed about this station?

$$
\begin{array}{r|r}
\text { Landscaping } & \square 1 \\
\text { Hotel Sign } &
\end{array}
$$

2. Would you describe the area surrounding this station as inviting?

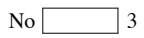

2a. Would you describe this station as comfortable and inviting?

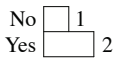

2b. Are there any parts of this station that you try to avoid?

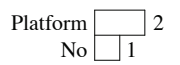

2c. Is there anything that you would change about this station?

$$
\begin{array}{r|r}
\text { No } \\
{ }^{2} 2
\end{array}
$$

\section{What makes you prefer to use this station?}

$$
\text { Necessity } \square 2
$$

4. How often do you use public transit?

$$
\begin{array}{r}
\text { Everyday } \\
\text { Rarely } \\
\end{array}
$$

5. What are the best and worst things about using public transit?

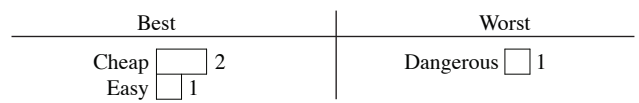

6. When you think of this area, which buildings come to mind? Hotel $\square 1$

Figure 34 - Quantitative Findings From Surveys, Hollywood and Vine ( $n=3$ respondents) 


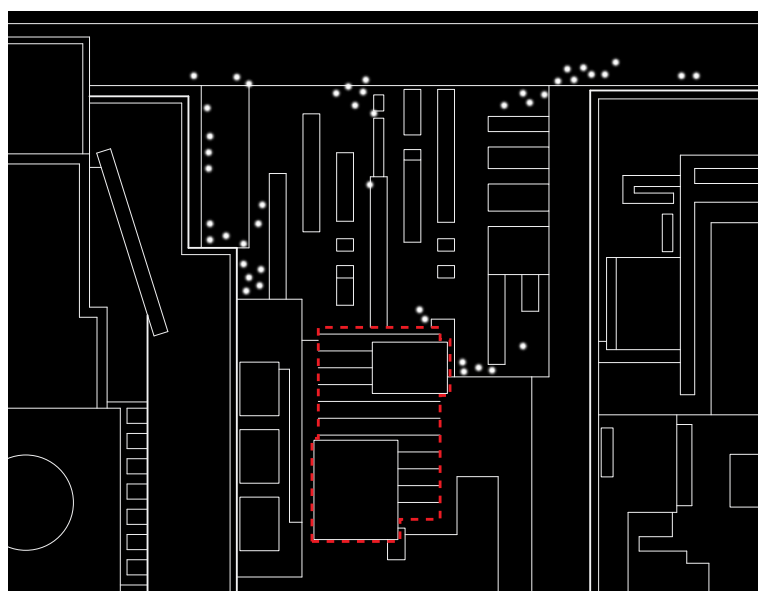

Figure 35 - Hollywood and Vine Metro Portal and Plaza, Traveler Congregation Areas
All three travelers said they would not consider the station's surroundings to be inviting. However, once on the site, two respondents answered that the station itself felt comfortable and inviting. One individual mentioned that the subterranean hallways and platform were the places in the station that felt the least safe. This individual used the station to travel between work and home on a daily basis. He noted that the station platform acted as a gathering spot for local transients due to its long distance from the action on the street above. When asked if there was anything he would change about the station if given the option, he answered that the numerous security cameras were beneficial, but the presence of security guards would make him more confident in using the station during early morning hours.

Travelers mentioned that they used the station out of necessity and on a regular basis. Their favorite thing about public transportation was that it is less expensive than other alternatives and it is easy to use. The worst thing is that it can be dangerous at times.

Although the majority of station users did not stay on the premises once they exited the train, behavioral observation revealed that if they were going to stop for a short amount of time, it was in the plaza at the only entrance to the subterranean station. These points of congregation were focused on the west side of the plaza, against the wall of the neighboring W Hotel. While few chose to stop at any time on site, the Hollywood Boulevard sidewalk, directly in front of the station plaza and entrance, was constantly crowded with local residents, vendors, and tourists. The 
tourist would mostly take pictures of themselves as well as the sidewalk where golden stars on the ground pay tribute to various public figures. There is also a bus stop just outside the northwest corner of the plaza where many congregate to wait for their ride.

\subsection{Professional Interviews}

Professional interviews were initially conducted via email correspondence. When possible, further information was gathered through in-person discussion to clarify and highlight key design objectives. Each design professional was presented with identical questions concerning current practices, projects goals, and predictions for future trends in transportation design.

\section{Interview \#1}

The first interview was conducted with a Principal for RRM Design Group who specializes in planning and urban design. RRM is involved in various aspects of transportation design and facility placement, which allows this professional to provide responses from a holistic perspective of the urban landscape where multiple systems interact to define current environments. His education is in City and Regional Planning and has been with RRM for 29 years (rrmdesign.com).

Information from this interview described programming requirements, user needs, and station context within the local community as the main responsibilities of architectural design in public transportation projects. Universal goals mentioned within the interview were ease of accessibility, convenience for travelers, security, and safety.

When asked about specific qualities that are looked for when evaluating a potential site, the respondent mentioned proximity to services and size of surrounding populations as well as a the potential for a convergence of transportation modes. This attention to interconnectivity is further 
emphasized through a direct acknowledgement of the strong relationships between each individual station and the networks they are connected to. The respondent noted, "Without a well designed network, the functionality of individual stations would be limited."

Also according to interview responses, spatial programming is recognized as an important factor concerning aspects such as site ingress and egress, connections between different forms of transportation systems, and parking demand. Furthermore, important on-site amenities include the provision of adequate seating, food services, clearly defined spaces, proper lighting, and clear signage for effective navigation through the site.

When asked how station design has evolved over the last 10 years, the respondent noted population shifts to urban areas as well as a growing preference for public transportation in highly populated areas. Reasons for these recent trends were attributed to a growing environmental awareness. It is also mentioned that future station designs will need to be context sensitive as technological advancements will cause changes that require an increasing amount of attention toward both personal and overall system needs.

\section{Interview \#2}

The second interview was conducted with an Associate at Gensler Architects. Gensler is a global architecture office and is widely considered to be one of the leading firms in innovative transportation design. This professional designer works specifically in Transportation Business Development, where large design projects are realized in both public and private sectors. He has an education in architecture and has been working in the field for 18 years.

According to interview responses from this professional, the two primary responsibilities of architectural design concerning public transit are to best serve and inform the owner/ agency and to protect the public safety and public health. In doing this, station designs "are based on a spatial program that describes historic and projected ridership" as well as "commercial and administrative square footage needs." Basic services provided by the architect include schematic design, 
design development, various construction documents, and bidding. These items are included in the preparation of design concepts, which are sometimes referred to as "Alternatives Analysis" or "Advanced Preliminary Planning."

Important objectives in station design projects include the mitigation of any negative impacts on the environment, staying within the project budget, site planning and building design, project aesthetics, coordination amongst members of the design team, and to provide community outreach and project presentations. According to the architect, the number one goal of station design is to "provide the best possible experience for all people, regardless of age or ability." The budget associated with each project is noted as a more prominent factor concerning transit experience as most transit endeavors are governmentally funded (local, state, and/or federal). Other factors that affect the transit experience include local culture, surrounding development, future needs, and connectivity.

Furthermore, according to information gathered from the interview, site qualities that affect station design are observed at two scales. The first is at the local level, where the use and occupancy of surrounding structures, alignment of the site and transit vehicle type, expected ridership, and pedestrian and vehicle access have an important impact on the design of the proposed station. Also at the local level, the possibility of an underground structure, existing utilities and easements, grade contours, sun orientation, predominant wind direction, and views are thoroughly considered. At the larger scale, proximity to affordable housing and downtown areas is taken into account in order to provide proper urban planning and design services. Connections to national transit systems are also recognized as important factors when planning for individual stations.

Similar to the first interview, the importance of a complete network and it's effects on the successes of the individual station is mentioned when the respondent is asked about the relationship 
between individual structure and larger system. The ability for travelers to efficiently change between different modes of transportation is imperative as incomplete networks often lead to a decreased ridership.

When asked about programmatic relationships and their influence on user experience, responses were concerned with the connections between the entrance to the site and the station platform. Stations built at ground level were described as being able to connect better with their surroundings. However, the fact that these stations often demand at-grade crossings can create difficulties with other pedestrian and automobile travel routes. Concurrently, elevated stations avoid the difficulties associated with at-grade crossings, but can sometimes become isolated from their surroundings. Elevated stations also often require additional pedestrian connections in order to allow ease of access. The third type of station, the underground station, alleviates the need for at-grade crossings and additional pedestrian connections as it also provides for a larger possible capacity. However, the underground station demands a considerable amount of new infrastructure when compared to the other types. 


\section{Data Analysis}

A central focus for this study is to illuminate both significance and responsibility of the built environment through the comparison of information gathered from those outside the design realm to information from those within. Due to the fact that rationality in design is not always translated clearly between designer and user, a simple comparison of beliefs concerning station capacity can possibly reveal disparities between both parties and lead toward future opportunities in infrastructural implementation.

It is recognized that many projects are limited by factors such as transit regulations and budget, which can lead to a final design that may deviate from what the architect may have originally envisioned. However, the focus of each comparison remains to consider how an increased ridership may stem from building design elements. Therefore, it is important to examine each stations successes and failures, according to station users, in the context of their individual design.

\subsection{User Surveys and Behavioral Analysis}

Responses from each survey participant were reviewed based on the characteristics of each station where data collection occurred. Station designs have also been closely examined in order to 
provide justification for prominent feelings, both positive and negative. These efforts are made in order to reach an increased understanding of the relationship between building design and traveler sentiment.

While the majority of responses focused on social and monetary factors such as time spent waiting in the station, cleanliness, and affordability, the connections between these factors and architectural design are most important to the outcome of the study as this project aims to harmonize design intentions and usage while searching for patterns that may increase ridership.

\section{Station \#1 (12th and Imperial Transit Center)}

Social inconsistencies in surrounding districts cause this station to exist in two worlds at one time. A direct neighbor to the station is the East Village district, where gentrification and homelessness define local appearances. As much of the recent downtown revitalization funds have been focused in the areas surrounding the 12th and Imperial Station, the residential nature of East Village ensures its originality among adjacent development projects. To the west of the station is the Gaslamp Quarter, which has become a focal point for San Diego nightlife and tourism.

Given its location away from many of the downtown centers, it is unrealistic to expect a large number of travelers to use this station outside event times. Since Downtown San Diego is not very big, many trolley stations are located within a few blocks of each other, which allows numerous opportunities to board and exit the trolley without having to walk a considerable distance.

Furthermore, a segregated location causes the station site to be more strongly influenced by the East Village district. This is mainly attributed to PETCO Park, as the baseball stadium acts as a large barrier between the station and more densely populated streets of the Gaslamp Quarter. The inconsistent presence of visitors in the direct vicinity of the station creates opportunities for homeless populations to occupy these spaces during times of reduced traffic in the area. The magnified appearance of vagrancy undoubtedly defines the station as less desirable qualities overshadow regular station appearances and conditions. Responses that the station is noticeably dirty, 
but still considered to be comfortable and inviting show how sentiments concerning local landscapes are translated between site surroundings and station interior. However, feelings of danger or uneasiness are not translated to the interior of the station due largely to the visible presence of the San Diego Police.

When asked if the surrounding landscape was considered to be inviting, respondents replied "No". However, it is relevant to consider that a total of 5 respondents replied "Yes" or "Sometimes" to the same question, indicating the effect that stadium patronage has on the perceptions of the station. During times of an event at the stadium, the barrier between the station and the Gaslamp Quarter is minimized by a large influx of people to the area, which causes the station environment to temporarily adopt a cleaner, more acceptable appearance.

When compared to other stations visited in this study, this site yielded the most information regarding traveler desires and opinions. This can be attributed to the fact that opportunities for gathering information in this station were much more abundant due to the large numbers of travelers waiting to switch trains. However, throughout the survey process, individuals in this station were much more willing to contribute to the project and voice their opinion on public transit.

\section{Station \#2 (American Plaza Trolley Station)}

In contrast to station \#1, station \#2 is surrounded by many buildings and attractions that cater to large crowds on a daily basis. Even though the hotels, business high rises, restaurants, and San Diego Bay waterfront consistently draw people to the area, the station remains slow for much of the day, especially during expected peak travel times. After an examination of local travel routes, it was discovered that a main reason for this particular station's underutilization lies in the trolley 
routes it is connected to. The station acts as a terminus for the "Blue Line" as it carries passengers south. Concurrently, the station acts as the first stop on the "Orange Line", which connects the downtown area to much of the southeastern parts in the county.

Concerning the observed low ridership among permanent San Diego residents, the majority of individuals using this station are traveling south from the downtown area. Although it is expected that a considerable amount of individuals who work in the downtown area may live in southern parts of San Diego County (and travel between work and home via trolley), there were few observed instances within this study that alluded to this travel route being significantly popular among local workers. Provided these connections, travelers must take the "Green Line" to visit the northernmost areas connected to any trolley lines. This line connects only to the neighboring Santa Fe Train Station without extending to the American Plaza Station, which renders the American Plaza Station useless when travelling north. For those using public transit in San Diego on a regular basis, this station is a great example of how the overall transit network affects the individual station itself, regardless of its design. Even though there are many appealing design characteristics present within this station, the feasibility of using it on a daily basis for many is low.

Also according to numbers gathered within the study, the majority of those who use this station for public transit purposes are not from the area. They consist mostly of individuals visiting the city from other parts of the world. The station itself is surrounded by hotels, which would allow these tourists to catch short rides throughout the northwest corner of the downtown area. However, if they wanted to travel outside the region, they would choose to use the nearby Santa Fe station due to the fact that connecting routes in the American Plaza Station are limited to those moving toward southern parts in the county, which are composed mainly of residential and industrial areas. The included "Orange Line" connects to some parts of eastern San Diego County, but based on observations within the study, the amount of riders traveling in this direction is not enough to create a busy environment within the station.

The station is designed with large openings at each end of the platform. A lack of walls at these entrances, combined with numerous opportunities for natural light to reach the interior spaces 
between the roof and neighboring buildings, allow the station to blend seamlessly with the local landscape. The connection between station interior and urban district is so strong that they appear from many angles to be the same. People from local businesses do come here for food during the middle of the day, which supports survey responses that say it is an inviting and comfortable atmosphere to be in. It is open, illuminated, and easy to access from the street.

When compared to other stations in the Downtown San Diego area, this station is one of the more architecturally relevant structures. The arched roof of the station, which is the focal point of the design, gracefully sweeps around its rectilinear neighbors as it provides shade for the platform during the day and protection from the elements during times when San Diego experiences poor weather. The added curvature also breaks up an otherwise rigid appearance to the area. During the late afternoon, the setting sun is absorbed by the metal structure, resulting in a golden glow that is very noticeable and beautiful. Unfortunately, these characteristics are lost on many due to the consistent lack of travelers on site. The station remains empty compared to others in the area during peak times as most would not choose to use it due to its limited connectivity to the more central regions within San Diego County.

\section{Station \#3 (Hollywood and Vine Metro Portal and Plaza)}

As this station is located on Hollywood Boulevard, one of the busiest streets in Los Angeles due to the amount of tourism in the area, the atmosphere may often seem chaotic and overwhelming. Survey responses describing the station's plaza as uninviting may be attributed to multiple vendors selling goods and services along the street. A plaza would simply concentrate these vendors in one area by allowing them to approach many people at one time. Furthermore, additional complications associated with the plaza can be observed through the habits of the local homeless population. As with any urban environment where there are large gatherings of people in one concentrated area, opportunities for vagrancy are elevated.

A catalyst for difficulties concerning movement could be the fact that this social space is so small. The size of it does not allow people to stay for an extended period of time because it 
becomes crowded easily and blocks the flow of pedestrians in and out of the station. Conversely, this smaller plaza size could be seen as a quality that would make crime related issues easier to prevent, as minimal security would be able to ensure a safe environment for visitors and travelers alike.

Transparency in design is difficult at this location due to the fact that visitors lose touch with the outside world as they enter the subterranean space. Once underground, with the absence of security guards or police, travelers are away from many of the safeties normally associated with public spaces, leading them to avoid these situations when possible. While separation between platform and exterior are often unavoidable in many subterranean stations, communication between street level and platform proves to be an important design quality that influences ridership.

\subsection{Professional Interviews}

\section{Interview \#1}

Due to the fact that it is necessary to approach station design from multiple perspectives, responses concerning design objectives that view each structure in the context of surrounding urban systems can be especially relevant when analyzing information. Based on data gathered in this interview, the strong relationship between each individual station and its expanded network emphasizes the need for interconnectivity between different transit types in order to make multiple-mode trips more efficient. The constant attention to improving travel experience is apparent through the consideration of user needs within each structure as well as throughout adjacent landscapes.

On a smaller scale, relationships between structure and landscape are reinforced through clarity in station design. Based on information gathered in the interview where design objectives such as clearly defined spaces, proper lighting, and clear signage were highlighted as imperatives, it 
can be concluded that a main responsibility of the transit station is to provide a specific service without being unnecessarily complex. The simplification in design makes travel easier, which in turn, becomes more appealing to potential users.

Safety and comfort are also emphasized as essential components of proper station design. Objectives such as egress and proper lighting create interior environments supporting the unobstructed movement of travelers. The recognition of ventilation, adequate seating, and the provision of food services also ensure comfort levels are maintained within site boundaries.

\section{Interview \#2}

The second interview recognizes similar approaches to station design, which reinforce their relevance among other objectives mentioned throughout this study. Responses indicate that visitor experience is held as one of the most important concerns for station design. Other concerns addressed by design objectives include safety for all site visitors as well as exceptional interconnectivity between multiple types of travel. These prominent themes combine to integrate transit station sites with surrounding development and ensure higher levels of accessibility and ease of use.

Relationships between separate programmatic elements are also addressed by responses to interview questions. Connections between major station entrances and interior vehicle platforms were highlighted as prominent among others as they regularly support large, mobile groups of people. The fact that these specific routes describe the majority of on-site travel allows them to be viewed as the backbone, or primary route; with other pathways and spaces existing as subordinate in the organization of the comprehensive station layout.

The insight provided by this interview into station project funding is also relevant, as future sources of funding will likely come from private partnerships and large corporations. The often 
strict regulations that control current station designs may be altered by a desire for more of a financial return on investment in future projects when compared to current projects that are mostly supported by governmental agencies. 


\section{Conclusions}

\subsection{Key Themes}

Through the examination of human interactions with their surroundings and various reasons for current perspectives toward transit station development, prominent design principles can be underlined for future utilization. Based on information gathered by behavioral analysis methods, personal interviews, and the interpretation of relevant precedents, these recommendations reflect compositional parallels as connections are made between reoccurring elements within the data.

Main themes observed within this study include interconnectivity, transparency, and communication. The concept of interconnectivity is traditionally associated with complete transit networks, where the total number of connections in a system often dictates that network's overall usage. While these large-scale connections remain important to the individual station, data within this study has also emphasized the importance of relationships between each station and it's local surroundings as well as connections between different transit types. Transparency in design is exemplified by unobstructed views throughout the interior of the station as well as visual connections between interior and exterior spaces. Information gathered in this study suggests that a visually passive structure is successful in connecting station program to surrounding environments as adjacent land uses provide context for organization. The concept of communication in transit design can be described as the shared influences between separate station elements based on their relationship and proximity. This concept also describes the various ways in which information from surrounding environments is translated through design to inform station users. 


\subsection{Design Recommendations}

Through further analysis and comparison of data gathered from all sources within this study, specific design recommendations can be highlighted to emphasize key elements in transit station design projects. Identified practices are expected to have numerous applications based on site-specific variables and do not represent an exhaustive collection of required station design principles.

\section{Recommendation 1: Visual Connections Between Interior and Exterior Spaces}

Initially, an emphasized relationship between the interior and exterior of a station is highlighted due to implications toward improved safety for travelers, effective navigation through the station, improved interior lighting, and a more direct connection to local surroundings. The importance of visual connections between interior and exterior is exemplified in included precedents such as the Liège-Guillemins Station by Santiago Calatrava, and the Gateway T Station by EDGE Studio (“Liége Guillemins TGV Station”, 2009; TPlus, 2012).

During site visits to each of the three stations included in this methodology, information gathered through user surveys indicates that qualities describing station surroundings can influence the perceived condition of interior spaces. The majority of responses concerning initial user observations at the 12th and Imperial Transit Center describe station interior spaces and surroundings as "dirty". Furthermore, the same interior spaces are also described as comfortable and inviting through responses to later questions.

The interior of the nearby American Plaza Trolley Station is also described as comfortable and inviting. However, a more populated surrounding landscape causes interior spaces to be perceived as clean, despite similar conditions to the 12th and Imperial Station. The fact that interior spaces from both stations

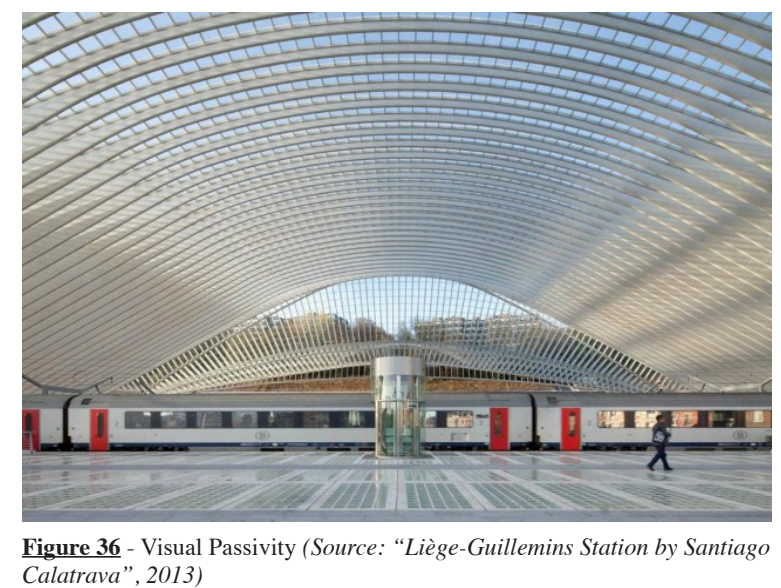


reflected similar qualities, the differences in surrounding landscapes appeared to have greatly influenced user perceptions of each station, implying a significant correlation between the interior and exterior of each structure.

Responses from user surveys at the Hollywood and Vine Metro Portal and Plaza also allude to the importance of visual passivity between interior and exterior spaces. According to station occupants surveyed at this site, the subterranean hallways and platform are areas within the station where they feel the least comfortable, due to the separation from the activity at street level. These sentiments are also reflected through responses from professional interviews, where connections to surrounding developments, usages, and occupancies can allow the individual structure to become more context sensitive.

\section{Recommendation 2: Direct Linkages Between Entrances and Main Platforms}

Another recommendation for future transit station design is a strengthened relationship between entrances and main vehicle platforms. A focused connection between these important programmatic elements allows the majority of station users to move efficiently within the structure; and when supplemented by retail and leisure facilities, locates prominent amenities in an easily accessible position to improve convenience for station visitors. Furthermore, a central corridor or focused interior space can often reinforce the station's role as a social center as well as a transportation hub.

The strong relationship between entrance and platform is illustrated by information from behavior maps describing events at both the 12th and Imperial Transit Center and American Plaza Trolley Station. Based on information collected using these maps, the main entrances at each station attract visitors through the high visibility of the main platform and included retail stores. Despite the simple and compact layouts of each station, most visitors enter and exit the structure through 
similar locations, which are mainly defined by their exposure to adjacent streets and connecting transportation lines. The direct relationship between these prominent entrances and station platforms allows visitors to travel through each structure in an unobstructed manner.

Furthermore, information gathered through responses to professional interview questions also reflects the significance of platform accessibility concerning ridership numbers. Since highly emphasized connections between station entrances and platforms make the act of traveling more efficient, it can be expected that stations with these direct relationships may appeal to a larger number of travelers.

\section{Recommendation 3: Interconnectivity Between Different Platforms}

Emphasized interconnectivity between included transit modes is also underlined within this study. A focus on spatial relationships between individual station platforms enables a more effective transfer between vehicles, improving the convenience of public transportation for current and prospective riderships. Interconnectivity between various transit types is observed in the design of the Al Rashidiya Metro Station, and highlighted through survey responses gathered from the 12th and Imperial Transit Center, where a main reason for using the station is attributed to it's connections with local bus lines (“Rashidiya”, 2013).

Also through the implementation of behavioral analysis methods at each of the three stations included in this methodology, it was noticed that most travelers enter and exit the station site by some form of public transportation. These observations are further supported by responses to survey questions, where many travelers said they used each station because of convenience and 
necessity rather than personal preference. Based on the fact that the majority of observed station users travel between different transit modes while on the station site, it is necessary to highlight the interconnectivity between these included transit types as an imperative for effective travel.

\section{Recommendation 4: Clearly Defined Spaces}

It is also recognized that the provision of clearly defined areas within the station aids in the development of a hierarchy of space, where popular programmatic elements are organized away from the less-utilized areas. The most frequently traveled corridors are better able to support social functions on a large scale, allowing subordinate spaces to cater to smaller, more specific ridership populations. This hierarchical reorganization is supported by responses from both professional interviews in this study, where comfort and convenience as well as an emphasis on well-defined spaces are described as important amenities to be included in each station design.

Furthermore, the utilization of behavioral analysis methods during each site visit has illuminated specific areas within the included station layouts where occupants tend to congregate while waiting for their preferred mode of transit. These specified areas, located along the main platform and away from any included retail or restaurant outlets, also delineate movement corridors within large interior spaces. As observed during the site visit to the American Plaza Trolley Station, spaces used for waiting on transit vehicles can sometimes interfere with required pathways, causing occupants to have difficulty moving within the station. Based

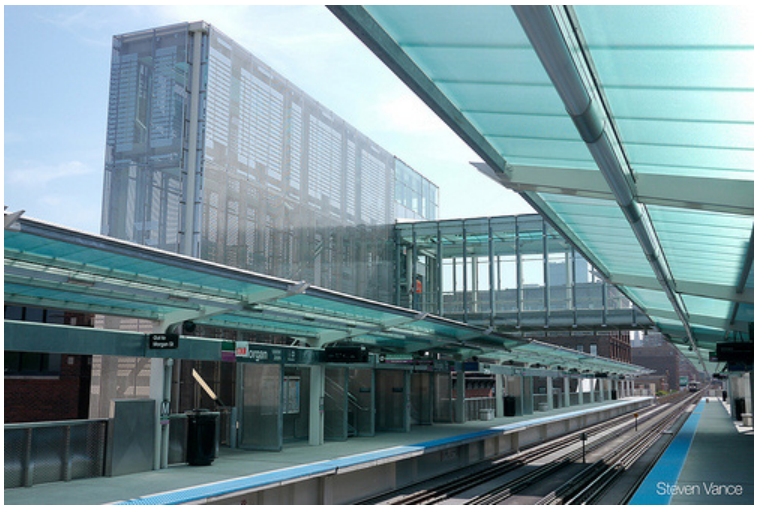

Figure 37 - Programmatic Organization (Source: Vance, 2012) on these observations, and in order to allow 
effective and safe movement throughout each structure, it can be proposed that the organization of fast-paced programmatic elements away from slow-paced elements may reduce platform congestion during times of high traffic.

\section{Recommendation 5: Lighting and Ventilation}

The final recommendation to be highlighted in this study focuses on the provision of adequate lighting and ventilation within a station structure. These necessities create a comfortable and safe environment for travelers, and lead to the improved successes of other design principles by enhancing interior environments for station visitors. In addition to ensuring safety for travelers and ease of navigation within the station, lighting can also be utilized to enhance specific design efforts and add to the overall travel experience.

During the site visit to the 12th and Imperial Transit Center, behavioral analysis methods showed the importance of proper lighting in station design. During the day, when all parts of the station platform were naturally lit by the sun, station occupants chose to spread out along the 300-foot long platform. After dark, when only half of the platform was fully illuminated by the lights on the overhang, travelers were forced to crowd into the smaller space to avoid standing in the dark. A similar situation was observed during the site visit to the American Plaza Trolley Station, as the majority of the light within the structure came from included retail outlets.

While information collected through survey and behavioral analysis methods did not specifically address the importance of proper ventilation in station design, responses from professional interviews highlighted the importance of temperature and airflow within these types of structures. According to professionals interviewed within this study, temperature within the station structure is underlined as one of the most important amenities for creating a pleasant station environment. 
Given the fact that these interviews also accentuate the provision of a comfortable and safe environment as a universal goal for station design, it is necessary to include proper airflow and temperature regulation as an important design objective.

\subsection{Further Research}

Resulting from the outlined methodology, and the identification of specific design objectives to be utilized in future transit station design projects; additional questions are presented to facilitate further research. Initially, the detailed examination of specific transit stations has illuminated differences in station identity. These differences mainly stem from their location along a larger system, classifying them as (i) a destination station, (ii) a transfer station, or (iii) an intermediate station.

The destination station, exemplified by the American Plaza Trolley Station in San Diego, CA, is traditionally located near major landmarks or places with higher population densities. These nodes often act as a terminus for their connected networks, and cater to travelers entering the specified site by means other than public transportation. Although a large number of travelers may still reach the site via public transit vehicle, the exterior of the station is more regularly perceived in the context of it's urban surroundings when compared to the other two types. Therefore, priorities associated with each of the underlined designed recommendations may be altered as specific objectives take precedence over others concerning their role in attracting travelers into the structure.

Additionally, research has unveiled the 12th and Imperial Transit Center in San Diego, CA as a major transfer station for the sprawling city. Behavioral analysis and short, personal interviews with station users have shown that the majority of travelers moving through this structure are doing so in order to switch between trains. While the highlighted objectives in this study all affect the interior of the station to some extent, specific recommendations may explicitly address 
travellers who only experience the station from within. Traveller perceptions of each station will therefore be dependent on interior qualities, without an overwhelming recognition of exterior features.

The Hollywood and Vine Metro Portal and Plaza represents an intermediate station, where the majority of travelers passing through the structure will understand it's identity through a visually-dominated experience as they are not expected to exit their occupied vehicle. A shifting hierarchy of the previously-specified design principles will again dictate each traveler's experience as some objectives may need to take precedence over others in order to provide a favorable impression of the station.

Given the fact that the highlighted objectives in this study are not intended to represent an exhaustive list of design practices for successful transit projects, the pursuance of future opportunities regarding further analysis and applicational understanding is necessary in order to implement each objective in the most effective manner possible. Future research along these trajectories may also lead to additional design recommendations that can further emphasize the importance of the public transportation system within an urban environment, resulting in an improved comprehension of public transit and the encouragement of it's use. 


\section{Design Proposal}

\subsection{Project Description}

Following the identification of specific objectives for future station designs, conceptual strategies can be combined with fundamental practices to provide a visual representation for the relationships between individual structure and surrounding environment. The design section of this thesis understands the transit structure as an important node within the city where multiple systems (public transportation, pedestrian, automotive, etc.) converge on a single site. This focused interaction between individual traveler and comprehensive landscape creates an opportunity to celebrate the station as a viewport into the often hidden systems that define our urban environments.

The design of the station emphasizes clearly defined spaces and organizes transit-focused programmatic elements away from leisure spaces. At ground level, an immediate adjacency between the included bus stop and main trolley platform ensures strong connectivity between different modes of transportation. Four retail spaces are also included at ground level to effectively serve travelers as they move through the site.

The second level of the station features a cantilevered walkway and restaurant space, extending the downtown landscape into the air and framing views of nearby landmarks and social districts through large apertures in the structure's skin. These apertures also allow the structure to be naturally illuminated during daytime hours, reducing energy consumption and providing a safe environment for visitors. The walkway becomes the focal point of the design as it follows the pe- 
rimeter of the ground-level platform and celebrates the constant movement of the city by focusing attention toward the center of the station, where passing trains and hurried travelers provide an unrehearsed spectacle for observers.

The project also features a relocation of previously-included Metropolitan Transit System (MTS) offices to the east side of the site. The proposed placement of this building allows it to operate independently from the busy station, ensuring privacy for employees. However, direct connections to both the main platform and elevated walkway maintain necessary on-site adjacencies.

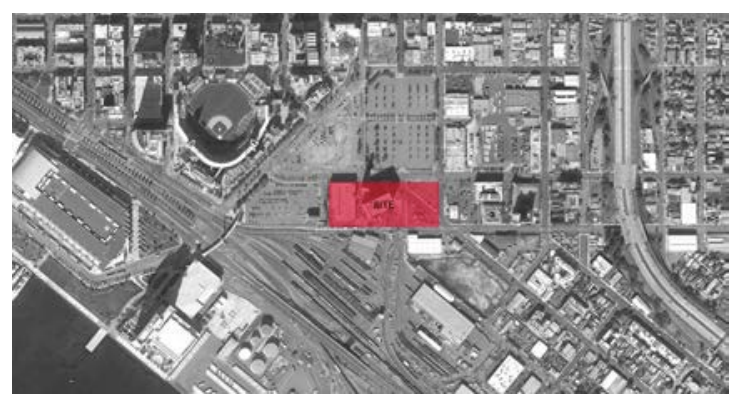

Figure 38 - Site Location, Downtown San Diego

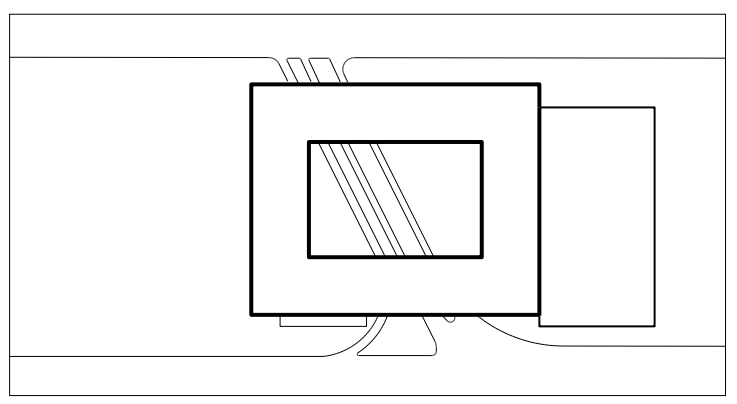

Figure 39 - Diagrammatic Site Plan

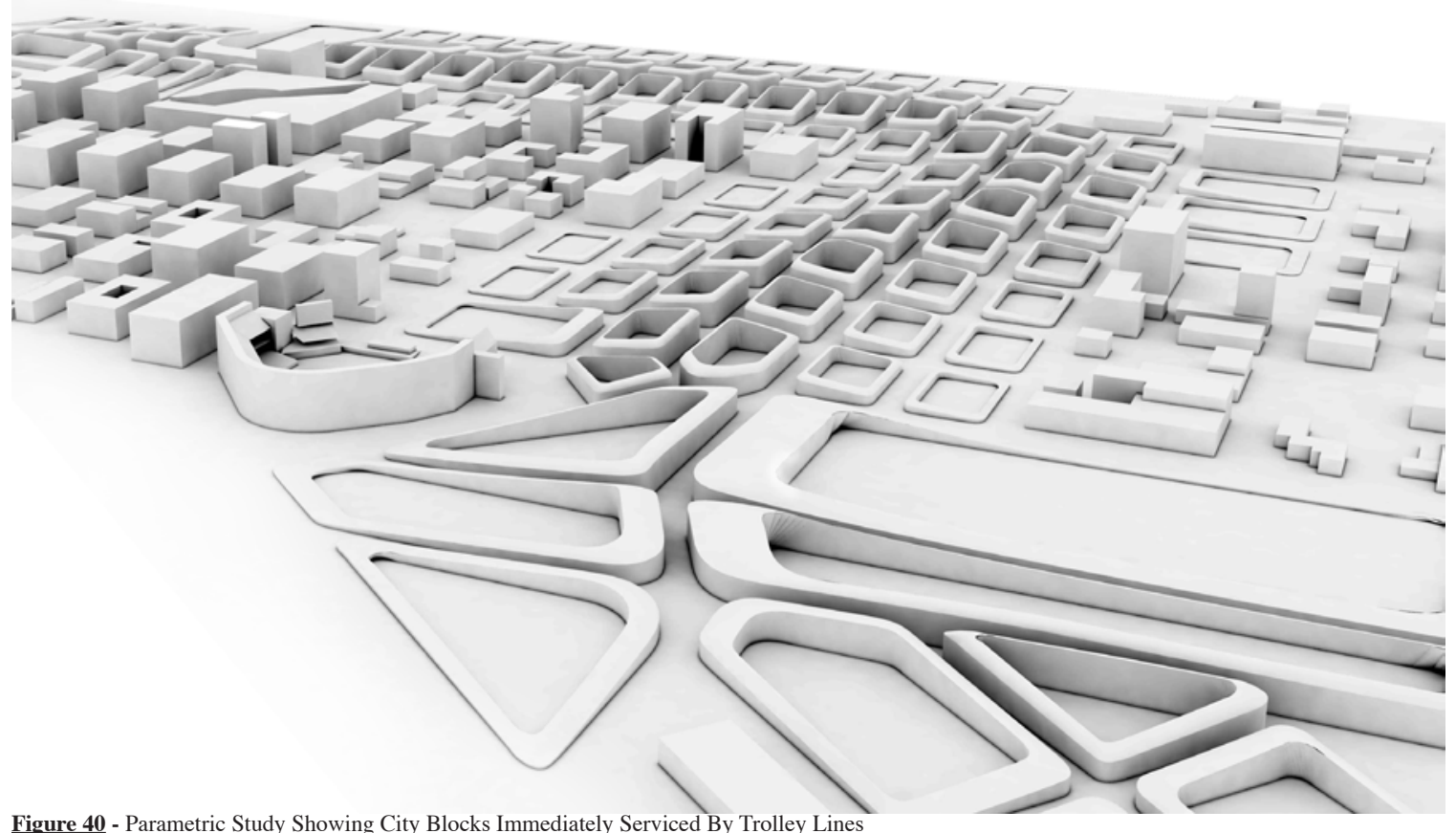

Figure 40 - Parametric Study Showing City Blocks Immediately Serviced By Trolley Lines 


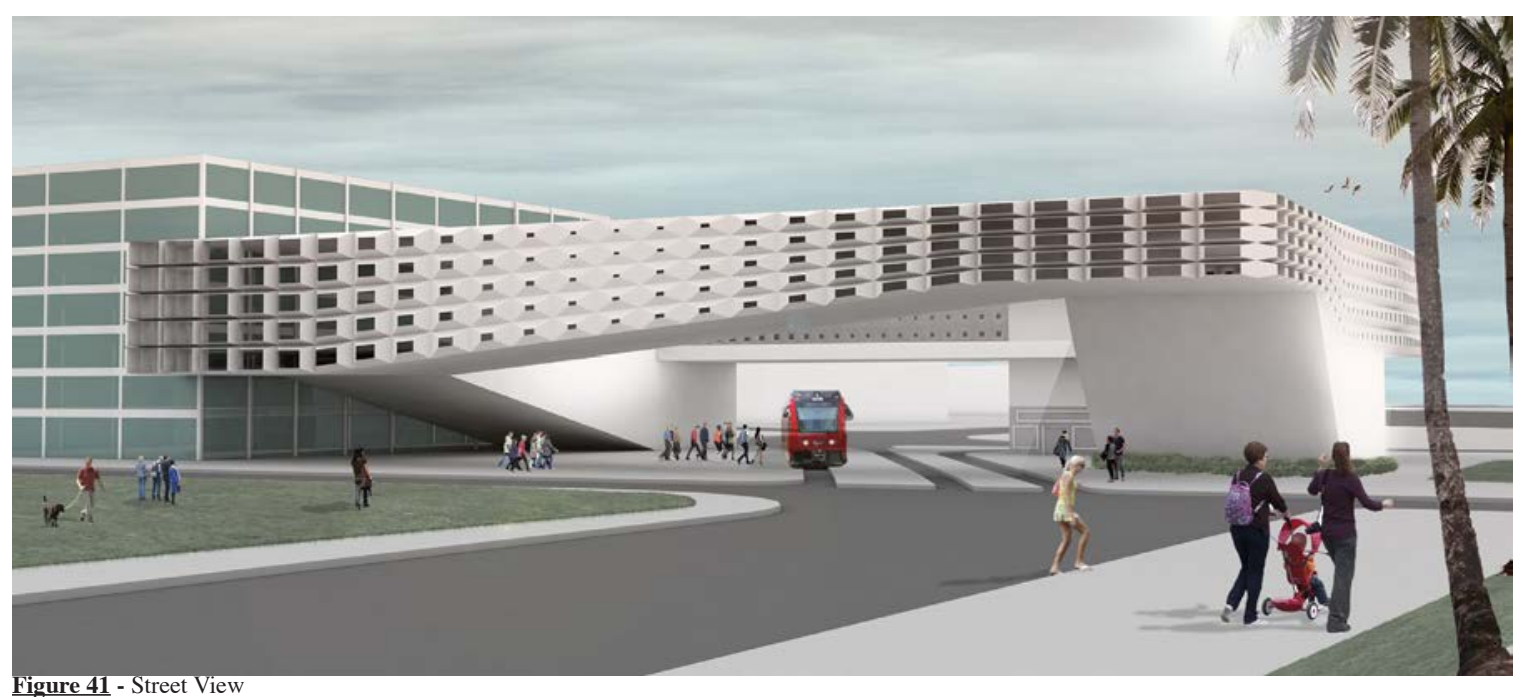

Figure 41 - Street View

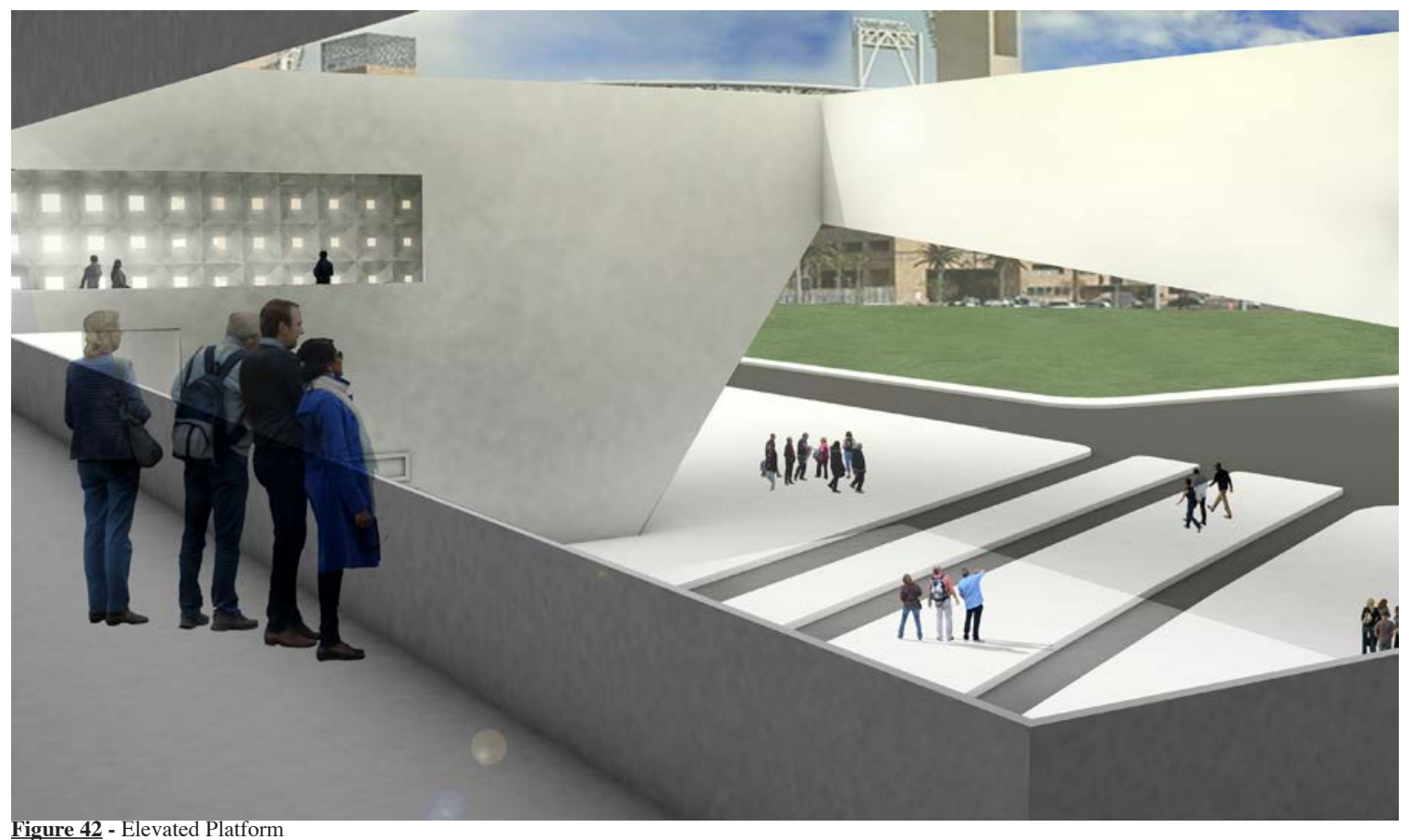




\section{Bibliography}

“Amsterdam Central Station.” Amsterdam.info, 2013. http://www.amsterdam.info/central-station/.

Armstrong, Paul J., Richard Florida, and Paul Hardin Kapp. Reinventing the Postindustrial City. Baltimore, MD: University of Illinois Press, 2012.

"Bilbao Metro." Foster + Partners. Accessed November 7, 2013. http://www.fosterandpartners. com/projects/bilbao-metro/.

Cervero, Robert, Kanako Iuchi, and Hiroaki Suzuki. Transforming Cities With Transit. Urban Development Series. Washington, DC: The World Bank, 2013.

“Dalmarnock Station/ATKINS.” Arch Daily, August 19, 2013. http://www.archdaily. com/416915/.

“Dalmarnock Station.” Architype, August 12, 2013. http://architype.org/project/dalmarnock-station/.

"Dalmarnock Station Redevelopment, United Kingdom.” Exporail, 2013. http://www.railway-technology.com/projects/dalmarnock-station-redevelopment/.

"Dresden Station Redevelopment." Foster + Partners. Accessed November 7, 2013. http://www. fosterandpartners.com/projects/dresden-station-redevelopment/.

“Dubai Metro.” Aedas. Accessed May 4, 2014. http://www.aedas.com/Dubai-Metro.

"Dubai Station Architecture." ArabianBusiness.com, September 19, 2009. http://www.arabianbusiness.com/dubai-station-architecture-12668.html.

Edwards, Brian. Sustainability and the Design of Transport Interchanges. New York, New York: Routledge, 2011.

"Gateway Station.” Archinect.com. Accessed November 17, 2013. http://archinect.com/people/ project/18712076/gateway-station/18714497.

Gerfen, Katie. “CTA Morgan Street Station.” Architect Magazine, April 29, 2013. http://www. architectmagazine.com/transportation-projects/cta-morgan-street-station.aspx.

“Grand Central Station’s \$20 Million Clock.” I Spy NYC, June 8, 2009. http://ispynyc.wordpress. com/2009/06/08/grand-central-stations-20-million-clock/.

"History." Grand Central Terminal, 2013. http://www.grandcentralterminal.com/info/history-popup.

"History of Paddington Station." Network Rail, 2013. http://www.networkrail.co.uk/aspx/7047. aspx. 
Holl, Steven, Juhani Pallasmaa, and Alberto Pérez-Gómez. Questions of Perception: Phenomenology of Architecture. San Francisco, CA: William Stout Publishers, 2006.

"Hollywood and Vine Metro Portal and Plaza." Arch Daily. Accessed June 6, 2013. http://www. archdaily.com/86722/hollywood-and-vine-metro-portal-and-plaza-rios-clementi-hale-studios/.

“Kanazawa Tourist Information Guide.” Kanazawa Tourism, 2008. http://www.kanazawa-tourism.com/eng/guide/guide1_3.php.

"Liége-Guillemins Railway Station." MIMOA, 2013. http://www.mimoa.eu/projects/Belgium/ Li\%E8ge/Li\%E8ge-Guillemins\%20Railway\%20Station.

"Liège-Guillemins Station by Santiago Calatrava." Wordless Tech, February 21, 2013. http:// wordlesstech.com/2013/02/21/liege-guillemins-station-by-santiago-calatrava/.

"Liége Guillemins TGV Station." Arcspace.com, November 2, 2009. http://www.arcspace.com/ features/santiago-calatrava/liege-guillemins-tgv-station/.

Lockton, Dan. "Architecture, Urbanism, Design and Behaviour: A Brief Review." Architectures, December 9, 2011. http://architectures.danlockton.co.uk/2011/09/12/architecture-urbanism-design-and-behaviour-a-brief-review/.

Mitrovic, Branko. Philosophy for Architects. New York, New York: Princeton Architectural Press, 2011.

"Modern Structure - Kanazawa Station.” Magxics, 2013. http://www.magx.com/tag/kanazawa-station.

Moore, Gary T. "Architecture and Human Behavior: The Place of Environment-Behavior Studies in Architecture." Wisconsin Architect, September 1979.

Motchan, Bill. "Two Neighboring L Stations, Separated by 120 Years." The Chicago Architecture Blog, January 28, 2013. http://blog.chicagoarchitecture.info/2013/01/28/two-neighboring-l-stations-separated-by-120-years/.

Muza-chan. "Japanese Architecture, Kanazawa Station.” Muza-chan's Gate to Japan, June 17, 2013. http://muza-chan.net/japan/index.php/blog/japanese-architecture-kanazawa-station.

NBTC. “The Hague.” Holland. Accessed November 5, 2013. http://www.holland.com/us/tourism/ cities-in-holland/the-hague-1.htm.

Nelson, Arthur C. Reshaping Metropolitan America: Development Trends and Opportunities to 2030. Metropolitan Planning + Design 6. Washington, DC: Island Press, 2013.

Ortiz, Sergio. "Straight From England.” Recommend, March 28, 2012. http://www.recommend. com/destinations/europe/straight-from-england/.

Pagnotta, Brian. "In Progress: Gateway Center Station/ EDGE Studio, Pfaffmann \& Associates." 
Arch Daily, September 1, 2011. http://www.archdaily.com/165471/in-progress-gateway-center-station-edge-studio-pfaffmann-associates/.

Pallasmaa, Juhani. The Eyes of the Skin. Great Britain: Wiley-Academy, 2005.

"Presentation." MetroBilbao.net. Accessed November 7, 2013. http://www.metrobilbao.net/en/ about-us/presentation.

"RandstadRail Station Beatrixlaan Den Haag / Zwarts \& Jansma Architecten.” Arch Daily, April 1, 2009. http://www.archdaily.com/18304/.

“Rashidiya.” My Dubai Metro, 2009. http://www.mydubaimetro.com/en/station/stop/rashidiya. html.

“Rashidiya Metro Station.” DubaiMetro.tel, 2009. http://rashidiya-metro-station.redline.dubaimetro.tel/.

RRM Design Group. Accessed April 23, 2014. http://www.rrmdesign.com/about/people

"RTA Opens Bridges Leading to Entry \& Exit Points of Rashidiya Metro Station on 15 July." Interior Home Design. Accessed November 7, 2013. http:/quacktitioner.blogspot.com/2010/06/ rta-opens-bridges-leading-to-entry-exit.html.

Sangeeta. "What Do You Need to Unlearn Today?" Serene Reflection, June 22, 2012. http://serenereflection.wordpress.com/2012/06/22/what-do-you-need-to-unlearn-today/.

Schumacher, Patrik. "Parametric Order - 21st Century Architectural Order." Harvard Graduate School of Design, February 15, 2012. http://www.youtube.com/watch?v=zG2WMVkD5dw.

Silva, Ana. “Amsterdam Centraal Station.” 1001 Scribbles, June 7, 2012. http://1001scribbles. wordpress.com/2012/06/07/amsterdam-centraal-station/.

Staff Report. "Al Rashidiya Stop To Be Functional on September 9.” GulfNews.com, September 5, 2009. http://m.gulfnews.com/al-rashidiya-stop-to-be-functional-on-september-9-1.538312.

“Summer Is Dubai.” INSEEC Travel Tips, October 5, 2014. http://www.inseec-travel-tips. com/2013/summer-is-dubai.

“TPlus - North Shore Access Points.” TPlus, 2012. http://tplus.org/new-stations/.

“Train Stations: Who Has the Prettiest One in Japan?" Sumo Joe Says. Accessed May 5, 2014. http://sumojoesays.com/train-stations-who-has-the-prettiest-one-in-japan/.

Transportation Research Board. Enhancing the Visibility and Image of Transit in the United States and Canada. Washington, DC: National Academy Press, 2000.

Vance, Steven. "West Loop Gains New Transit Option with Today's Opening of CTA Morgan Station.” Grid Chicago, 18 2012. http://gridchicago.com/2012/west-loop-gains-new-transit-option-with-todays-opening-of-cta-morgan-station/. 
Witcher, T.R. "Chicago Transit Builds First Station in 15 Years." Civil Engineering, July 10, 2012. http://www.asce.org/CEMagazine/ArticleNs.aspx?id=25769810003\#.UnlxaZR4bqI.

"York Railway Station.” History of York, 2013. http://www.historyofyork.org.uk/themes/victorian/york-railway-station.

Welch, Adrian. "Dresden Station - Building Redevelopment." E-architect, March 6, 2014. http:// www.e-architect.co.uk/dresden/dresden-station. 


\section{APPENDIX A: 12TH AND IMPERIAL TRANSIT CENTER FIELD NOTES}

Behavior Map:

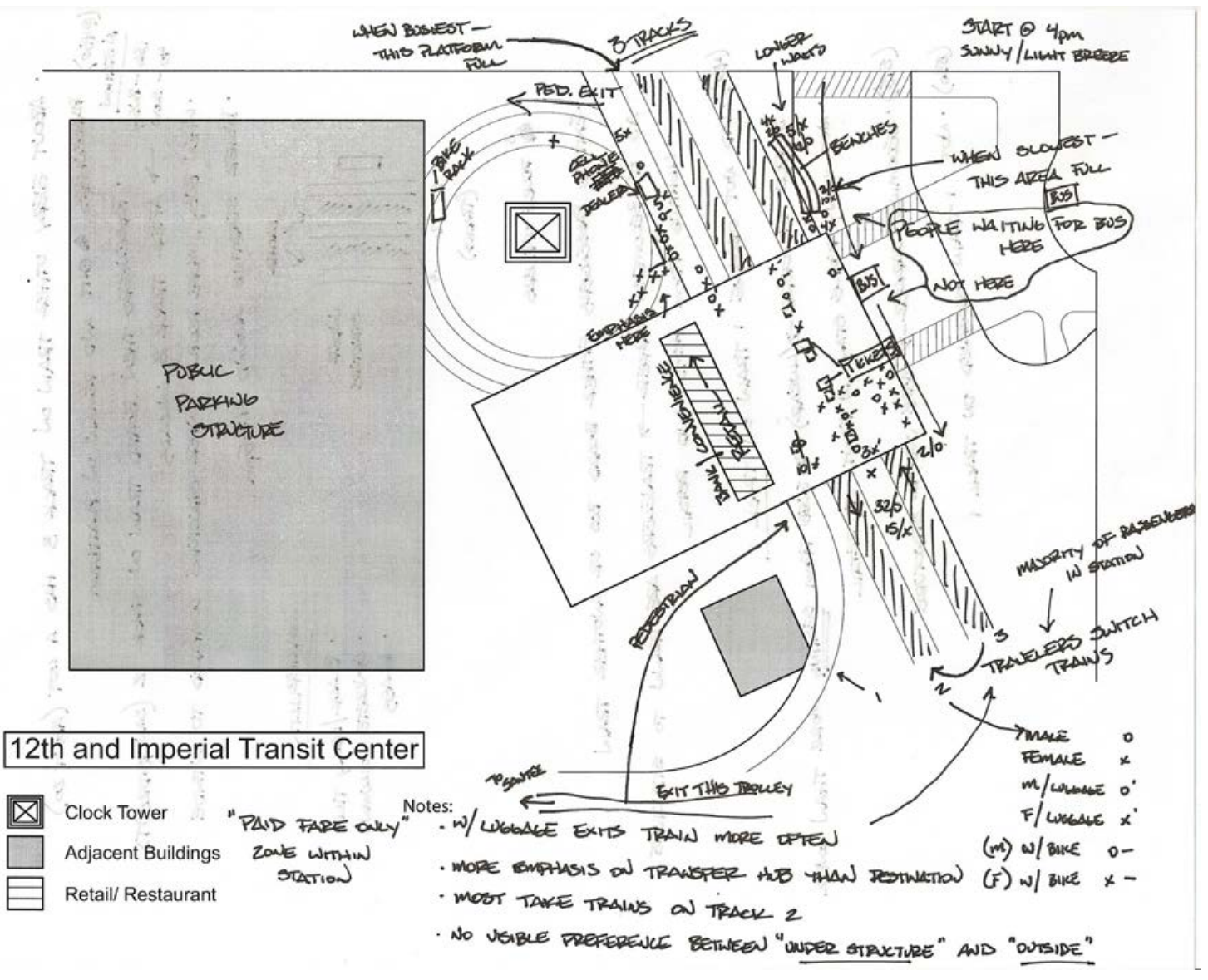


Field Notes:

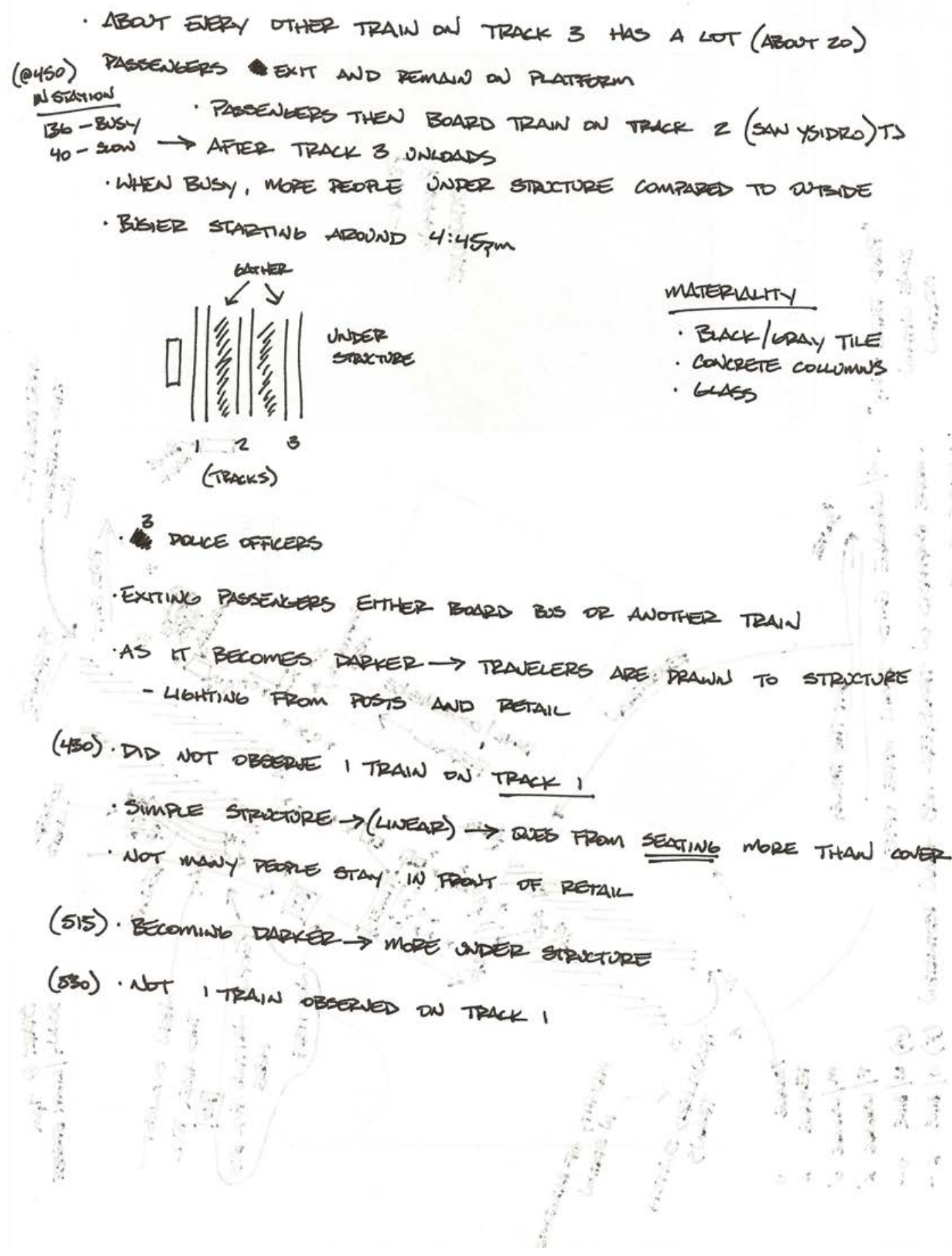


Behavior Map:

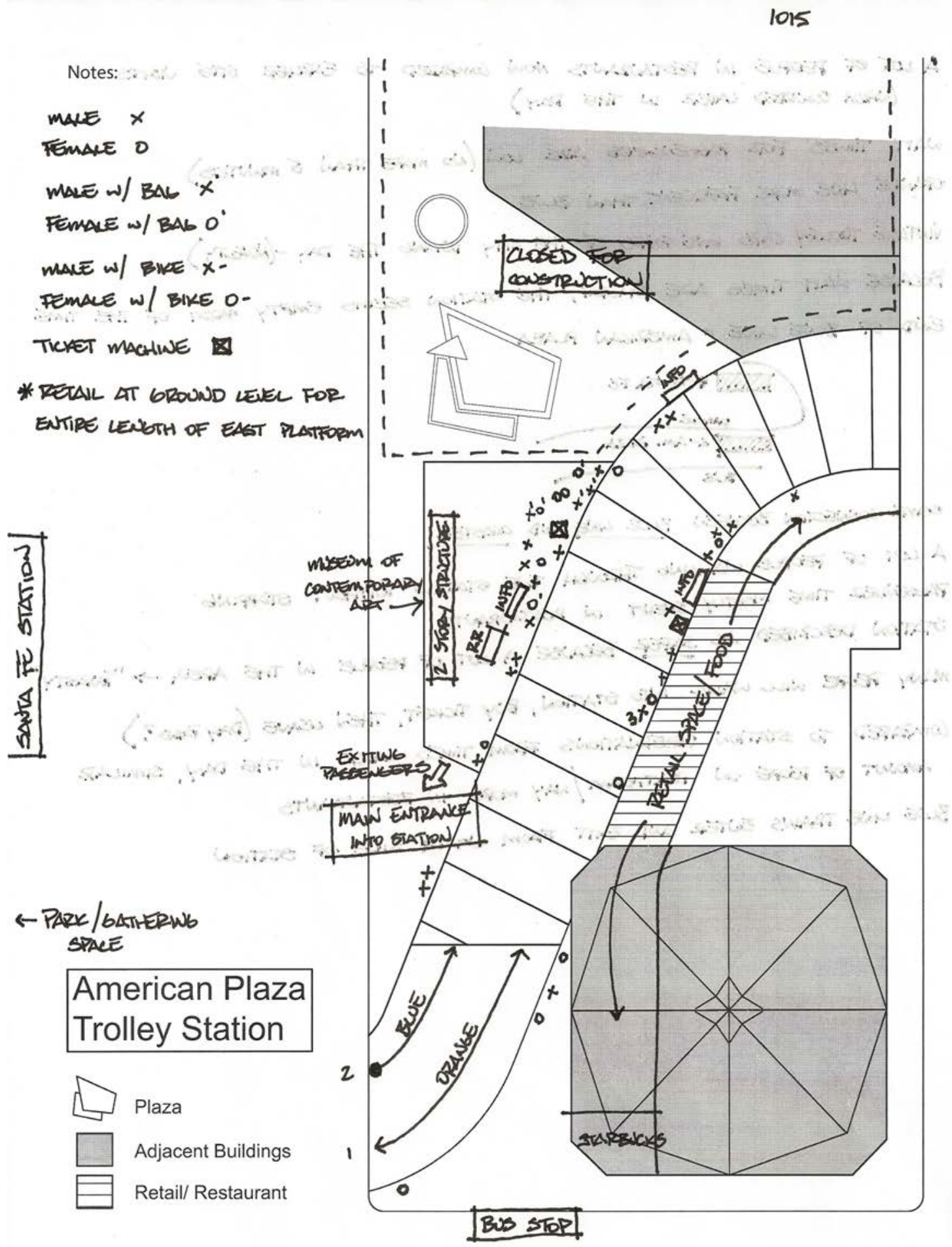


Field Notes:

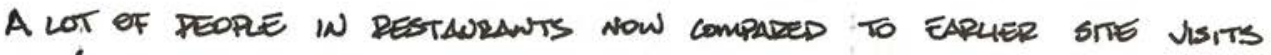

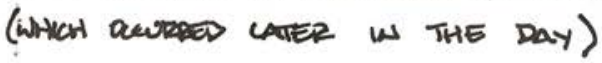

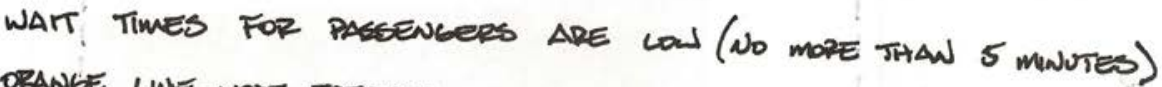
ORANGE LWE MOPE FREQUENT THAN BWE

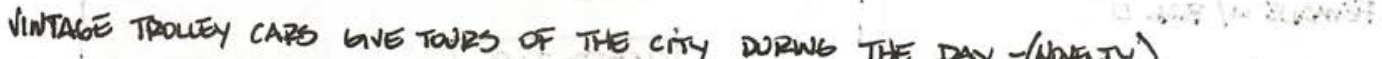
DURng THE DAY -(Novety)

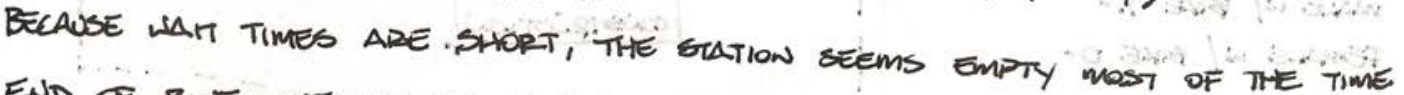
END of BWE LINE = AMERICAN PLARA

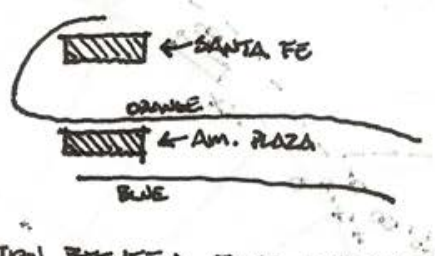

SOME CONNECTION BETWEEN BWE LINE AND COASTER

A LOT OF FEOPLE WAIKKWE THROUG

pAssenber TIME mOETLY SPENT IN REST GTATIDW WITHTONT STOPPING STATION DESCRIBED AS SÁFER IN RESTAORANTS.

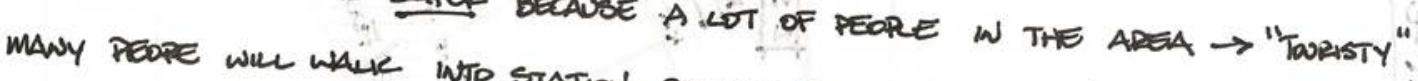
COMPARED TO STATION OBSESUTIOWS, BOY TICKET, THEN LEAVE (DAY PASS?)

AMONT OF PEOPE ON PLATFORM/WAY MOPE TIMES LATER, IN THE DAY, SIMILAR

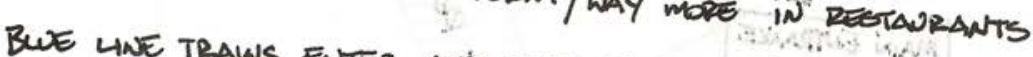
$\therefore$. $2 . . .1 \%$

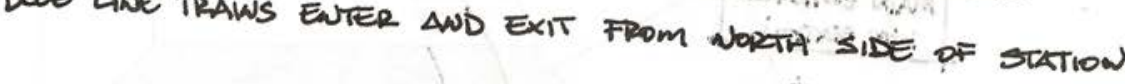

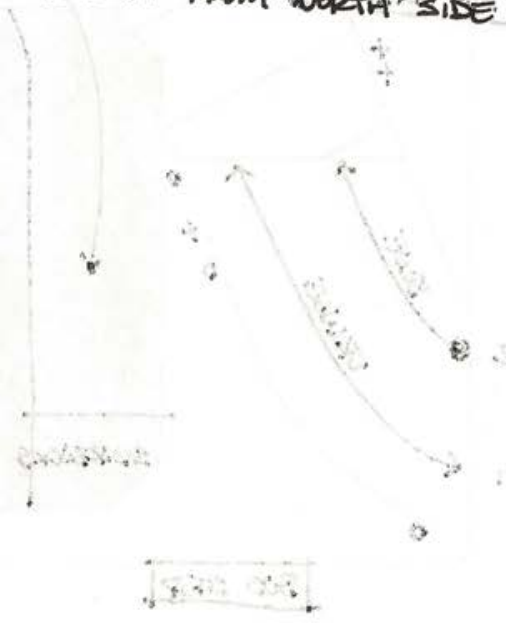


Behavior Map (Afternoon):

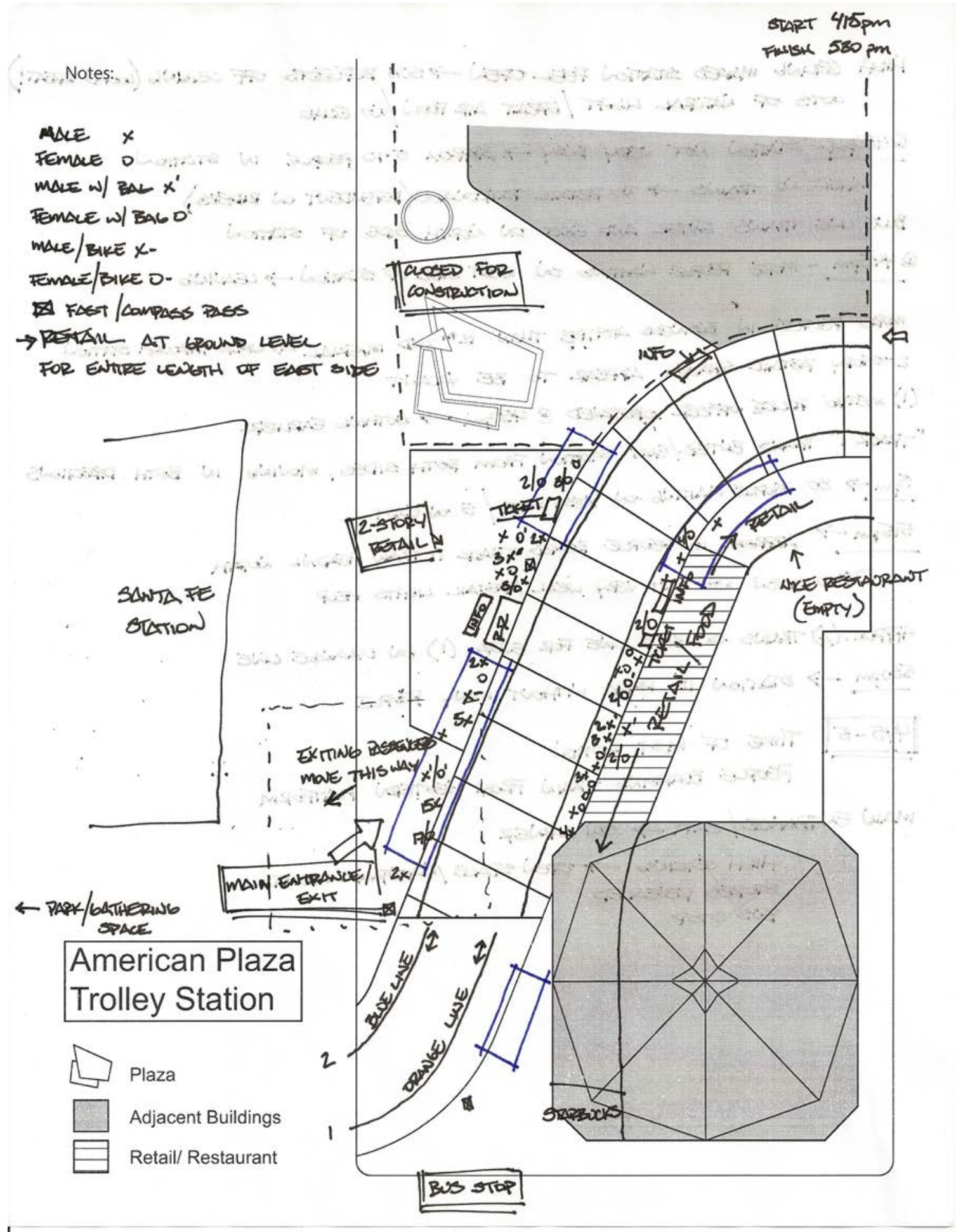


Field Notes (Afternoon):

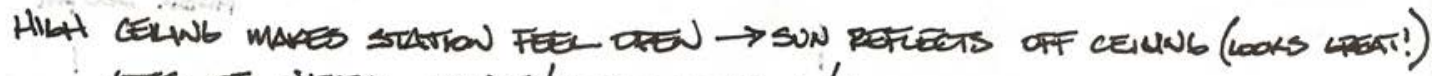
LOTS of NATURAL LWHT/GEAT AR FLOW/NO ECHO

Q430PM-SUTION Nor VERY BUSY $\rightarrow$ ARPROX S.10 FEOPLE IN STATION WIEN NO TRAINS $\rightarrow$ No PETAIL PATRONAE (DEREUDENT on RIDERS)

BUE UNE TRAWS ENTER AWP EXTT ON NOROH SDE OF STATION

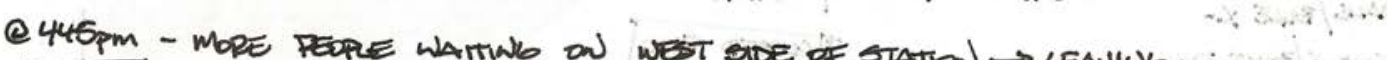
W

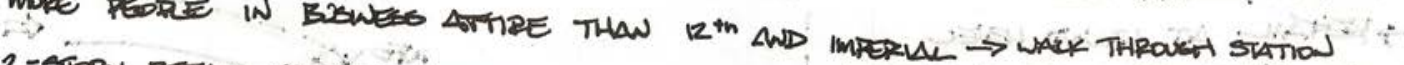
2-story petan spaces apfear to be nacant

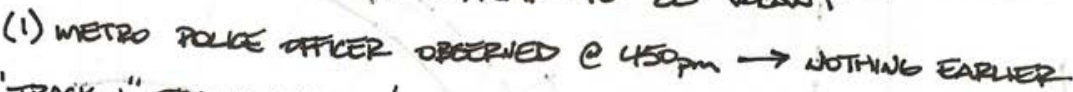
"TRACK I" TRAWUS EUTER/EXT STATION From BOTH SI

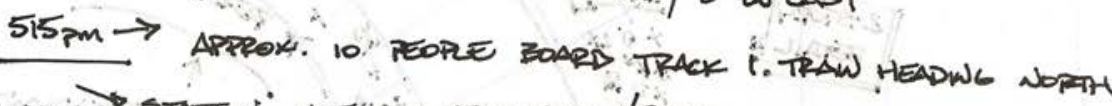

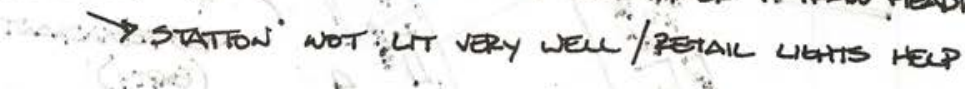
ARPROX. (2) TRAWS DN BLIE LWE FOR EVERY (1) OW ORAWLE LWE 530pm $\rightarrow$ STATION IS DARK WITHOUT MANY PEOPLE 445-5 TIME of MOST ACTID

PEOPLE BOAFANG TRANN FROM WESTERN PAATFORM MAW ENTRANE / EXIT $\rightarrow$ OW CORNER

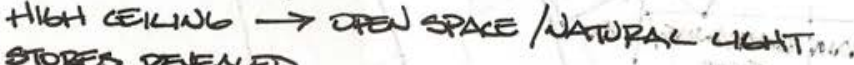
stopes pelenLed BUS STOP

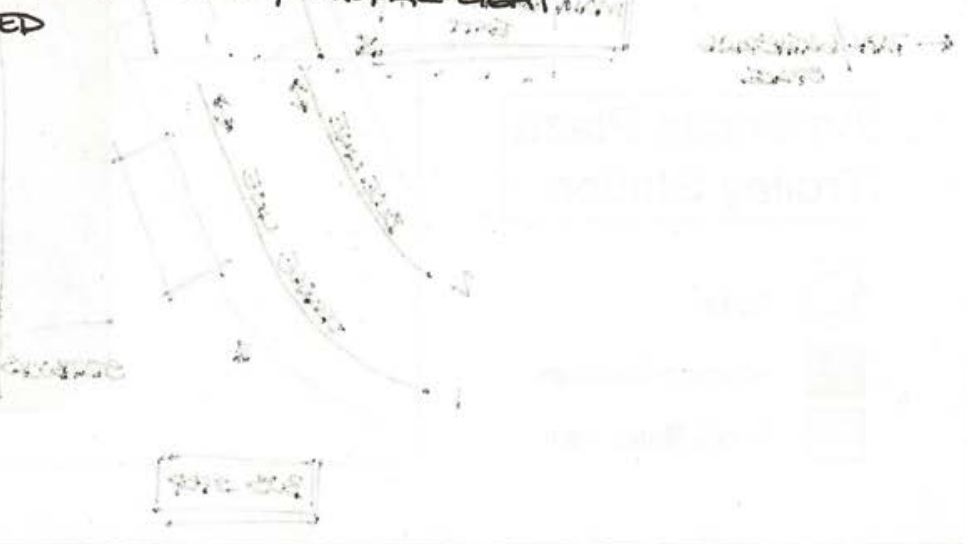


Behavior Map:

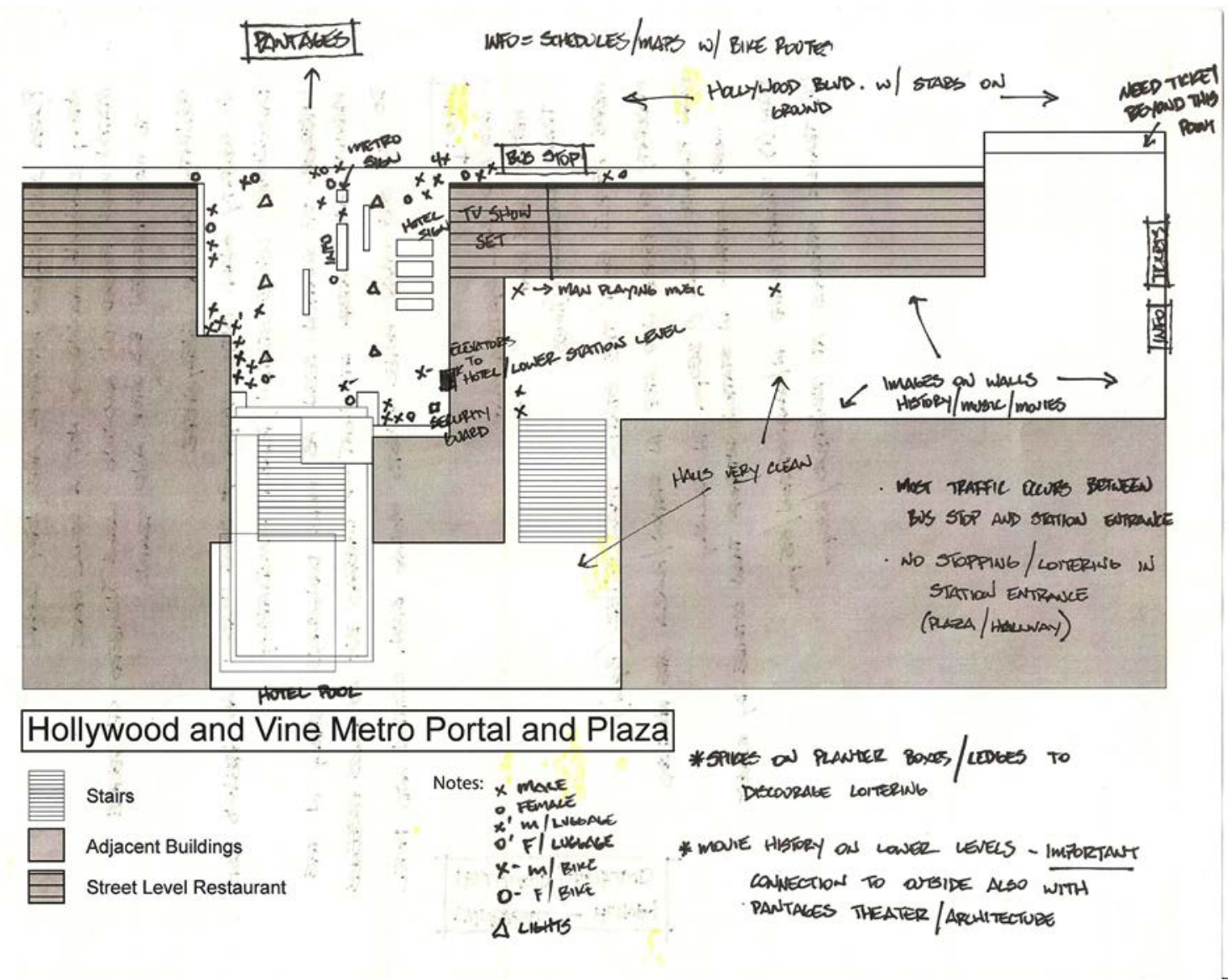


Field Notes:

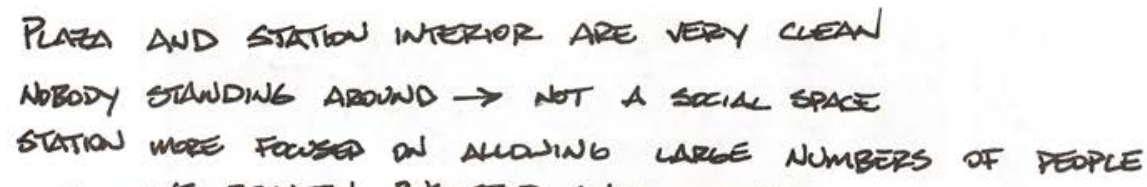

To MOVE BETWEEN BUS STOP AND TRAINS

SECURTY CAMERAS EVERYWHERE

No SEURTY GLARD UNTIL $230 \mathrm{pm} \rightarrow$ SAME LOCATIOW AS PREIOUS VISTT

passenters leave station/plaza immediatemy

INTERTOR OF STATION SEEN AS MDRE DANGerous EARUY IN THE MORNING AND LATER AT NIGHT $\rightarrow$ CAWERAS BUT NO POLLE PROEENKE DO WOT SEE MANY HOTEL bUESTS MONING GTWW. STATION AND HOHEL

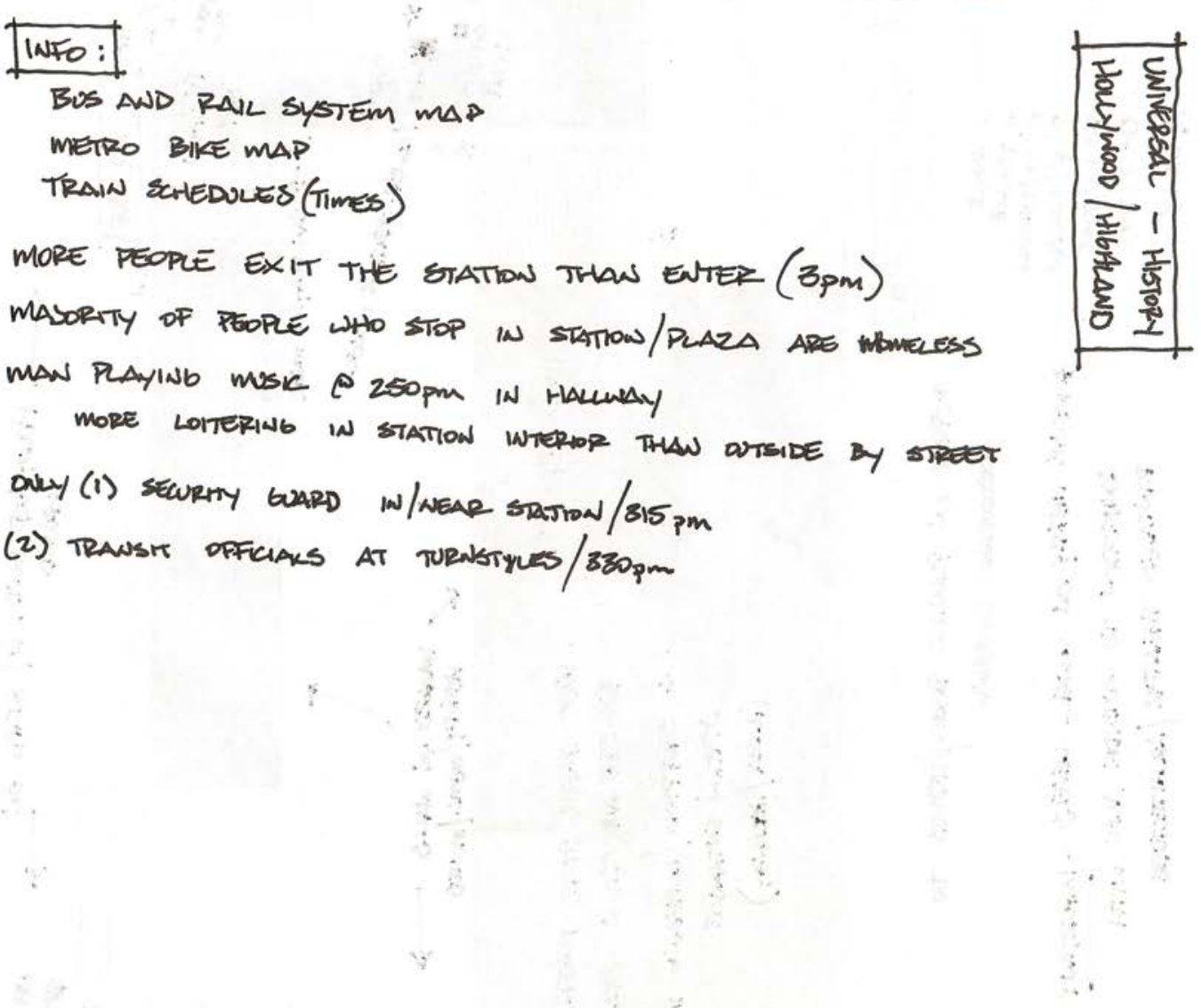

